\title{
The Volta Review Alexander Graham Bell Association for the Deaf and Hard of Hearing
}

Longitudinal Study of Speech Perception, Speech, and Language for Children with Hearing Loss in an Auditory-Verbal Therapy Program

By Dimity Dornan, Ba.Sp.Th., F.S.P.A.A., LSLS Cert. AVT; Louise Hickson, B.Sp.Thy. (Hons), M.Aud., Ph.D.;

Bruce Murdoch, B.Sc. (Hons), Ph.D., D.Sc.;

and Todd Houston, Ph.D., CCC-SLP, LSLS Cert. AVT

Building the Alphabetic Principle in Young Children who are Deaf and Hard of Hearing By Jessica Page Bergeron, M.E.D.; Amy R. Lederberg, Ph.D.; Susan R. Easterbrooks, Ed.D. Elizabeth M. Miller, M.Ed.; and Carol McDonald Connor, Ph.D.

The Development and Piloting of a Decision Aid for Parents Considering Sequential Bilateral Cochlear Implantation for Their Child With Hearing Loss

By J. Cyne Johnston, Ph.D.;

Andrée Durieux Smith, Ph.D.;

Annette O'Connor, Ph.D.;

Karen Benzies, RN, B.Sc.N., M.N., Ph.D.;

Elizabeth M. Fitzpatrick, Ph.D.;

and Douglas Angus, B.Com., M.A.

Contemporary Reflections on Speech-Based

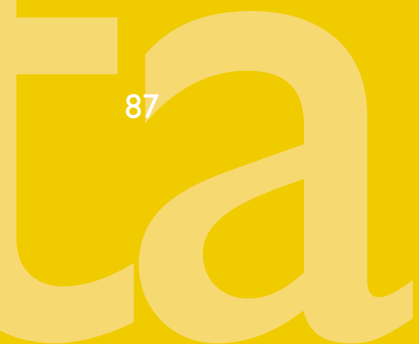

By Marianne Gustafson, M.S., CCC-SLP 


\section{The Volta Review}

Volume 109, Numbers 2-3

Fall/Winter 2009

ISSN 0042-8639

The Alexander Graham Bell Association for the Deaf and Hard of Hearing helps families, health care providers and education professionals understand childhood hearing loss and the importance of early diagnosis and intervention. Through advocacy, education, research and financial aid, AG Bell helps to ensure that every child and adult with hearing loss has the opportunity to listen, talk and thrive in mainstream society. With chapters located in the United States and a network of international affiliates, AG Bell supports its mission: Advocating Independence through Listening and Talking!

\section{Editors' Preface}

Joseph Smaldino, Ph.D., and Kathryn L. Schmitz, Ph.D.

\section{Research}

6 Longitudinal Study of Speech Perception, Speech, and Language for Children with Hearing Loss in an Auditory-Verbal Therapy Program

By Dimity Dornan, Ba.Sp.Th., F.S.P.A.A., LSLS Cert. AVT; Louise Hickson, B.Sp.Thy. (Hons), M.Aud., Ph.D.; Bruce Murdoch, B.Sc. (Hons), Ph.D., D.Sc.; and Todd Houston, Ph.D., CCC-SLP, LSLS Cert. AVT

87 Building the Alphabetic Principle in Young Children who are Deaf and Hard of Hearing By Jessica Page Bergeron, M.E.D.; Amy R. Lederberg, Ph.D.; Susan R. Easterbrooks, Ed.D.; Elizabeth M. Miller, M.Ed.; and Carol McDonald Connor, Ph.D.

I21 The Development and Piloting of a Decision Aid for Parents Considering Sequential Bilateral Cochlear Implantation for Their Child With Hearing Loss

By J. Cyne Johnston, Ph.D.; Andrée Durieux Smith, Ph.D.; Annette O’Connor, Ph.D.;

Karen Benzies, RN; B.Sc.N., M.N., Ph.D.; Elizabeth M. Fitzpatrick, Ph.D.;

and Douglas Angus, B.Com., M.A.

\section{Commentary}

143 Contemporary Reflections on Speech-Based Language Learning By Marianne Gustafson, M.S., CCC-SLP

\section{Book Review}

\section{Regular Features}

Permission to Copy: The Alexander Graham Bell Association for the Deaf and Hard of Hearing, as copyright owner of this journal, allows single copies of an article to be made for personal use. This consent does not extend to posting on Web sites or other kinds of copying, such as copying for general distribution, for advertising or promotional purposes, for creating new collective works of any type, or for resale without the express written permission of the publisher. For more information, contact AG Bell at 3417 Volta Place, NW,Washington, DC 20007, email editor@agbell.org, or call (202) 337-5220 (voice) or (202) 337-522I (TTY). 


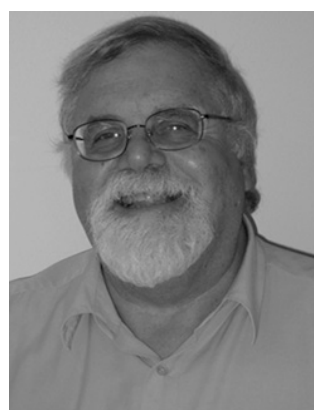

Joseph Smaldino, Ph.D., Editor

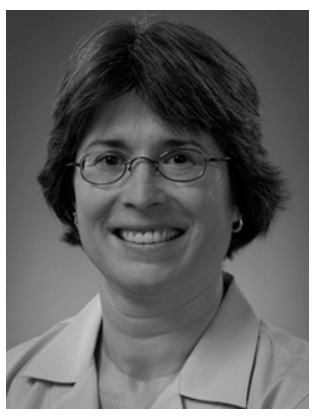

Kathryn L. Schmitz, Ph.D., Senior Associate Editor

\section{Editors' Preface}

\section{Value Added: The Volta Review Monographs}

Over its 110-year history, The Volta Review has served as a primary source for the latest in cutting-edge research, professional commentary, and reviews of materials and technology that explore a listening and spoken language outcome for individuals with hearing loss. Keeping its readership informed is an important goal of The Volta Review and we continue to improve on that mission.

In addition to the regular serial issues, The Volta Review is best known for its outstanding monographs focused on important or emerging issues in the area of listening and spoken language development of individuals who are deaf and hard of hearing. Monograph issues provide in-depth information that often cannot be obtained from any other single source. Each monograph is highly regarded and used as a springboard for further research and the development of guidelines and policies for listening and spoken language intervention. Past topics have included early hearing detection and intervention, mechanisms of aminoglycoside otoxicity and strategies for prevention, children with hearing loss and special needs, assessment of hearing in infants and toddlers, speech and language benefits of cochlear implantation, classroom acoustics, and language, speech, and socio-emotional development of children who are deaf or hard of hearing.

In keeping with the cutting-edge nature of previous The Volta Review monographs, the next monograph edition will focus on the important issue of professional development in the field of listening and spoken language. Edited by Drs. Todd Houston and Christina Perigoe, this monograph will highlight models of professional preparation and development that have emerged in both pre-service and in-service training of listening and spoken language professionals who work with young children who are deaf or hard of hearing. The rapidly expanding AG Bell Academy for Listening and Spoken 
Language Specialist certifications - LSLS Cert. AVEd and LSLS Cert. AVT highlights the urgency of what is quickly becoming a "Crisis of Capacity" between the number of children seeking a listening and spoken language outcome and the number of qualified professionals to support them. This "must read" monograph will serve as an important guidepost for training the next generation of service providers. Look for it in June 2010.

In addition, The Volta Review is pleased to announce that online archives of the journal are now available. Visit www.agbell.org/TheVoltaReview to view past archives up to 2006. Earlier issues will be posted as available.

This issue contains some important research concerning speech, spoken language, and literacy skill development; decision-making tools for parents considering a second cochlear implant for their children; and commentary on speech-based language acquisition. We hope you enjoy this issue, and please don't hesitate to contribute to The Volta Review.

Sincerely,

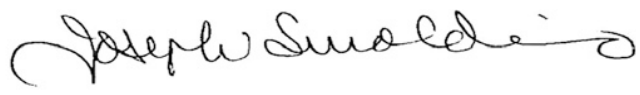

Joseph Smaldino, Ph.D. Professor and Chair, Department of Communication Sciences Illinois State University jsmaldi@ilstu.edu

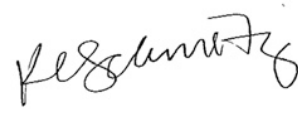

Kathryn L. Schmitz, Ph.D.

Associate Professor and Interim Chair, Liberal Studies Department National Technical Institute for the Deaf/Rochester Institute of Technology kls4344@rit.edu 


\title{
Longitudinal Study of Speech Perception, Speech, and Language for Children with Hearing Loss in an Auditory- Verbal Therapy Program
}

\author{
Dimity Dornan, Ba.Sp.Th., F.S.P.A.A., LSLS Cert. AVT; \\ Louise Hickson, B.Sp.Thy. (Hons), M.Aud., Ph.D.; \\ Bruce Murdoch, B.Sc. (Hons), Ph.D., D.Sc.; and \\ Todd Houston, Ph.D., CCC-SLP, LSLS Cert. AVT
}

This study examined the speech perception, speech, and language developmental progress of 25 children with hearing loss (mean Pure-Tone Average [PTA] $79.37 \mathrm{~dB}$ $H L)$ in an auditory-verbal therapy program. Children were tested initially and then 21 months later on a battery of assessments. The speech and language results over time were compared with those for a control group of children with typical hearing who were matched for initial language age, receptive vocabulary, gender, and socioeconomic level. Speech perception scores for the children with hearing loss showed significant improvement $(p<0.05)$ for live-voice presentations, but not for recorded voice. For both groups there was significant improvement over 21 months in scores for auditory comprehension, oral expression, total language, and articulation of consonants

Dimity Dornan, Ba.Sp.Th., F.S.P.A.A., LSLS Cert. AVT, is a postgraduate student in the School of Health and Rehabilitation Sciences, University of Queensland in Australia, and the Managing Director and Founder of the Hear and Say Centre in Brisbane, Australia. Louise Hickson, B.Sp.Thy. (Hons), M.Aud., Ph.D., is a Professor of Audiology in the School of Health and Rehabilitation Sciences, University of Queensland in Australia. Bruce Murdoch, B.Sc. (Hons), Ph.D., D.Sc., is a Professor of Speech Pathology and Director of the Motor Speech Research Centre in the School of Health and Rehabilitation Sciences, University of Queensland in Australia. Todd Houston, Ph.D., CCC-SLP, LSLS Cert. AVT, is the Director of Graduate Studies Program in Auditory Learning \& Spoken Language in the Department of Communicative Disorders and Deaf Education, Utah State University in the United States. Correspondence concerning this article should be addressed by email to Ms. Dornan at dimity@hearandsaycentre.com.au. 
$(p<0.001)$; the amount of improvement was not significantly different between groups $(p>0.05)$. At the 21 -month test point, $84 \%$ of the children with hearing loss scored within the typical range for total language age, compared to $58.6 \%$ at the initial assessment. Receptive vocabulary scores were an exception, with the children with typical hearing showing significantly more gain than the children with hearing loss ( $p$ $<0.05)$. Nevertheless, the group with hearing loss scored within the typical range for receptive vocabulary. Overall, the results show that the children with hearing loss had improved speech perception skills over time and that their rate of progress for speech and language skills was similar to that of children with typical hearing.

\section{Introduction}

This research is part of a longitudinal study examining the outcomes for children with hearing loss who are enrolled in an auditory-verbal therapy program and who are seeking a listening and spoken language outcome. Between 2 and 3 newborns per 1,000 children are born with permanent sensorineural hearing loss $>35 \mathrm{~dB}$ HL per year, the most common congenital disorder that can be detected in the newborn period (Fortnum, Summerfield, Marshall, Davis, \& Bamford, 2001; Joint Committee on Infant Hearing, 2007; Uus \& Bamford, 2006). This incidence is likely to be higher in developing countries (Olusanya, Ruben, \& Parving, 2006). Untreated hearing loss in children has a significant impact on auditory brain development (Sharma, Dorman, \& Kral, 2005), with serious lifetime consequences for speech, language, literacy, academic achievement, and social/emotional development (Bat-Chava, Martin, \& Kosciw, 2005; Blamey et al., 2001; Nunes \& Moreno, 2002; Sininger, 1999; Traxler, 2000). Hearing loss also significantly impacts the family and community (Olusanya et al., 2006). Treatment of childhood hearing loss has made many advances in the last decade, and clinical evidence shows that life-changing improvements in outcomes for children with hearing loss are now possible with the combination of new technology and intervention techniques (Geers, 2004). Rigorous research is needed to develop an evidence base that will inform professionals, decision makers, and funding bodies about the effectiveness of intervention strategies for children with hearing loss who seek a spoken language outcome.

Early diagnosis and immediate audiological and educational intervention, preferably by 6 months of age, are vital in order to capitalize on the optimal developmental periods of the auditory brain (Joint Committee on Infant Hearing, 2007; Sharma et al., 2005; Yoshinaga-Itano, Sedey, Coulter, \& Mehl, 1998). Modern diagnostic technology, such as frequency-specific electrophysiological measurements (Cone-Wesson, Dowell, Tomlin, Rance, \& Ming, 2002), and hearing technology, such as cochlear implants and digital hearing aids, are offering new opportunities for children with significant hearing loss to acquire listening and spoken language (Geers, 2004). Fitting of amplification accompanied by immediate and appropriate educational intervention must quickly follow diagnosis if the new opportunities are to lead to an improvement in 
spoken language outcomes (Nicholas \& Geers, 2007). As technology for diagnosis and audiological intervention for hearing loss continues to advance, better speech and language outcomes have become possibilities for children with hearing loss. These developments have created more demand for listening and spoken language outcomes (Rhoades, 2006).

However, there is a lack of high-level research (as defined by the "Levels of Evidence" of the Oxford Centre for Evidence Based Medicine, 2001) on any of the educational approaches available today (Sussman et al., 2004). There is a great need to conduct research focusing on the measurement of outcomes as evidence for "best practices" in the treatment of various populations of children with hearing loss. Prior to the use of cochlear implants, the rate of language progress for children with profound hearing loss wearing hearing aids was reported as half a year of progress in a 1-year time span (Boothroyd, Geers, \& Moog, 1991). With new hearing technology, many authors consider that progress of children with hearing loss may be appropriately compared to that of children with typical hearing (Geers, 2006). This study is part of a longitudinal research project that aims to contribute to research evidence by comparing the developmental progress of speech and language skills for children in an auditory-verbal therapy program to that of children with typical hearing.

Auditory-verbal therapy is an early intervention education option that facilitates optimal acquisition of spoken language through listening by young children with hearing loss. It promotes early diagnosis, one-on-one therapy, and state-of-the-art audiologic management and technology. Parents and caregivers actively participate in therapy. Through guidance, coaching, and demonstration, parents become the primary facilitators of their child's spoken language development. Ultimately, parents and caregivers gain confidence that their child can have access to a full range of academic, social, and occupational choices throughout life (AG Bell Academy for Listening and Spoken Language, 2007).

A number of authors have published reviews of research on auditory-verbal therapy outcomes (see Dornan, Hickson, Murdoch, \& Houston, 2008; EriksBrophy, 2004; Rhoades, 2006). Eriks-Brophy (2004) cited significant problems related to research design, including the fact that most studies were retrospective and were without control groups. She concluded that the research overall was sparse and incomplete, and provided only limited evidence in favor of auditory-verbal therapy, a view that was supported by Rhoades (2006) and Dornan et al. (2008). The research design problems highlighted by these authors means that comparison between studies on outcomes of auditory-verbal therapy, or indeed between studies on any of the other communication options, is extremely difficult. However, several large retrospective studies (e.g., Goldberg \& Flexer, 2001; Durieux-Smith et al., 1998), and a few prospective ones (e.g., Duncan, 1999; Duncan \& Rochecouste, 1999; Rhoades, 2001; Rhoades \& Chisolm, 2000), have provided limited evidence for the potential of auditory-verbal therapy for some children with hearing loss. The latter two papers on the same population reported that the children had progressed at 
the same rate as children with typical hearing, and entered school with ageappropriate language skills. However, these two studies did not actually have a control group of children with typical hearing, and such a comparison would have been appropriate and informative.

In an earlier stage of our own research (Dornan, Hickson, Murdoch, \& Houston, 2007), the speech and language developmental progress of children with hearing loss using an auditory-verbal therapy approach was compared over a 9-month period to that of a matched group of children with typical hearing. The original group of children with hearing loss consisted of 29 children ages 2-6 years with a mean Pure-Tone Average (PTA) in the better ear of 76.17 $\mathrm{dB} H L$ at $0.5,1$ and $2 \mathrm{kHz}$. The 29 children in the control group were matched with the children in the auditory-verbal therapy program for language age and receptive vocabulary at the start of the study, and for gender and parental education level. A battery of standardized speech and language tests was administered to all children at the start of the study, and again 9 months later. Results showed that both groups improved over time and that there was no significant difference in progress between the two groups.

In this paper, we report on the second stage of this longitudinal study with testing occurring at 21 months after the initial assessments. The aims of the research were to investigate the developmental progress of speech and language skills for 25 pairs of the same children who remained in the study for 21 months. Developmental progress for speech and language was again compared between the two groups. This study also aimed to extend the original study by including additional measures of speech perception and speech production skills for consonants in spontaneous discourse for the children with hearing loss.

\section{Method}

The study employed a matched group, repeated-measures design in which children with hearing loss in an auditory-verbal therapy program were individually matched with a comparison group of children with typical hearing. The rate of change for various language and speech variables was compared for the auditory-verbal therapy group (AVT group) and the typical hearing group (TH group). Participants in both groups were assessed at the start of the study (pretest) and at the 21-month point (posttest) using an assessment battery. The children in the AVT group received additional assessments of speech perception and speech production in discourse.

\section{Participants}

\section{Auditory-Verbal Therapy Group}

At the 21-month stage of the study, 25 members of the original AVT group remained in the longitudinal study, and only the original child matched from 
the TH group was used for comparison $(n=25)$. The 4 original AVT group children who withdrew from the study included 2 children who had commenced investigation for other additional disorders during the first 9 months of the study and were subsequently transferred to a different type of educational program, and 2 who moved to a different area and were unavailable. The remaining 25 AVT group children had a range of sensorineural hearing losses, used hearing aids and/or cochlear implants to access sound, and were assessed on a battery of speech perception, speech, and language tests. These children attended one of four regional centers of an auditory-verbal therapy program in Queensland, Australia, which offers a range of services including audiological, early intervention, and cochlear implantation. The auditoryverbal therapy program adheres to the Principles of Listening and Spoken Language - Auditory-Verbal Therapy (endorsed by the AG Bell Academy for Listening and Spoken Language, 2007). All children in the AVT group were receiving regular audiologic follow-up to ensure optimal amplification, and attending weekly individual therapy sessions in which parents were guided and coached to be the primary language models for their child. Diagnostic teaching principles were also employed and children were fully integrated into mainstream education at the earliest possible age. Potential participants at the start of the study included all of the program's 75 children ( 2 months to 6 years of age) who were in the early intervention program, satisfied the selection criteria, were geographically accessible, and whose parents agreed to participate in the research. Selection criteria were as follows:

- Pure-Tone Average (PTA) at $500 \mathrm{~Hz}, 1000 \mathrm{~Hz}, 2000 \mathrm{~Hz}$, and $4000 \mathrm{~Hz}$ of $\geq 40 \mathrm{~dB}$ hearing threshold levels in the better ear.

- Prelingually deafened (at $\leq 18$ months old).

- Attended the educational program weekly for intensive one-to-one, parent-based auditory-verbal therapy for a minimum of 6 months.

- Wore consistent hearing amplification (hearing aids and/or cochlear implants).

- Had aided hearing within the speech range or had received a cochlear implant.

- No other significant cognitive or physical disabilities reported by parents or educators.

- Ages 2-6 years at the pretest session.

- Both parents spoke only English to the child.

Although the selection criteria precluded children with other significant disabilities, the group included one child who had mild cerebral palsy. The characteristics of the AVT group are summarized in Table 1. Their mean age at pretest was 3 years, 9 months, and at posttest was 5 years, 8 months ( $\mathrm{SD}=15$ months). The 25 participants had bilateral sensorineural hearing loss ranging from moderate to profound, with a mean PTA of $79.37 \mathrm{~dB}$ HL. All 
Table I. Characteristics of AVT group and TH group at 21-month posttest

\begin{tabular}{lll}
\hline & AVT Group & TH Group \\
\hline N & 25 & 25 \\
Mean age in months (SD) & $68.4(15)$ & $57.42(14.75)$ \\
Gender & 18 & 18 \\
Male & 7 & 7 \\
Female & 24.6 & $\mathrm{n} / \mathrm{a}$ \\
Age at identification in months & $79.37(22.79)$ & $\mathrm{n} / \mathrm{a}$ \\
Mean PTA better ear (SD) & & \\
Onset of loss & 23 & $\mathrm{n} / \mathrm{a}$ \\
Congenital & 2 & $\mathrm{n} / \mathrm{a}$ \\
Prelingual & $27(5.8)$ & $\mathrm{n} / \mathrm{a}$ \\
Age at CI in months (SD) & $41(16.34)$ & $\mathrm{n} / \mathrm{a}$ \\
Time spent in AVT program in months (SD) & & $\mathrm{n} / \mathrm{a}$ \\
Hearing Device: & 10 & $\mathrm{n} / \mathrm{a}$ \\
Number of children with bilateral HA & 1 & $\mathrm{n} / \mathrm{a}$ \\
Number of children with unilateral HA & 12 & $\mathrm{n} / \mathrm{a}$ \\
Number of children with HA in one ear & & \\
$\quad$ and CI in the other & 2 & \\
Number of children with one CI only & & \\
\hline
\end{tabular}

$\mathrm{HA}=$ Hearing Aids

$\mathrm{CI}=$ Cochlear Implant

children were fitted with hearing aids and commenced intervention within 3 months of diagnosis of the hearing loss. Three of the children had been diagnosed and commenced intervention before the critical age of 6 months identified by Yoshinaga-Itano and others (1998). These 3 children had a profound bilateral sensorineural loss, and subsequently received a cochlear implant before 19 months of age. All children with implants in this study had received unilateral Cochlear Nucleus CI 24 implants and used an Advanced Combined Encoder (ACE) processing strategy. The median age at implantation was 23.04 months $($ mean $=27.54$ months, $\mathrm{SD}=15.24)$. This relatively late mean time of implantation was due to the fact that 2 children received a unilateral cochlear implant around 4 years of age during the first 9 months of the study. All but 2 children in the study who use cochlear implants also wore a hearing aid in the contralateral ear. Both hearing devices were balanced by an audiologist according to the recommendation of Ching, Psarros, and Incerti (2003). All children wore their hearing aids consistently at the first follow-up ( 9 months after pretest), and continued to do so at the posttest (21 months after pretest).

\section{Typical Hearing Group}

Children in this group were recruited by families and staff of the auditoryverbal therapy program. Selection criteria were as follows: 
- Unaided hearing threshold levels within the range of 0 to $20 \mathrm{~dB}$ at $500 \mathrm{~Hz}$, $1000 \mathrm{~Hz}, 2000 \mathrm{~Hz}$, and $4000 \mathrm{~Hz}$ for both ears.

- No delay in phonetic development as assessed using the Goldman-Fristoe Test of Articulation-2 (GFTA-2) (Goldman \& Fristoe, 2001). Australian norms for articulation (Kilminster \& Laird, 1978) were used and results within 1 standard deviation (SD) of the mean for age were required for inclusion.

- No significant cognitive or physical disabilities (as evidenced by case history or parent report).

- Both parents spoke only English to the child.

The characteristics of the control group are summarized in Table 1. Hearing level expressed as PTA is not reported for this group. Sixty-four children with typical hearing were initially tested to ensure appropriate matching of children in the two groups. For the longitudinal study, the 25 children with typical hearing selected for the TH group were individually matched with children in the AVT group for total language age on the Preschool Language Scale (PLS-4) or the Clinical Evaluation of Language Fundamentals (CELF-3) ( \pm 3 months), for receptive vocabulary on the Peabody Picture Vocabulary Test (PPVT-3) ( \pm 3 months), for gender, and for socioeconomic level as assessed by education level of the head of the household. The mean age at pretest was 2 years, 11 months, and at posttest was 4 years, 9 months ( $\mathrm{SD}=14.75$ months). This meant that the AVT group were 10 months older than the TH group. Had chronological age been used for matching (instead of language age), as was done in the study reported by Duncan (1999) and Duncan and Rochecouste (1999), the children with typical hearing generally would have had a higher language level than the children with hearing loss of the same chronological age (Blamey et al., 2001), introducing the possibility that the children in the $\mathrm{TH}$ group might progress faster.

In addition, the study was conducted in Queensland, Australia. At the time, the average age for diagnosis of a sensorineural hearing loss in Australia was over 2 years because newborn hearing screening programs were not yet in place (Wake, 2002). Thus, it was highly likely that if the children were matched by chronological age, participants in the TH group would have had a significant language age advantage over participants in the AVT group. It is also possible that matching children for language age could have resulted in the children with hearing loss being significantly older than the children with typical hearing (Blamey et al., 2001), introducing the potential that they may progress faster because of their advanced cognitive skills. However, it was considered that the potential cognitive "advantage" afforded to the children with hearing loss who were older was likely to be offset by the delays they may experience in speech and language development.

When matching the control group with the experimental group, it was difficult to achieve a complete match for each individual child for both the 
total language score (PLS-4 or CELF-3) and the receptive vocabulary score (PPVT-3) as the range of total language and receptive vocabulary scores was wide. However, both groups of children were initially matched for total language scores, and then for receptive vocabulary. Deciding how to define socioeconomic level for matching purposes was difficult because there are many different perspectives and a number of different possible measures (Kumar et al., 2008). Some factors that might have been measured include family income, education level of the parents, and parental occupation (Marschark \& Spencer, 2003). However, it was thought that questions about family income might deter parents from long-term commitment to the longitudinal study before it had commenced. Consequently, the occupations of both groups were placed in categories according to those developed by Jones (2003) for parents in education programs, as occupation category has been found to impact the vocabulary learning of a child with hearing loss (Hart \& Risley, 1995) (see Table 2).

The heads of the household were then matched for highest education level reached (the father in the case of two-parent families or the mother/ income-earning partner in the case of other family models). All except one parent in both groups had undertaken education beyond high school, suggesting a moderate to high socioeconomic level in both groups. Earlier studies have found that parents of children in auditory-verbal therapy programs are likely to come from moderate to high socioeconomic levels (Dornan et al., 2007; Easterbrooks, O'Rourke, \& Todd, 2000; Rhoades \& Chisolm, 2000). This is acknowledged as a limitation of the study.

A preliminary analysis was carried out to ensure the validity of matching participant groups at the pretest; that is, the matching of language age and receptive vocabulary as indicated by total language age on the PLS- 4 or CELF3 , and the PPVT-3 results, respectively. The AVT group's PLS-4/CELF-3 mean age equivalent was 3.58 years $(\mathrm{SD}=1.39)$, and the mean for the TH group was 3.48 years $(\mathrm{SD}=1.38)$. Between-group $t$ tests showed no significant difference between these values $(t=0.260, p=0.796)$. Similarly, there was no significant difference between groups for the mean vocabulary age equivalents on the PPVT-3 $(t=2.80, p=0.906)$. The mean age equivalent on the PPVT-3 for the AVT group was 2.8 years $(\mathrm{SD}=1.29)$ and the mean for the TH group was 2.84 years $(\mathrm{SD}=1.31)$.

Table 2. Occupation category of head of the household for AVT group and TH group

\begin{tabular}{lcc}
\hline \multicolumn{1}{c}{ Occupation } & AVT Group & TH Group \\
\hline Manager & $43 \%$ & $15 \%$ \\
Professional & $14 \%$ & $65 \%$ \\
Technical/Trade & $29 \%$ & $5 \%$ \\
Community/Personnel & $7 \%$ & $0 \%$ \\
Clerical/Administrative & $7 \%$ & $10 \%$ \\
Sales & $0 \%$ & $5 \%$ \\
\hline
\end{tabular}


All speech perception and speech and language assessments are summarized in Table 3 (next page). A battery of speech perception tests were used to measure the level of understanding of speech and to ensure that the children in the AVT group were receiving sound optimally. Because of variation in the level of speech perception ability and the different ages of the AVT group, a battery of speech perception assessments was necessary to best assess the children's performance. The tests are shown in Table 3 in ascending order of difficulty. An audiologist administered the tests in this order according to the age and stage of listening of the child both at pretest and posttest. All speech perception tests were administered in a soundproof booth that met Australian Standards AS1269. Live-voice tests were presented in the audiologist's own voice, and recorded-voice tests were presented by using a recording at $65 \mathrm{dBA}$ in a quiet space.

\section{Procedure}

Clearance for this project was sought from the ethics committee of the auditory-verbal therapy program and was then referred to the program board of directors, which approved the project. Ethical clearance was also obtained from the Behavioural and Social Sciences Ethical Review Committee of the University of Queensland in Brisbane, Australia. After consent was obtained from the parents of each participant, arrangements were made to conduct the assessments.

The mean time between pretests and posttests was 21.88 months for the AVT group ( $\mathrm{SD}=1.22$ ) and 21.65 months for the TH group $(\mathrm{SD}=0.84)$, which was not significant $(t=1.095, p=0.279)$.

\section{Speech Perception}

The speech perception battery was presented to children in the AVT group in a soundproof booth by experienced pediatric audiologists at the child's auditory-verbal therapy program center. All speech perception tests were given either by live voice or by recorded voice and in the best aided condition. For children with cochlear implants, the child's optimally functioning MAP, as assessed by an audiologist and an auditory-verbal therapist, was used. Both " $\mathrm{T}$ " levels (threshold, or minimum amount of current allowing sound to be detected) and " $\mathrm{C}$ " levels (maximum amount of current causing discomfort) for the child's MAP were measured behaviorally and confirmed objectively where necessary. Optimal implant performance was verified by the stability of the MAP, and consistent identification by the child of the seven sound test, the Australian adaptation of Ling's Six Sound Test (Romanik, 1990). The "Ling sounds" are a range of speech sounds encompassing the frequencies that are 


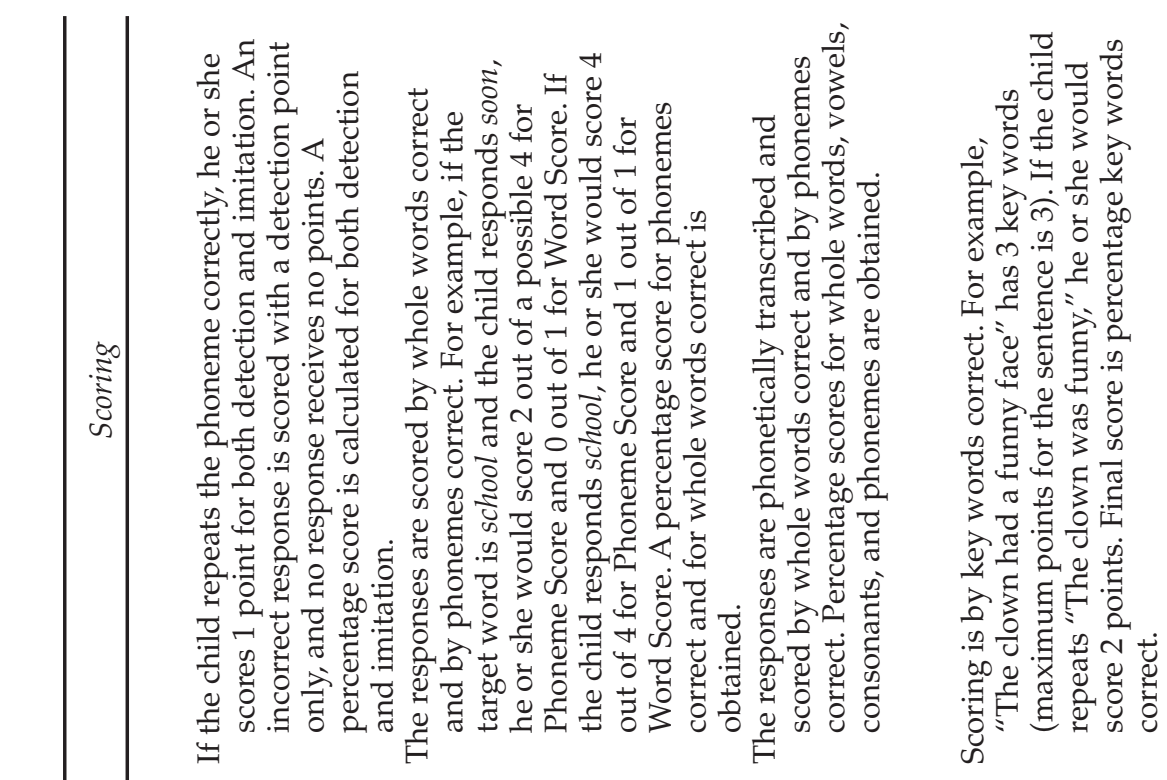




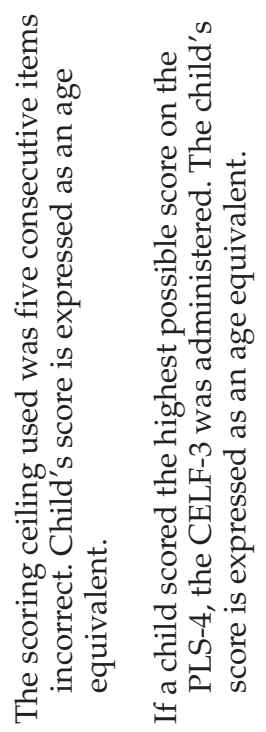

요<smiles>[131In]</smiles>

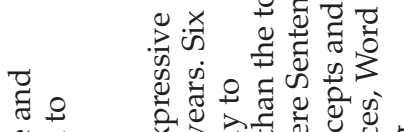

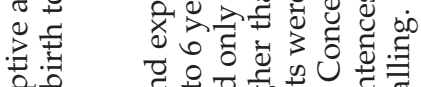
월 \&

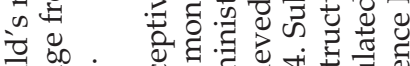

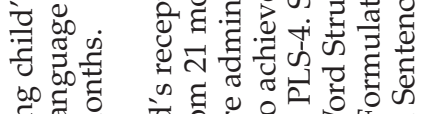

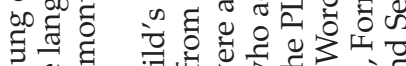

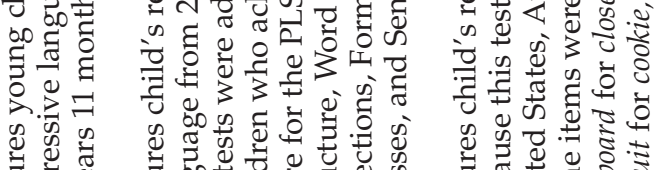

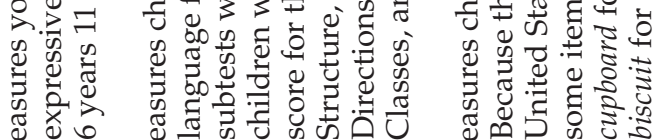
एक

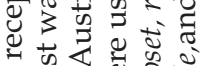

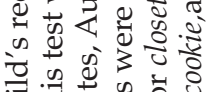

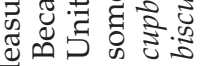

+1
0
0
0
0
0
0
0
0
0
0
0
0
0
0
0
0
0
0
0
0
0
0
0
0
0
0
0
0
0

$\dot{0}$
0
0
0
0
0
0
0
0
0
0
0
0
0
0
0
0
0
0
0
0
0
0
0
0
0
0
0
0

氙

荡贾

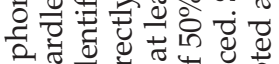
당

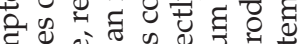

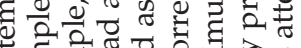

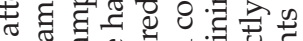
5 ऽ

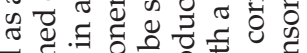

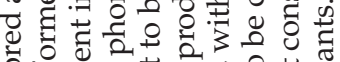
운 के

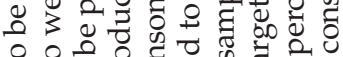

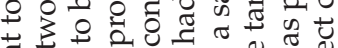

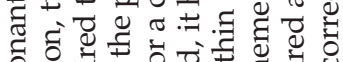
证.

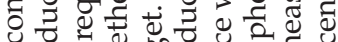

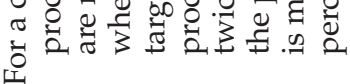

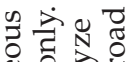

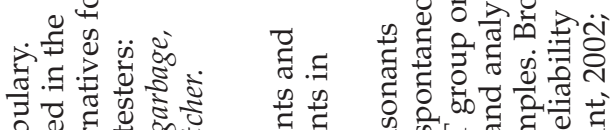
क्षे

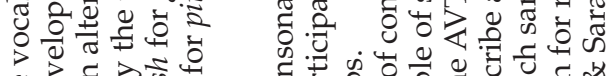

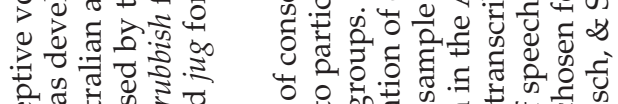

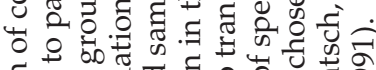

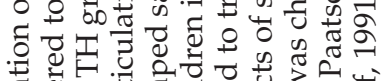

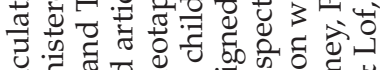

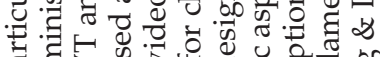

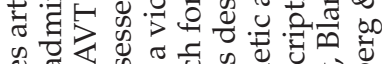
की

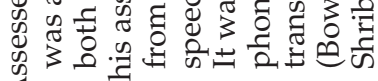

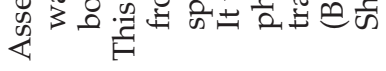

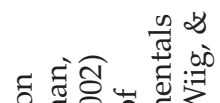

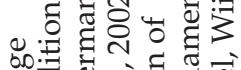
of:

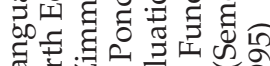
త

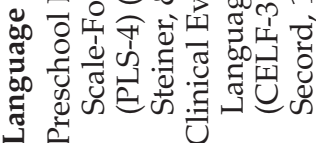

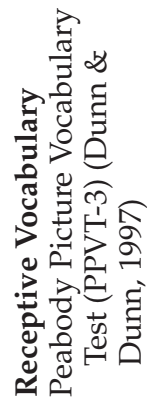


widely used clinically to verify the effectiveness of hearing aid fitting in children (Agung, Purdy, \& Kitamura, 2005). The Ling Six Sound Test was originally developed for the North American population (Ling, 2002), and in the seven sound test, / $/ \mathrm{J}$ was added to account for the differences in the production and spectral content of Australian vowels (Agung et al., 2005). Optimal implant performance was also verified through the use of other speech perception tests and the cochlear implant-assisted audiogram (a record of the child's cochlear implant-aided thresholds for responses at $250 \mathrm{~Hz}, 500 \mathrm{~Hz}, 1000 \mathrm{~Hz}$, $2000 \mathrm{~Hz}$, and $4000 \mathrm{~Hz}$ ). For the children who wore hearing aids, best aided condition was determined by an audiologist and an auditory-verbal therapist, performance of the seven sound test, speech perception tests, and the child's aided audiogram.

\section{Language and Speech}

The AVT group's assessments took place at the child's program center. For the TH group, testing was performed either at the head office of the child's auditory-verbal therapy program, at the child's education setting in a quiet room, or at the child's home. Speech and language testing was performed by experienced and qualified speech-language pathologists. Because of geographic constraints, the most convenient and available qualified staff performed the testing, and frequently, different testers assessed the children at the pretest and posttest. Tester reliability was not examined in the standardized assessments, as these were administered according to the standardized instructions in the test manuals. For the CASALA (Computer Aided Speech and Language Analysis; Serry, Blamey, Spain, \& James, 1997), inter-rater reliability was performed by having each of the speech-language pathologists perform an analysis on the samples of the same 8 children. The pair-wise intertester reliability ranged from $79 \%$ to $82 \%$ for broad transcription. These levels were similar to those obtained by Shriberg, Austin, Lewis, Sweeney, \& Wilson (1997), who also used CASALA to study speech development in children.

If possible, the language and speech tests were administered over one session; however, several children required two sessions because of age or attention difficulties. Children were given rest breaks between assessments, and the session was discontinued if a child showed evidence of fatigue or distress. The children's responses to the GFTA-2 were not transcribed and scored at a later date. Instead, whether consonant production was correct or not was decided by the tester at the time of testing.

The order of presentation of the standardized tests used was as follows. For the pretest, the AVT group were first administered the PLS-4 or CELF-3, the PPVT-3, and the GFTA-2. A spontaneous speech sample for CASALA analysis was tape recorded at this time. The group also received speech perception assessments and a parent survey. The order of testing for the TH group was different from the AVT group in order to account first for screening and then to 
establish a match with a child in the AVT group before the child was unnecessarily tested. The TH group was initially screened using pure-tone audiometry in both ears to determine thresholds at $500 \mathrm{~Hz}, 1000 \mathrm{~Hz}, 2000 \mathrm{~Hz}$, and 4000Hz. Thresholds needed to be within the range of $0-20 \mathrm{~dB}$ HL at all frequencies for both ears for inclusion in the TH group. If a child passed the screen, no further audiological tests were given to the TH group. Middle ear status was not checked unless the parent reported recent ear pain or reduced hearing. The GFTA-2 screen was also performed in the same initial session. Children who passed the screen were administered the PLS- 4 or CELF- 3 and the PPVT- 3 for matching purposes. The TH group children were then matched for total language, receptive vocabulary, gender, and socioeconomic level with the AVT group. At posttest, both groups received the same assessments, without the screening for the children in the TH group.

\section{CASALA}

A 5- to 7-minute spontaneous speech sample of each child with hearing loss was videotaped under predefined conditions at pretest and at posttest. These conditions included using a wall-mounted video camera, not easily identified and set 2 meters above the ground, allowing for full vision of the child's face. The child was seated in a high chair at a table 3 meters from the camera, with a high-quality microphone set on the table at 1 meter from the child. The parent was seated at the child's best hearing ear and was given instructions to interact with the child using a set group of toys. The parent was also given specific instructions that the session was not a therapy lesson but a play activity. The choice of toys was grouped under different scenarios ("babies," "transport," "animals," and "craft"). The aim was to obtain a sample of approximately 50 utterances, or 250 words.

\section{Results}

\section{Speech Perception}

The speech perception results for the AVT group on a battery of speech perception tests and results for the changes in scores at pretest and posttest are summarized in Table 4 (next page). Box plots were generated that showed some skewness in some variables at the 21 -month posttest. Where possible and appropriate, changes in speech perception skills from pretest to posttest were tested for significance using a Wilcoxon signed rank test, and the results are also reported in Table 4 . In two subtests, PLOTT Phoneme Detection $(100 \%$ at pretest $[\mathrm{N}=25]$ and $100 \%$ at posttest $[\mathrm{N}=24])$ and $\mathrm{CNC}$ Vowels $(95 \%$ at pretest $[\mathrm{N}=11]$ and $98.18 \%$ at posttest [ $\mathrm{N}=22])$, there was a ceiling effect at both pretest and posttest for some children, and statistical testing was not conducted. 


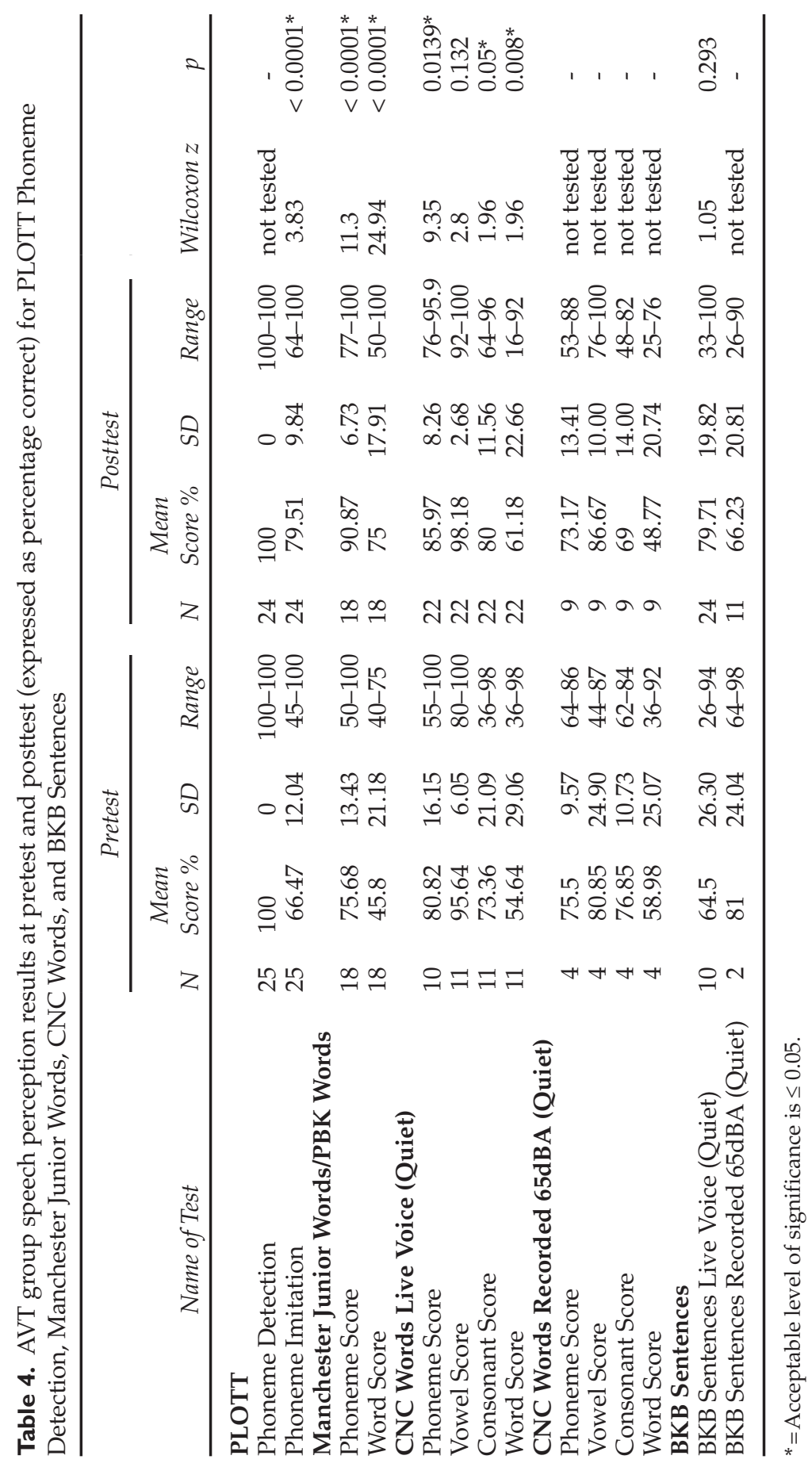


The tests were readministered at the posttest because testers were careful to check that hearing levels were consistent over time.

Also, not all tests were administered to each child because the AVT group had a wide range of speech perception abilities, which the battery of tests was chosen to cover. If a child had not attempted a test because it was too difficult, only the child's responses on the tests that were attempted were scored. The number of children completing more difficult recorded assessments was sometimes too few for analysis. The assessments that showed significant average improvement were PLOTT Phoneme Imitation ( $\mathrm{N}=24$ at both pretest and posttest); Manchester Junior Words/PBK Words with Word Score (N = 18 at both pretest and posttest); Phoneme Score ( $\mathrm{N}=18$ at both pretest and posttest); CNC Words with Phoneme Score ( $\mathrm{N}=10$ at pretest and $\mathrm{N}=24$ at posttest); Consonant Score ( $\mathrm{N}=11$ at pretest and $\mathrm{N}=22$ at posttest); Word Score ( $\mathrm{N}=11$ at pretest and $\mathrm{N}=22$ at posttest); and BKB Sentences Live Voice $(\mathrm{N}=10$ at pretest and $\mathrm{N}=24$ at posttest). All of these tests were administered via live voice (maximum $65 \mathrm{~dB}$ ) in a quiet setting.

\section{Standardized Language and Speech Assessments}

Table 5 contains a summary of the age-equivalent scores of the pretests and posttests for both groups on total language, receptive vocabulary, and speech. Paired sample $t$-tests were used to investigate change scores in each group. Two children from each group had reached the ceiling of the PLS-4 and were tested on the CELF-3 for language, and separate auditory comprehension and oral expression scores are not available for the CELF-3. Therefore, only 23 pairs were analyzed for these parameters, but 25 total language scores expressed as age equivalents were included in the analysis. The age-equivalent scores for the AVT group for auditory comprehension were 3.56 years at pretest $(\mathrm{SD}=1.06)$ and 5.17 years $(\mathrm{SD}=0.7)$ at posttest, which showed significant

Table 5. Summary of changes in age-equivalent scores in years for AVT group and TH group over 21-month test period and results of statistical analysis of change scores over time

\begin{tabular}{|c|c|c|c|c|c|c|c|c|c|}
\hline \multirow[b]{2}{*}{ Test } & \multirow[b]{2}{*}{ Group } & \multicolumn{3}{|c|}{ Pretest } & \multicolumn{3}{|c|}{ Posttest } & \multicolumn{2}{|c|}{ Statistical Result } \\
\hline & & $N$ & Mean & $S D$ & $N$ & Mean & $S D$ & $t$ & $p$ \\
\hline \multirow{2}{*}{$\begin{array}{l}\text { Total Language } \\
\text { (PLS-4/ CELF-3) }\end{array}$} & AVT & 25 & 3.58 & 1.33 & 25 & 5.56 & 1.15 & 20.84 & $<0.001^{*}$ \\
\hline & $\mathrm{TH}$ & 25 & 3.46 & 1.39 & 25 & 5.47 & 1.19 & 13.74 & $<0.001^{*}$ \\
\hline \multirow{2}{*}{$\begin{array}{l}\text { Receptive Vocabulary } \\
\text { (PPVT-3) }\end{array}$} & AVT & 25 & 2.79 & 1.29 & 25 & 4.77 & 1.21 & 12.26 & $<0.001^{*}$ \\
\hline & $\mathrm{TH}$ & 25 & 2.86 & 1.32 & 25 & 5.67 & 1.65 & 17.06 & $<0.001^{*}$ \\
\hline \multirow[t]{2}{*}{ Speech (GFTA-2) } & AVT & 25 & 3.02 & 1.33 & 25 & 4.58 & 1.17 & 8.10 & $<0.001^{*}$ \\
\hline & $\mathrm{TH}$ & 25 & 3.45 & 1.35 & 25 & 5.05 & 1.20 & 8.54 & $<0.001^{*}$ \\
\hline
\end{tabular}

* =significant difference 
improvement $(t=10.28, p=<0.001)$. Similarly, for oral expression, the AVT group had age-equivalent scores of 3.30 years $(\mathrm{SD}=1.02)$ at pretest and 5.27 years $(\mathrm{SD}=0.96)$ at posttest, which was also significant $(t=15.99$, $p=<0.001$ ). Significant improvements were found over time for both groups for total language, receptive vocabulary, and speech skills (see Table 5).

Between-group $t$-tests were used to investigate possible differences in change scores from pretest to posttest for both groups. The change scores for both groups were not significantly different for auditory comprehension $(t=1.44, p=0.157)$, oral expression $(t=0.21, p=0.834)$, total language $(t=0.12$, $p=0.905)$, or speech skills $(t=0.8, p=0.936)$. However, the change scores were significantly different for receptive vocabulary $(t=3.44, p=0.001)$ with the TH group showing significantly greater improvement than the AVT group.

\section{CASALA Speech Assessment}

A within-subject analysis of variance (ANOVA)was used to analyze the AVT group's CASALA results for percentage consonants attempted and percentage correct (see Table 6). The ANOVA showed that there were significant differences between the percentage of consonants attempted at the two points in time $(F=63.59, p=<0.0001)$, and that these differences varied for different consonants. Paired $t$-tests were subsequently conducted to determine if there was a difference between the number of consonants attempted at pretest and at posttest (Table 4). These tests showed that for five consonants $(/ \mathrm{n} /, / \mathrm{j} /$, $/ \mathrm{s} /, / \mathrm{J} /$, and $/ 1 /)$, there was strong evidence for an increase over time $(p=$ $<0.006)$. A conservative level of $p$ was chosen to guard against Type 1 error. For six additional consonants $(/ \mathrm{m} /, / \mathrm{t} /, / \mathrm{k} /, / \mathrm{f} /, / ð /$, and $/ \mathrm{z} /)$, there was less strong evidence for an increase over time $(p=<0.05)$. However, the percentage increase varied depending on the particular consonant being attempted.

The mean increase in percentage of consonants produced correctly was also analyzed using within-subject ANOVA. There was evidence of a significant increase in percentage consonants correct from pretest to posttest $(\mathrm{F}=16.32$, $p=<0.0001)$. Paired $t$-tests showed measurable significant increases for four consonants $(/ \mathrm{p} /, / \mathrm{k} /, / \mathrm{g} /$, and $/ \mathrm{f} / ; p=\leq 0.006)$, and positive but less strong evidence for six consonants $(/ \mathrm{n} /, / \eta /, / \mathrm{b} /, / \mathrm{v} /, / \mathrm{s} /$, and $/ \mathrm{t} \mathrm{f} / ; p=<0.05)$.

\section{Discussion}

The results showed that the AVT group made significant progress over a 21-month period in speech perception, auditory comprehension, oral expression, total language, and speech skills. Results also proved that the developmental progress of the AVT group for auditory comprehension, oral expression, total language development, and speech skills over a 21-month period was the same as that for the TH group. Both groups made the same progress in auditory comprehension, oral expression, and total language development as 


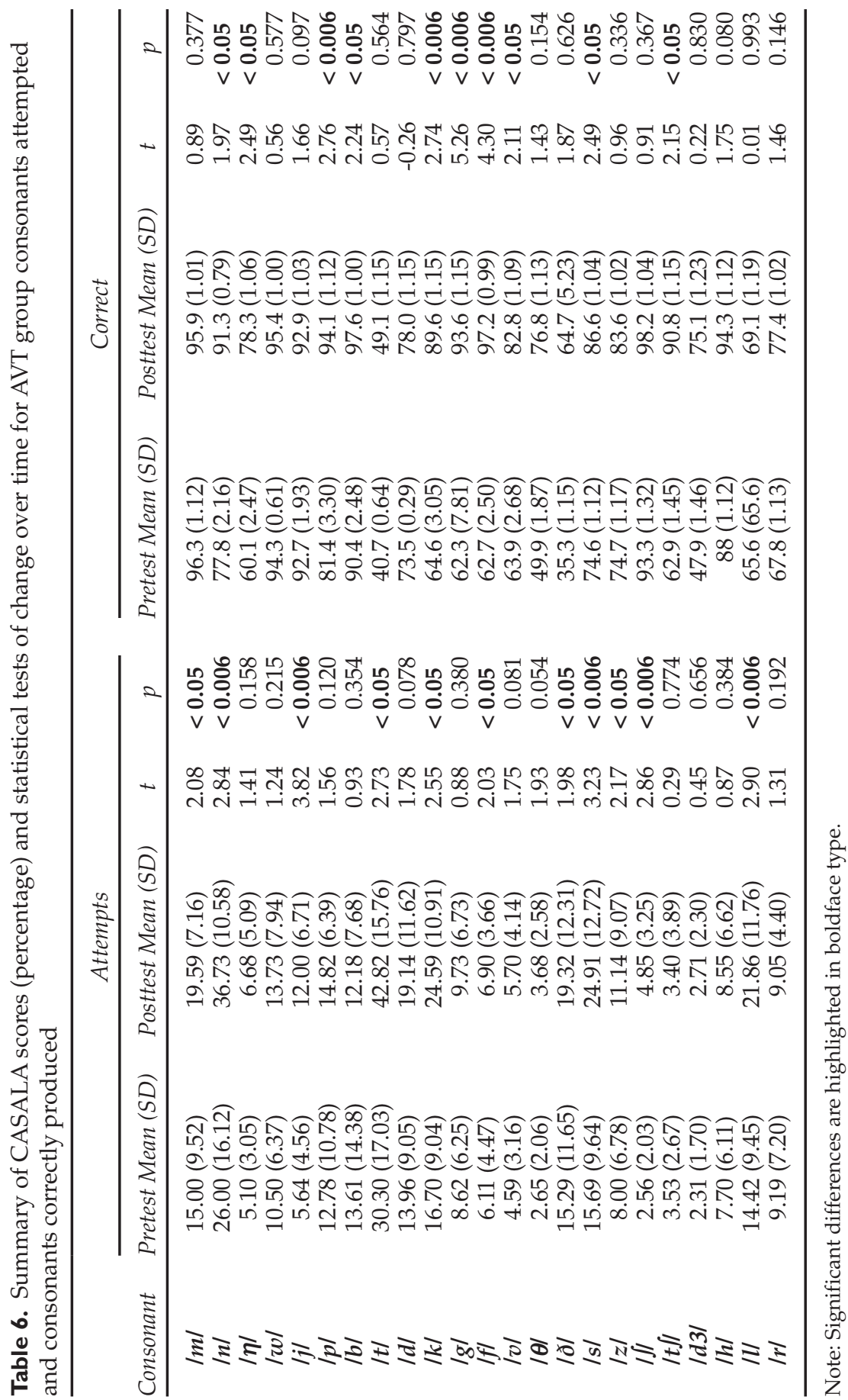


measured on the PLS-4 or the CELF-3 as well as speech skills as measured on the GFTA-2. However, a significant advantage was found in the TH group for receptive vocabulary as measured by the PPVT-3. Nevertheless, the AVT group scored within the typical range of the PPVT-3 for receptive vocabulary.

The AVT group showed significant improvement in speech perception skills for live-voice stimuli over the 21 months. It is suggested this may be a product of both their experience with their hearing devices and the effects of auditoryverbal therapy, but this study does not provide adequate evidence to prove the latter point. Improvements in speech perception following hearing aid fittings or cochlear implantation are well documented (e.g., Blamey et al., 2001; Svirsky, Teoh, \& Neuburger, 2004). However, while increasing numbers of the children in the study were able to perform open-set, live-speech perception tasks over time, it was much more difficult when the speech was a recorded signal; only small numbers of children were able to complete the tests administered via recording. Chute and Nevins (2000) have advocated for the use of live-voice testing with this population, as recorded-voice testing is too difficult for them.

The developmental progress for language skills of the AVT group was at the same rate as the control, TH group, and also the same as that expected for the population of children with typical hearing. Another study of developmental progress of total language in children with hearing loss was conducted by Blamey et al. (2001). The children in that study attended a listening and spoken language program and had a mean PTA of $78 \mathrm{~dB}$ HL. Findings indicated that these children, on average, progressed at half to two-thirds the rate expected for children with typical hearing; however, a typical hearing control group was not included in the research by Blamey and others (2001). This rate of development was not as fast as in the present study; however, it is not possible to draw definitive conclusions about the reasons, as other variables (i.e., beyond the type of educational intervention) may be involved.

At the 21-month posttest, the majority of children in the AVT group $(84 \% ; 21 / 25)$ had total language scores within the age-appropriate range (i.e., $+1 \mathrm{SD}$ or above) for their chronological age. At the pretest, only $55 \%$ $(16 / 29)$ of the group had age-appropriate total language scores. At the posttest, $84 \%(21 / 25)$ were within the typical range for receptive language, and $80 \%(20 / 25)$ were within the typical range or above for expressive language. At posttest, 2 children in the AVT group had language test scores that were more than 2 SD above the mean, while a further 2 children had scores that were more than 1 SD above the mean for their chronological age. Four children in the AVT group had scores that were $1 \mathrm{SD}$ below the mean. These results for language contrast with the results of Geers, Nicholas, and Sedey (2003), who reported that only $30 \%$ of 181 children ages 8 to 9 years old with cochlear implants (received implants before 5 years of age) scored within the typical range for receptive language, and $47 \%$ did so for expressive language. However, in the Geers et al. (2003) study, the mean age of implantation was 3.5 years and 
may have been influential, as the mean age of implantation for the AVT children in the present study was 2.29 years and the median age of implant was 1.92 years.

The change in PPVT-3 scores for the TH group was significantly higher than the change for the AVT group, with the TH group progressing 33.68 months in 21 months compared to 23.8 months for the AVT group. Nevertheless, the mean score for the AVT group was within the typical range for the test. Similar results were found by Schorr, Roth, and Fox (2008), who reported a statistically significant difference between PPVT-3 scores for a group of 39 children who are congenitally deaf, use a cochlear implant, and attend a range of different educational programs, and a matched group of children with typical hearing. As in the present study, the mean score for the children with hearing loss was still within the typical range for the test. Similarly, Pittman, Lewis, Hoover, and Stelmachowicz (2005) found that PPVT-3 scores for 37 children with moderate sensorineural hearing loss were consistently poorer when compared to scores for 60 children with typical hearing, with 5 children scoring more than 1 $\mathrm{SD}$ below the mean. The type of educational approach the children with hearing loss had experienced was not specified, but the authors concluded that children with hearing loss in that study had significantly less ability to learn new vocabulary than children with typical hearing.

The speech skill results for the AVT group show that their rate of progress for acquisition of consonants on the GFTA-2 was statistically the same as for the TH group. Articulation of consonants has been shown to be the major factor in speech intelligibility (Ling, 2002). At the start of the study, the results of consonant articulation for the AVT group were not statistically different from the TH group. This may reflect the fact that the children were matched for language age and had been in the AVT program for a mean of 20 months at the pretest. The excellent developmental results for speech found in the present study for the AVT group disagree with Marschark, Lang, and Albertini (2002), who reported that articulation skills are a primary area of difficulty for this population. They also disagree with Eisenberg (2007), who reported that the speech development of children with even a mild-to-moderate hearing loss is delayed. These results are in agreement with those of Schorr and others (2008), who compared GFTA-2 results for 39 children with cochlear implants (ages 5 to 14 years) with those of a group of children with typical hearing, matched for gender and chronological age. They found that the mean scores of the children with cochlear implants were within 1 SD of the mean of the group with typical hearing. The speech progress rate for the AVT group may have been the effect of experience following amplification with hearing aids or a cochlear implant (e.g., Allen, Nikolopoulos, \& O'Donohue, 1998), better language skills (Coerts \& Mills, 1995; Svirsky, 2000; Svirsky, Robbins, Kirk, Pisoni, \& Miyamoto, 2000), or an emphasis on communicating with listening and spoken language (Tobey, Geers, Brenner, Altuna, \& Gabbert, 2003). However, an interaction of factors is the most likely explanation for improved speech. 
Research has indicated that the combination of the use of listening and spoken communication plus early, intensive speech intervention increases the likelihood that children with significant hearing loss can acquire speech skills that are comparable to children with typical hearing of the same age, at least at the isolated single-word level (Schorr et al., 2008). The AVT group in the present study had attended the auditory-verbal therapy program for a minimum of 4 years, wore their amplification technology constantly, used listening and spoken language communication, had language skills that were not significantly different from the TH group, and received early, intensive speech intervention as an integral part of their auditory-verbal therapy program.

In addition to the positive findings for articulation of individual consonants in single words, the study of consonant development in spontaneous speech using CASALA indicated that the AVT group's acquisition of consonants appeared to follow the typical developmental sequence of consonants for Australian children (Kilminster \& Laird, 1978). These results are in agreement with an early study by Serry, Blamey, and Grogan (1997), who found that the speech of children with cochlear implants followed a development similar to that of children with typical hearing.

The present research has addressed some of the criticisms reported in studies on outcomes of auditory-verbal therapy by including a control group and carefully matching the participants in both groups, thereby providing a higher level of evidence (Oxford Centre for Evidence Based Medicine, 2001). The study design was prospective and included standardized assessments, and assessments were made at multiple points over time for both the AVT and TH groups. Also, the reasons for children dropping out of the study were described. The authors acknowledge that this group of children had minimal other disabilities, spoke only English, and were from relatively high-level socioeconomic backgrounds, which might reduce the comparability of this population with others. Further research is necessary to investigate the influence of socioeconomic status on outcomes for children with hearing loss, to determine the most appropriate way to measure this variable, and to determine if access to auditory-verbal therapy services due to socioeconomic level affects outcomes for a range of populations.

\section{Conclusion}

Overall, the AVT group of children maintained their promising developmental progress for auditory comprehension and oral expression, total language, and articulation of consonants demonstrated in the first 9 months of this study (Dornan et al., 2007). They continued this developmental progress at a rate statistically the same as that of the TH group of children who were matched for initial language age, receptive vocabulary, gender, and socioeconomic level. However, after the 9-month point, the TH group accelerated their progress for receptive vocabulary skills, performing significantly better than 
the AVT group. Nevertheless, acquisition of receptive vocabulary for the AVT group also progressed steadily at a rate similar to that of children with typical hearing (a change of 23.76 months in a 21-month period), with the vast majority $(84 \%)$ achieving scores that were age appropriate. This study will now continue to be extended longitudinally, using the same tests but with the addition of measures of literacy, numeracy, and self-esteem as the majority of the children enter formal schooling. In summary, for this particular population of children with hearing loss, auditory-verbal therapy was found to be an effective communication option, but more information is needed over longer time periods and with different populations.

\section{Acknowledgments}

Financial support for this study has been provided by the Hear and Say Centre; School of Health and Rehabilitation Sciences at the University of Queensland in Brisbane, Australia; Queensland Council of Allied Health Professionals; and the Commonwealth of Australia through the Cooperative Research Centre for Cochlear Implant and Hearing Aid Innovation (CRC HEAR, Australia). The authors also wish to acknowledge the support of the staff and parents of the Hear and Say Centre, Ellen McKeering, Dr. Melody Harrison, and Peter Dornan. Statistical analysis was performed by Dr. Ross Darnell of the School of Health and Rehabilitation Sciences at the University of Queensland in Australia and Gabriella Constantinescu of the Hear and Say Centre. Special thanks are due to Jane Thompson and Renee O'Ryan, who have helped prepare this manuscript.

\section{References}

Agung, K.B., Purdy, S.C., \& Kitamura, C. (2005). The Ling sound test revisited. Australian and New Zealand Journal of Audiology, 27(1), 33-41.

AG Bell Academy for Listening and Spoken Language. (2007). Auditory-verbal therapy. Retrieved January 12, 2008, from http:/ / www.agbellacademy.org/ AuditoryVerbalTherapy.htm.

Allen, M.C., Nikolopoulos, T.P., \& O’Donohue, G.M. (1998). Speech intelligibility in children after cochlear implantation. American Journal of Otology, 19(6), 742-746.

Bat-Chava, Y., Martin, D., \& Kosciw, J. (2005). Longitudinal improvements in communication and socialization of deaf children with cochlear implants and hearing aids: Evidence from parental reports. Journal of Child Psychology and Psychiatry, 46(12), 1287-1296.

Bench, J., \& Bamford, J.M. (1979). Speech hearing tests and the spoken language of hearing impaired children. London, England: Academic Press.

Blamey, P.J., Sarant, J., Paatsch, L., Barry, J.G., Bow, C.P., Wales, R.J., et al. (2001). Relationships among speech perception, production, language, hearing loss 
and age in children with impaired hearing. Journal of Speech, Language and Hearing Research, 44(2), 264-285.

Boothroyd, A., Geers, A., \& Moog, J.S. (1991). Practical implications of cochlear implants in children. Ear and Hearing, 12(4 Suppl.), 81S-89S.

Bow, C.P., Blamey, P., Paatsch, L., \& Sarant, J. (2002). Comparison of methods in speech acquisition research. Clinical Linguistics and Phonetics, 16(2), 135-147.

Ching, T., Psarros, C., \& Incerti, P. (2003). Management of children using cochlear implants and hearing aids. The Volta Review, 103(1), 39-57.

Chute, P.M., \& Nevins, M.E. (2000). Cochlear implants in children. In M. Valente, H. Hosford-Dunn, \& Roeser, R.J. (Eds.), Audiology Treatment (p. 525). New York, NY: Thieme.

Coerts, J., \& Mills, A. (1995). Spontaneous language development of young deaf children with a cochlear implant. Annals of Otology, Rhinology, and Laryngology, 166(Suppl.), 385-387.

Cone-Wesson, B., Dowell, R. C., Tomlin, D., Rance, G., \& Ming, W.J. (2002). The auditory steady state response: Comparisons with the auditory brain stem response. Journal of American Academy of Audiology, 13(4), 173-187.

Dornan, D., Hickson, L., Murdoch, B., \& Houston, T. (2007). Outcomes of an Auditory-Verbal Therapy program for children with hearing loss - A comparative study with a matched group of hearing children. The Volta Review, 107(1), 37-54.

Dornan, D., Hickson, L., Murdoch, B., \& Houston, T. (2008). Speech and language outcomes for children with hearing loss educated in Auditory-Verbal Therapy programs: A review of the evidence. Communicative Disorders Review, 2(3-4), 157-172.

Duncan, J. (1999). Conversational skills of children with hearing loss and children with typical hearing in an integrated setting. The Volta Review, 101(4), 193-211.

Duncan, J., \& Rochecouste, J. (1999). Length and complexity of utterances produced by kindergarten children with impaired hearing and their hearing peers. Australian Journal of Education of the Deaf, 5, 63-69.

Dunn, L.M., \& Dunn, L.M. (1997). Peabody Picture Vocabulary Test. Circle Pines, $\mathrm{MN}$ : American Guidance Service.

Durieux-Smith, A., Olds, J., Fitzpatrick, E., Eriks-Brophy, A., Duquette, C., Cappelli, M., et al. (1998). Outcome of AVT: Results of a follow-up study. American Speech and Hearing Association Leader, 3(16), 99.

Easterbrooks, S.R., O'Rourke, C.M., \& Todd, N.W. (2000). Child and family factors associated with deaf children's success in auditory-verbal therapy. American Journal of Otology, 21(3), 341-344.

Eisenberg, L.S. (2007). Current state of knowledge: Speech recognition and production in children with hearing impairment. Ear and Hearing, 28(6), 766-772.

Eriks-Brophy, A. (2004). Outcomes of Auditory-Verbal Therapy: A review of evidence and a call for action. The Volta Review, 104(1), 21-35. 
Fortnum, H.M., Summerfield, A.Q., Marshall, D.H., Davis, A.C., \& Bamford, J.M. (2001). Prevalance of permanent childhood hearing impairment in the U.K. and implication for universal neonatal hearing screening: Questionnaire based ascertainment study. British Medical Journal, 323(5), 536-539.

Geers, A. (2004). The ears of the deaf unstopped: Changes associated with cochlear implantation. Seminars in Hearing, 25(3), 257-268.

Geers, A. E. (2006) Spoken language in children with cochlear implants. In M. Marschark \& P. Spencer (Eds.) Advances in Spoken Language Development (pp 244-270). New York, NY: Oxford University Press.

Geers, A., Nicholas, J., \& Sedey, A. (2003). Language skills of children with early cochlear implantation. Ear and Hearing, 24(1), 46S-57S.

Goldberg, D.M., \& Flexer, C. (2001). Auditory-verbal graduates: An updated outcome survey of clinical efficacy. Journal of the American Academy of Audiology, 12(8), 406-414.

Goldman, R., \& Fristoe, M. (2001). Goldman-Fristoe Test of Articulation-2. Shoreview, MN: American Guidance Service.

Hart, B., \& Risley, T.R. (1995). Meaningful differences in the everyday experience of young American children. Baltimore, MD: Paul H. Brooks.

Joint Committee on Infant Hearing. (2007). [Year] 2007 position statement: Principles and guidelines for early hearing detection and intervention. Pediatrics, 102(4), 893-921.

Jones, R. (2003). Parental occupation coding. Report submitted to Performance Measurement and Reporting Taskforce, Ministerial Council on Education, Employment Training and Youth Affairs. Appendix 4, 33-34. Retrieved June 8, 2009, from http://www.curriculum.edu.au/verve/_resources/ parentaloccupation_file.pdf

Kilminster, M.G.E., \& Laird, E.M. (1978). Articulation development in children aged three to nine years. Australian Journal of Human Communication Disorders, 6(1), 23-30.

Kumar, S., et al. (2008). Literature review of current best practice in early intervention for children with a permanent hearing loss. Technical report produced for Queensland Health. Retrieved June 7, 2009, from http://www.health.qld.gov.au/healthyhearing/pages/publications.asp.

Ling, D. (2002). Speech and the hearing impaired child: Theory and practice (2nd ed.). Washington, DC: Alexander Graham Bell Association for the Deaf and the Hard of Hearing.

Marschark, M., Lang, H.G., \& Albertini, J.A. (2002). Educating deaf students: From research to practice. New York, NY: Oxford University Press.

Marschark, M., \& Spencer, P.E. (2003). Oxford handbook of deaf studies, language, and education. New York, NY: Oxford University Press.

Nicholas, J.G., \& Geers, A. (2007). Will they catch up? The role of age of cochlear implantation in the spoken language development of children with severe to profound hearing loss. Journal of Speech, Language, and Hearing Research, 50(4), 1048-1062. 
Nunes, T., \& Moreno, C. (2002). An intervention program for promoting deaf pupils' achievement in mathematics. Journal of Deaf Studies and Deaf Education, 7(2), 120-133.

Olusanya, B.O., Ruben, R.J., \& Parving, A. (2006). Reducing the burden of communication disorders in the developing world: An opportunity for the Millennium Development Project. Journal of the American Medical Association, 296(4), 441-444.

Oxford Centre for Evidence Based Medicine. (2001). Levels of evidence and grades of recommendation. Retrieved May 22, 2008, from http://www.cebrn.net/levels_of_evidence.asp

Peterson, G.E., \& Lehiste, I. (1962). Revised CNC lists for auditory tests. Journal of Speech and Hearing Disorders, 27, 62-70.

Pittman, A.L., Lewis, D.L., Hoover, B.M., \& Stelmachowicz, P.G. (2005). Rapid word-learning in typical-hearing and hearing-impaired children: Effects of age, receptive vocabulary, and high frequency amplification. Ear and Hearing, 26(6), 619-629.

Plant, G. (1984). A diagnostic list for severely and profoundly hearing-impaired children. Australian Journal of Audiology, 6(1), 1-9.

Rhoades, E.A. (2001). Language progress with an auditory-verbal approach for young children with hearing loss. International Pediatrics, 16(1), 41-47.

Rhoades, E.A. (2006). Research outcomes of auditory-verbal intervention: Is the approach justified? Deafness Education International, 8, 125-143.

Rhoades, E.A., \& Chisolm, T.H. (2000). Global language progress with an auditory-verbal approach. The Volta Review, 102(1), 5-25.

Romanik, S. (1990). Auditory skills curriculum. Moorebank, Australia: New South Wales Department of Education and Training.

Schorr, E. A., Roth, F. P., \& Fox, N. (2008). A comparison of the speech and language skills of children with cochlear implants and children with typical hearing. Communication Disorders Quarterly, 29(4), 195-205.

Semel, E., Wiig, E. H., \& Secord, W. A. (1995). CELF Clinical Evaluation of Language Fundamentals (3rd ed.). San Antonio, TX: The Psychological Corporation, Harcourt Brace \& Company.

Serry, R., Blamey, P., \& Grogan, M. (1997). Phoneme acquisition in the first 4 years of implant use. American Journal of Otology, 18(6 Suppl.), 122S-124S.

Serry, R., Blamey, P., Spain, P., \& James, C. (1997). Computer Aided Speech and Language Analysis. Australian Communication Quarterly(Spring), 27-28.

Sharma, A., Dorman, M.F., \& Kral, A. (2005). The influence of a sensitive period on central auditory development in children with unilateral and bilateral cochlear implants. Hearing Research, 203(1-2), 134-143.

Shriberg, L.D., Austin, D., Lewis, B.A., Sweeney, J.L., \& Wilson, D.L. (1997). The percentage of consonants correct (PCC) metric: Extensions and reliability data. Journal of Speech, Language, and Hearing Research, 40(4), 708-722.

Shriberg, L.D., \& Lof, G.L. (1991). Reliability studies in broad and narrow transcriptions (phonetic). Clinical Linguistics and Phonetics, 5, 225-227. 
Sininger, Y. (1999). Auditory system development, experimental auditory deprivation, and development of speech perception and hearing. The case for early identification of hearing loss in children. Pediatric Clinics of North America, 46(1), 1-14.

Sussman, K.D., Duncan, J., Estabrooks, W., Hulme, J., Moog, J.S., \& McConkey Robbins, A. (2004). The option of spoken communication. Proceedings of 2004 Summit on Deafness-Spoken Language Options in the $21^{\text {st }}$ Century: Predicting Future Trends in Deafness. Washington, DC: Alexander Graham Bell Association for the Deaf and Hard of Hearing.

Svirsky, M.A. (2000). Language development in children with profound and prelingual hearing loss, without cochlear implants. Annals of Otology, Rhinology, and Laryngology, 185(Suppl.), 99-100.

Svirsky, R., Robbins, A.M., Kirk, K.I., Pisoni, D.B., \& Miyamoto, R.T. (2000). Language development in profoundly deaf children with cochlear implants. Psychological Science, 11(2), 153-158.

Svirsky, M.A., Teoh, S.W., \& Neuberger, H. (2004). Development of language and speech perception in congenitally, profoundly deaf children as a function of age at cochlear implantation. Audiology and Neuro-Otology, 9(4), 224-233.

Tobey, E.A., Geers, A., Brenner, C., Altuna, D., \& Gabbert, G. (2003). Factors associated with speech production skills in children implanted by age five. Ear and Hearing, 24(Suppl.), 36S-45S.

Traxler, C.B. (2000). The Stanford Achievement Test, $9^{\text {th }}$ Edition: National Norming and Achievement Standards for Deaf and Hard-of-Hearing Students. Journal of Deaf Studies and Deaf Education, 5, 337-348.

Uus, K., \& Bamford, J. (2006). Effectiveness of population-based newborn hearing screening in England: Ages of interventions and profile of cases. Paediatrics, 117(5), 887-893.

Wake, M. (2002). Newborn hearing screening: Decision time for Australia. Medical Journal of Australia, 177, 172-173.

Watson, T.J. (1957). Speech audiometry for children. In A.W.G. Ewing, Educational Guidance and the Deaf Child (pp. 278-296). Manchester, England: The University Press.

Yoshinaga-Itano, C., Sedey, A.L., Coulter, D.K., \& Mehl, A.L. (1998). Language of early and later identified children with hearing loss. Pediatrics, 102(5), 1161-1171.

Zimmerman, I.L., Steiner, V.G., \& Pond, R.E. (2002). Preschool Language Scale-4. San Antonio, TX: The Psychological Corporation, Harcourt Brace \& Company. 



\title{
Building the Alphabetic Principle in Young Children Who Are Deaf or Hard of Hearing
}

\author{
Jessica Page Bergeron, M.E.D.; Amy R. Lederberg, Ph.D.; \\ Susan R. Easterbrooks, Ed.D.; Elizabeth Malone Miller, M.S.; and \\ Carol McDonald Connor, Ph.D.
}

Acquisition of phoneme-grapheme correspondences, a key concept of the alphabetic principle, was examined in young children who are deaf or hard of hearing (DHH) using a semantic association strategy embedded in two interventions, the Children's Early Intervention and Foundations for Literacy. Single-subject design experiments using multiple baselines across content were used to examine the functional relationship between student outcomes and the intervention provided. Only students who were able to identify spoken words were included in the studies. Study One was conducted with 5 children 3.10-7.10 years of age in oral or signing programs. Study Two was conducted with 5 children 3.10-4.5 years of age in an oral program. All children acquired taught phoneme-grapheme correspondences. These findings provide muchneeded evidence that children who are DHH and who have some speech perception abilities can learn critical phoneme-grapheme correspondences through explicit auditory skill instruction with language and visual support.

Jessica Page Bergeron, M.E.D., is a Cognitive Developmental Specialist in the Department of Educational Psychology and Special Education at Georgia State University; Amy R. Lederberg, Ph.D., is a Professor in the Department of Educational Psychology and Special Education at Georgia State University; Susan R. Easterbrooks, Ed.D., is the Coordinator of the Deaf/Hard of Hearing Program in the Department of Educational Psychology and Special Education at Georgia State University; Elizabeth Malone Miller, M.S., is a Cognitive Developmental Specialist in the Department of Educational Psychology and Special Education at Georgia State University; Carol McDonald Connor, Ph.D., is an Associate Professor in Psychology at Florida State University and the Florida Center for Reading Research. Correspondence concerning this article should be addressed to Ms. Bergeron at jpage3@gsu.edu 


\section{Introduction}

Children and youth who are deaf or hard of hearing (DHH) frequently fail to attain proficient reading skills by the time they reach high school, a trend that has been well documented over the past three decades (Holt, 1994; Traxler, 2000). At the same time, educators of children who are DHH have endeavored to find appropriate and effective instruction for literacy skill development with limited success. For children with typical hearing, an auditory-based skill, such as the alphabetic principle (the knowledge that letters represent phonemes in spoken language and are blended to make spoken words), is considered an essential component of literacy development (National Reading Panel, 2000). The purpose of the current study is to determine the effectiveness of an intervention focused on the building of phoneme-grapheme correspondences, which is the foundation of the alphabetic principle, when implemented with young children who are DHH.

Traditional reading instruction in the education of children who are $\mathrm{DHH}$ has focused on the development of language and vocabulary (Spencer, Tomblin, \& Gantz, 1997) rather than on instruction of the alphabetic principle because of the children's lack of spoken word knowledge (Schirmer, 2001). For example, in a 1997 survey, more than $70 \%$ of teachers who work with children who are DHH stated that they used special basal readers and language experience approaches to teach reading (LaSasso \& Mobely, 1997). Perfetti and Sandak (2000) posited that lack of phonological representation of words was a factor in the lower literacy levels among students with severe to profound hearing losses: "[there is a] fundamental discrepancy between their incomplete spoken language system and the demands of reading a speech-based system" (p. 47).

In the past 10 years, more sophisticated technology, including cochlear implants, has mitigated at least some of the documented barriers to the development of an auditory-based phonological foundation for reading in children who are DHH. Federally mandated Newborn Hearing Screening (1993) has also allowed children who are DHH access to this technology and early intervention services at a much earlier age. Cochlear implants provide substantial auditory information as well as improved speech perception abilities for children who do not benefit from conventional amplification (Cheng, Grant, \& Niparko, 1999; Spencer \& Oleson, 2008). For children with hearing aids, improved technology has resulted in amplification that more closely matches their hearing loss, which allows for an overall increase in the quality and comprehension of sound (Parker, 2002).

These changes have yielded a new generation of children who are $\mathrm{DHH}$. Easterbrooks, Lederberg, Miller, Bergeron, and Connor (2008) found that more than $70 \%$ of children ages 3 to 7 years who attended either signing or oral selfcontained DHH classrooms in a large metropolitan area and who had no additional disabilities were able to identify spoken words. Compared to previous 
generations, a greater number of children who are $\mathrm{DHH}$ may now have the ability to read using processes similar to those used by children with typical hearing. In other words, many children who are DHH have a more complete representation of spoken language than previous generations.

\section{Building the Alphabetic Principle}

Alphabetic knowledge, the foundation of the alphabetic principle, is defined as the knowledge that "written graphemes correspond to the phonemes of spoken words" (Scarborough \& Brady, 2002, p. 322). The earliest building block of this skill is learning phoneme-grapheme correspondences. Higher levels of this letter knowledge are associated with a child's ability to detect and manipulate phonemes (Stahl \& Murray, 1994). The letter knowledge of children with typical hearing in preschool, kindergarten, and first grade is predictive of their growth in phonological awareness over a one- to two-year period (Burgess \& Lonigan, 1998; National Early Literacy Panel Report, 2009). For children who are DHH with spoken language abilities, Easterbrooks and others (2008) found that alphabetic knowledge, as measured by the number of phoneme-grapheme correspondences children knew, strongly correlated with phonological awareness and early literacy skills concurrently and over time. Unfortunately, many children who are DHH still have weak alphabetic knowledge (Aram, Most, \& Mayafit, 2006; Easterbrooks et al., 2008).

The National Reading Panel (2000) and the more recent National Early Literacy Panel (NELP, 2009) reported that for children with typical hearing, regardless of socioeconomic status, explicit instruction in building alphabetic knowledge strongly supports reading development, as it contributes to growth in decoding, comprehension, and spelling. For children who are DHH, Schirmer and McGough (2005) concluded that, at the time of publication, no studies specifically addressed building alphabetic knowledge. Since then, the limited research on interventions that include phoneme-grapheme correspondence instructions for young readers who are DHH suggests such instruction might have a significant effect on reading skills. Trezek and Malmgrem (2005) found that middle school students who are DHH were able to acquire phoneme-grapheme correspondences when instructed with SRA Corrective Reading where the phonemes are expressed using Visual Phonics (hand movements that represent articulation of phonemes; Waddy-Smith \& Wilson, 2003). Other studies of elementary-aged students who are DHH have found that instruction in phoneme-grapheme correspondences improved their performance on phonological awareness, word identification, and non-word decoding in standardized assessments (Aghababian, Nazir, Lancon, \& Tardy, 2001; Trezek \& Wang, 2006; Trezek, Wang, Woods, Gampp, \& Paul, 2007). The latter two studies used curriculum designed for children with typical hearing to teach phonics by making articulatory information "visible" through Visual Phonics. Visual Phonics is hypothesized to provide children who are DHH 
with multisensory experiences that support the acquisition of the alphabetic principle (Morrison, Trezek, \& Paul, 2008).

\section{Purpose}

The purpose of the current research was to assess the effectiveness of a semantic association strategy for teaching phoneme-grapheme correspondences in young children who are DHH. Research on children with typical hearing has found that instructional strategies that create meaningful associations between letters and sounds or names improve learning. Instructional strategies include picture mnemonics that create a meaningful association between a letter shape and a word that begins with the letter (e.g., drawing an $f$ to resemble a flower; Ehri, Deffner, \& Wilce, 1984), and providing a kinesthetic cue for producing the phoneme (e.g., LiPS picture cards; Lindamood \& Lindamood, 2005). Similar to LiPS picture cards, Visual Phonics provide haptic and kinesthetic cues to the articulatory sequences of phoneme production (Morrison et al., 2008).

The semantic association instructional strategy was based on a strategy used to teach phoneme-grapheme correspondences in the Children's Early Intervention (CEI) program (Tade \& Vitali, 1994), a curriculum developed for children with communication disorders. Phoneme-grapheme correspondences are taught through stories accompanied by a picture that builds an association between the phoneme and grapheme by embedding them in a meaningful context (e.g., the letter $/ \mathrm{m} /$ is associated with the phoneme $\mathrm{mmm}$ through a story in which a child eats ice cream and says mmm-mmm, that's good). While other approaches provide semantic cues to letters (e.g., picture mnemonics; Ehri et al., 1984), this approach provides semantic cues to remember the phonemes - a likely source of difficulty for young children who are DHH (Morrison et al., 2008). The semantic instructional strategy of teaching phoneme-grapheme correspondences can also incorporate other aspects important to early reading instruction, especially for children with language delays, such as vocabulary and comprehension of stories (Morrison et al., 2008; NELP, 2009). While the approach appeared successful in a local school program for children who are $\mathrm{DHH}$, no published research (to our knowledge) has established its effectiveness.

We expanded on the original strategy in two ways: First, after the story was read, the children enacted the story (e.g., made ice cream sundaes). In addition to further cementing the semantic association by ensuring children understand and "feel" the story, these language experiences provided multiple opportunities for teachers and students to produce the isolated phoneme in a fun context. Second, small picture cards, called concept cards, were used as semantic cues to the phonemes (e.g., picture of an ice cream sundae for the phoneme $/ \mathrm{m} /$ ) in activities where children were asked to recall the phonemes. For example, these concept cards were used in activities where the children decoded or sounded out words. 


\section{Theoretical Basis}

Paivio (1971) posited a Dual Coding Theory (DCT) of general cognition that in recent years has been applied to literacy (Sadoski \& Paivio, 2004) and provides an "account of the relationships among decoding, comprehension, and response" (p. 1329). DCT proposes that experiences are coded as logogens (language codes) or imagens (nonverbal codes), and that all experiences can contain elements of both representational systems. Further, haptic representations (i.e., kinesthetic or tactile) contribute to the mental models we make of experiences. The semantic association strategy is consistent with this theory, although no single theory can explain all the complexities of the literacy acquisition process (Strain, Patterson, \& Seidenberg, 2002). Concept cards provide the "glue" that binds a phoneme to a grapheme by focusing on a child's haptic representation of an experience. For example, the young child who experienced delicious enjoyment of an ice cream sundae while murmuring " $\mathrm{mmm}$ " may represent that haptic experience in his logogenic and imagenic system. The concept cards then provide an external representation of that haptic imagen (the deliciousness). This is then chained to, or provides a bridge between, grapheme and phoneme, activating a representation. "When enough input is received from any one source or a combination of sources, the representation is activated" (Sadoski \& Paivio, 2004, p. 1333). In other words, the haptic and mental imagery of an experience embedded contextually in the concept card provides the meaningful link between grapheme and phoneme. The mental model the child develops will be a combination of phoneme, imagen, and grapheme. Some children will take longer than others to link graphemes to phonemes. Some will quickly grasp the link between grapheme and phoneme and will drop the imagen earlier than others. Still others will need the "glue" for a longer period before associations between graphemes and phonemes become automatic.

\section{Research Design}

Study One occurred during the first year of a 4-year research project that developed an early literacy curriculum for young children who are $\mathrm{DHH}$ with some spoken word identification skills (and therefore have representation of English phonemes). We assessed the effectiveness of the semantic association strategy using stories and pictures from the CEI embedded in a 35-minute-a-day intervention program. Study Two, implemented in the fall following Study One, assessed the effectiveness of this strategy embedded in a newly created, 60-minute-a-day early literacy curriculum called Foundations for Literacy (Lederberg, Miller, Easterbrooks, Bergeron, \& Connor, 2009). This curriculum was designed to provide both code-based (alphabetic knowledge and phonological awareness skills) and meaning-based (vocabulary and comprehension) instruction (NELP, 2009) while specifically adapting to the needs 
of prekindergarten children who are $\mathrm{DHH}$ by providing multimodality support (Morrison et al., 2008).

A multiple-baseline probe design across content (i.e., correspondences) was used in both studies to determine if a functional relationship existed between the intervention and the acquisition of phoneme-grapheme correspondences for individual children who are DHH. Multiple-baseline design is a preferred design to assess acquisition of learned behaviors that cannot be "unlearned" (Kazdin, 1982), such as when examining literacy interventions (BargerAnderson, Domaracki, Kearney-Vakulick, \& Kubina, 2004). Evaluations of effective instructional techniques with children who are DHH can be challenging because of small sample sizes and large variability, which makes control groups very difficult to obtain. By using a single-subject design, children are used as their own controls, and individual differences in instructional effectiveness can be analyzed. The effectiveness of instruction for children who vary in age, language, and hearing abilities is apparent from analyzing the results by individual children. In addition, single-subject designs can determine the efficiency of the intervention by measuring how many instructional sessions are necessary for acquisition to occur (Kazdin, 1982).

\section{STUDY ONE}

\section{Method}

\section{Setting and Participants}

We implemented the intervention in two schools. The first was a 42-student, auditory/oral program (78.5\% received financial aid) within a larger, 401student school in which $6 \%$ of students were African-American, $85 \%$ were Caucasian, $2 \%$ were Hispanic or Latino, 3\% were Asian, and $4 \%$ were classified as Other (demographics from 2007-2008). The second school used Simultaneous Communication and American Sign Language (ASL) with its 193 students (referred to as the "signing program" in this paper). All the students were eligible for free or reduced-price meals, and $45 \%$ were AfricanAmerican, 22\% were Caucasian, 26\% were Hispanic or Latino, $4 \%$ were Asian, and 3\% were classified as Multiracial (demographics from 2006-2007).

All participants were selected based on the following criteria: (1) an unaided pure tone hearing (PTA) loss of $55 \mathrm{~dB}$ in the better ear, average or greater, (2) enrolled in a prekindergarten, kindergarten, or first grade classroom, (3) no additional disabilities of a significant nature, (4) no previous exposure to the CEI, (5) lack of knowledge of a majority of the targeted phoneme-grapheme correspondences, and (6) a score of 3 or 4 (i.e., at least some spoken word identification) on the Early Speech Perception Test (ESP) (Moog \& Geers, 1990). (The ESP assesses pattern and spoken word discrimination through pictures or objects in a closed set format. 
Table I. Participant demographics

\begin{tabular}{lllllllll}
\hline & & \multicolumn{1}{c}{$\begin{array}{c}\text { Standard } \\
\text { Score } \\
\text { WJAT-III } \\
\text { Participant }\end{array}$} & \multicolumn{1}{c}{ Age } & Gender & PTA & Age & $\begin{array}{c}\text { ESP } \\
\text { Expressive }\end{array}$ \\
\hline Adam & 3.10 & M & CI & 6 months & 4 & 92 & Auditory-Oral/preschool \\
Kyle & 4.2 & M & CI & 16 months & 4 & 97 & Auditory-Oral/preschool \\
Sid & 5.6 & M & CI & 22 months & 4 & 92 & Sign/kindergarten \\
Arnold & 6.8 & M & 68 & 42 months & 4 & 79 & Sign/1st grade \\
Jason & 7.10 & M & 76 & 34 months & 4 & 76 & Sign/1st grade \\
\hline
\end{tabular}

Note. Age expressed in years.months; Listening age $=$ chronological age minus age received first implant or amplification; PTA = pure tone hearing; ESP = Early Speech Perception Test; WJAT-III $=$ Woodcock-Johnson ${ }^{\circledR} I I I$ NU Test of Achievement-Expressive Vocabulary subtest.

The results place children into one of four speech perception categories: $1=$ no pattern perception, 2 = pattern perception, 3 = some word identification, and $4=$ consistent word identification.) School personnel assisted in identifying children who met our criteria. Because the auditory/oral program uses the CEI in its kindergarten curriculum, only five 4-year-olds were eligible for the study. Of those, 3 children already knew many of the targeted phoneme-grapheme correspondences and were therefore excluded from the study. As shown in Table 1, the 2 children included in the study were young (3.10 and 4.1 years of age) and used cochlear implants. At the signing school, $40 \%$ of the prekindergarten, kindergarten, or first graders had an ESP score of 3 or 4 ( 6 children). Baseline probes showed that 2 of these children already had a majority of the targeted phoneme-grapheme correspondences, and 1 child was anxious about leaving his classroom and therefore could not be considered an assenting participant in the study. The remaining 3 children met all six criteria and participated in the study. These children were in kindergarten or first grade and included 2 children who had a severe hearing loss and wore hearing aids and 1 child who used a cochlear implant. While participating in this study, all students wore their personal amplification devices.

The intervention took place over a period of 8 or 9 weeks, 4 days per week for about 35 minutes each day, in a pullout model of instruction. Children were instructed in small groups $(n=2$ or 3$)$ by two research-teachers who were employed as members of the research team. A state-certified teacher of the deaf with 5 years of experience working with the CEI curriculum in an auditory/oral setting instructed the two-student group in the auditory/oral program. A state-certified teacher of the deaf with 17 years of experience working with students who were DHH instructed the three-student group at the signing program. This teacher was fluent in ASL and used a mix of ASL and sign-supported speech for instruction. 


\section{Experimental Design}

A multiple baseline probe across content (phoneme-grapheme correspondences) was used to determine the effects of the intervention. Unlike many single-subject designs, instruction was implemented according to a prescribed scope and sequence, and was overall the same for all children regardless of prior knowledge or acquisition. This was because the goal of the study was to evaluate a curriculum the way it would be implemented in a typical school setting. This design was also used to determine effectiveness of the curriculum for individual students. Therefore, decision rules for criterion are based on individual performance and subsequent analysis is for the individual rather than for the instructional group.

\section{Independent and Dependent Variables}

The independent variable of this study was the semantic association strategy used to explicitly teach phoneme-grapheme correspondences embedded in the literacy intervention. The dependent variable assessed the acquisition of phoneme-grapheme correspondences through a spoken-production assessment. The expressive assessment consisted of a prompt, "What sound?" when shown a grapheme on either an index card or letter tile. Data were recorded as the number of correctly produced (spoken) correspondences when given three trials.

\section{Procedures for Intervention}

\section{Baseline}

Children were taken out of their regular classroom for 35 minutes over a period of 4 days during 1 week for baseline assessment. In addition to administering the baseline assessments, teachers read stories to and played with the children using activities that were unrelated to the intervention.

\section{Intervention}

The intervention used the pictures and stories from the CEI to teach phoneme-grapheme correspondences. The CEI was designed as a curriculum for children who have delays in speech, language, or reading, and emphasizes speech production and language development. The scope and sequence of the CEI curriculum introduces the sounds that are the easiest to produce first, based on the development of speech in children with typical hearing. Correspondences were taught in the following order: $m$, long $e, b$, long $o, t, s, p$, long $i$, and $f$. While some of these graphemes are associated with multiple phonemes (e.g., /e/), only one phoneme is introduced at a time. 
Teachers introduced a new phoneme-grapheme correspondence approximately every fourth session (with the exception of $m$ and long $e$, which were taught on the same day). The framework of the weekly lessons is described below, followed by an example from the first week's lessons. Only activities that are relevant to instruction of the phoneme-grapheme correspondences are described. The teacher's mouth was visible during introduction of each phoneme as well as during instruction.

\section{Day 1: Story}

The target phoneme-grapheme correspondence was introduced by reading the appropriate CEI story illustrated by a picture card (called large concept card).

Example of a lesson: Phoneme: /m/, Grapheme: Mm

Large concept card: A boy eating ice cream, with the letters $\mathbf{M}$ and $\mathbf{m}$ on the card.

Teacher: This is George, and he loves ice cream sundaes. When George looks at an ice cream sundae, he opens his eyes wide and says a long $/ \mathrm{m}-\mathrm{m}-\mathrm{m} /$. [Signals the children to make the sound $/ \mathrm{m} /$ ]. George likes to write $/ \mathrm{m} /$.

Children practiced saying $m$ while the teacher pointed to the $\mathbf{m}$ on the large concept card.

\section{Day 2: Language Activity}

The CEI story was again read while referring to the large concept card. Then, to build a strong semantic association between the picture and the phoneme, teachers and children enacted this story. Of note, these activities were not part of the CEI curriculum and thus represent an enhancement. The language experience activity always involved multiple opportunities to produce the isolated phoneme in a meaningful context. The teacher corrected the children's production when necessary. The large concept card and related letters were displayed and referred to during the language experience to build associations. For example, the teacher and children made real ice cream sundaes and, while eating, the children practiced saying $/ \mathrm{mmm} /$ in response to teacher model and prompts.

\section{Day 3: Review/Key Word Activity}

The CEI story was read again, and children were prompted to say the phoneme when the teacher pointed to the letters on the large concept card. Following the CEI curriculum, children were introduced to decoding and blending by "reading" "key words" that were made up of the taught phonemes. For example, after instruction on $m$ and $e$, the key word me was introduced. 
Example of a lesson: Key word: me

Teacher: What sound is this? [Holds up magnetic letter $\mathrm{m}$ ] 'Mmmm,' that's right. What sound is this? [Holds up magnetic letter e] 'Eeee,' that's right! Good job. Now that we know two sounds, we can make a word. I'm going to put these two sounds together to make a word. [Teacher slowly brings the letters together as she says the sounds] 'Mmmm-еeеeе.' 'Mmmm-еeеeе.' Say it with me: 'Mmmmm-еeеeеe.' Now let's put the sounds together: 'mmmmmeeeee.' What word is that? [Teacher answers] 'Me!' When I put 'mmmmeeee' together, it says 'me.'

Day 4

Using the key words, children had opportunities to develop phonological awareness skills through activities that focused on initial sound identification, blending, and phoneme segmentation skills. Teachers used blocks or small concept cards (picture cards to provide a semantic cue to the story and language activity) to represent the phonemes.

\section{Phoneme Books}

Books from the CEI, called "Funday Books," were used to give students opportunities to practice the phoneme-grapheme correspondences and the key words with the written text. The books contained all large concept cards and key words previously taught. Each page provided several examples of the grapheme and printed word, and the teacher led students in reading practice.

Results of single-subject assessment were used to initiate additional practice on taught phoneme-grapheme correspondences for individual students on all days. In addition to the activities that were specific to the semantic association strategies, daily activities included phonological awareness activities, writing games (e.g., picking out letters to write one's name), learning the alphabet song, and vocabulary instruction.

\section{Assessment Procedures}

\section{Original Baseline}

During the baseline week, teachers assessed students on the six consonant sounds $(m, b, t, s, p$, and $f)$ and three long vowel sounds (long e, long $o$, and long $i$ ) for four sessions (i.e., 4 days). Baseline consisted of three trials for each of nine phoneme-grapheme correspondences, for a total of 27 trials in random order. Students did not receive feedback during baseline or any other phase of the assessments.

\section{Intervention Assessment}

During days 2, 3, and 4 of an instructional week, assessment included only the targeted correspondences and any previously taught correspondences for 
which students had not reached criterion. Criterion was defined as $100 \%$ correct on four consecutive assessments (i.e., day 2-4 of intervention week, and day 1 of the following week).

\section{Probes}

On day 1 , prior to the start of a new lesson, the teacher administered a probe that consisted of three trials of all nine phoneme-grapheme correspondences, identical to the baseline assessment. This served as a baseline probe for those correspondences that had not yet been taught and a maintenance probe of previously taught correspondences. If a student dropped below $100 \%$ on any particular correspondence during maintenance, it was included in the intervention assessment until criterion was met again.

\section{Treatment Fidelity}

A member of the grant team (different from the research teachers) conducted treatment fidelity measures on all available videotapes (33\% percent of 36 total sessions) from the auditory/oral program and all available videotapes $(22 \%$ percent of 32 total sessions) from the signing program. The observer measured treatment fidelity using the checklist shown in Table 2.

Fidelity was measured by the percentage of critical elements for an activity that was observed, divided by the number of times the activity was observed. If the element was not in view on the videotape (e.g., "the large concept card was visible to the child"), it was not calculated toward the total. The average percentages for all elements were $75 \%$ or higher with a median of $100 \%$ (see Table 2).

\section{Results}

The dependent variable was graphed for all children. First, we inspected the graphs to determine which correspondences the children knew at baseline. To be conservative, knowledge of a correspondence was defined as a child producing the correct phoneme for at least two of the three trials in any given baseline assessment. Visual inspection of the data indicated that participants knew all of the long vowel phoneme-grapheme correspondences in the original baseline assessment. In addition, baseline probes showed that 3 students learned consonant correspondences, $f$ (Adam), $s$ (Jason), and $s$ and $p$ (Sid), between the original baseline and instruction on that correspondence. (Pseudonyms are used for all students.)

Further data analyses are reported only for the phoneme-grapheme correspondences students did not know (see Table 4 for listing of correspondences for each student). Figure 1 displays Adam's responses during baseline (to the left of the dotted line) and after intervention (to the right of the dotted line). 
Table 2. Treatment fidelity

\begin{tabular}{|c|c|c|c|}
\hline Group & $\begin{array}{l}\text { Auditory/oral } \\
\text { program }\end{array}$ & $\begin{array}{l}\text { Signing } \\
\text { program }\end{array}$ & Averages \\
\hline \multicolumn{4}{|l|}{ Story } \\
\hline Large concept card is visible to all children & $100.00 \%$ & $100.00 \%$ & $100.00 \%$ \\
\hline $\begin{array}{l}\text { Teacher reads/tells a story that includes } \\
\text { phoneme, letter name, and is represented } \\
\text { by picture on large concept card }\end{array}$ & $100.00 \%$ & $100.00 \%$ & $100.00 \%$ \\
\hline $\begin{array}{l}\text { Teacher produces phoneme while pointing } \\
\text { to each letter on large concept card }\end{array}$ & $100.00 \%$ & $100.00 \%$ & $100.00 \%$ \\
\hline Teacher provides written model of target letter & $50.00 \%$ & $100.00 \%$ & $75.00 \%$ \\
\hline $\begin{array}{l}\text { Teacher prompts student to imitate her } \\
\text { after each production }\end{array}$ & $100.00 \%$ & $50.00 \%$ & $75.00 \%$ \\
\hline $\begin{array}{l}\text { Children attempt to imitate teacher's } \\
\text { production }\end{array}$ & $100.00 \%$ & $100.00 \%$ & $100.00 \%$ \\
\hline Percentage observed for story & $91.67 \%$ & $91.67 \%$ & $91.67 \%$ \\
\hline \multicolumn{4}{|l|}{ Language activity } \\
\hline $\begin{array}{l}\text { Teacher refers to large concept card at } \\
\text { beginning of activity }\end{array}$ & $100.00 \%$ & $100.00 \%$ & $100.00 \%$ \\
\hline Large concept card is visible to children & $80.00 \%$ & $100.00 \%$ & $90.00 \%$ \\
\hline $\begin{array}{l}\text { Children engage in activity represented in } \\
\text { concept cards }\end{array}$ & $100.00 \%$ & $50.00 \%$ & $75.00 \%$ \\
\hline Teacher models target sound during activity & $100.00 \%$ & $100.00 \%$ & $100.00 \%$ \\
\hline $\begin{array}{l}\text { Child attempts/produces target sound } \\
\text { during activity }\end{array}$ & $100.00 \%$ & $100.00 \%$ & $100.00 \%$ \\
\hline Teacher provides corrective feedback if needed & $100.00 \%$ & $100.00 \%$ & $100.00 \%$ \\
\hline Percentage observed for language activity & $96.67 \%$ & $91.67 \%$ & $94.17 \%$ \\
\hline \multicolumn{4}{|l|}{ Review: grapheme-phoneme } \\
\hline Teacher shows grapheme and models sound & $80.00 \%$ & $100.00 \%$ & $90.00 \%$ \\
\hline $\begin{array}{l}\text { Teacher prompts students to imitate } \\
\text { sound while pointing to letter }\end{array}$ & $100.00 \%$ & $100.00 \%$ & $100.00 \%$ \\
\hline Students produce sound & $100.00 \%$ & $100.00 \%$ & $100.00 \%$ \\
\hline Large concept card visible to children & $100.00 \%$ & $100.00 \%$ & $100.00 \%$ \\
\hline Percentage observed for grapheme-phoneme & $95.00 \%$ & $100.00 \%$ & $97.50 \%$ \\
\hline \multicolumn{4}{|l|}{ Phoneme books } \\
\hline $\begin{array}{l}\text { Child attempts/produces target sound as } \\
\text { student or teacher points to each grapheme }\end{array}$ & $100.00 \%$ & $100.00 \%$ & $100.00 \%$ \\
\hline $\begin{array}{l}\text { Child moves from page to page to practice } \\
\text { grapheme-phoneme correspondences }\end{array}$ & $50.00 \%$ & $100.00 \%$ & $75.00 \%$ \\
\hline Percentage observed for phoneme books & $75.00 \%$ & $100.00 \%$ & $87.50 \%$ \\
\hline
\end{tabular}

The double dotted lines indicate baseline probes that preceded instruction. To conserve space, we have included only the figure for Adam's data but describe figures for all children (figures are available on request). Visual inspection of these graphs indicated that changes in the dependent variable (i.e., number correct out of three trials) consistently occurred when the 
independent variable was introduced for unknown correspondences. A functional relationship was established across all students between the instruction of unknown phoneme-grapheme correspondences using the semantic association strategy and its acquisition. Additionally, all students showed an ascending trend during the intervention phase and showed little variability during maintenance. All students reached criteria for unknown sounds within the allotted time before the end of the study. Three out of 5 students maintained $100 \%$ for the remainder of the study for all correspondences once criterion was reached. Of the other 2, 1 student, Adam, made one error for the $b$ correspondence but returned to $100 \%$ for the next (and last) three sessions (see Figure 1). Arnold made one error for $b$ correspondence then returned to $100 \%$ on the next probe. He also made an error for the $t$ correspondence and continued to accurately produce it only two out of the three trials on probes until the end of the study.

Statistical analysis confirmed visual inspection results. Table 3 summarizes the compiled results of averages across participants and includes (1) baseline mean, (2) intervention mean, (3) mean difference, and (4) percentage of overlapping data between baseline and intervention. Effectiveness of the intervention was measured using percentage of overlapping data between baseline and intervention (as opposed to non-overlapping data used in behavior reduction research as described in Olive and Smith [2005]), and a low average percentage of overlapping data at $15 \%$ (range $2 \%-22 \%$ ) for all 5 students across all unknown correspondences.

The efficiency of instruction was measured through latency, which is defined as the number of instructional sessions before reaching the first data point of criterion. The average latency was 4.49 sessions. Thus, on average, children needed a week of lessons to reach criterion. Table 4 describes latency data by correspondences and students. There were wide individual differences in average latency (range 1.8 to 7.2). Jason, the child who needed only minimal instruction, was the oldest student. In contrast, the youngest student, Adam, needed almost 2 weeks of instruction, on average, to reach criterion. Latency for the different correspondences also varied, but the lack of consistency across children for a given correspondence precludes any conclusion on their relative difficulty.

\section{Discussion}

The results suggest that an intervention with instruction using a semantic association strategy is an effective method to teach phoneme-grapheme correspondences to children who are DHH and who have spoken word identification skills. All children in the study reached criteria for all correspondences. Three children never made an error after reaching criterion. The other 2 made only minimal errors. Four of the 5 children needed the full week of lessons before they reached criterion. Not surprisingly, children's age seemed to 


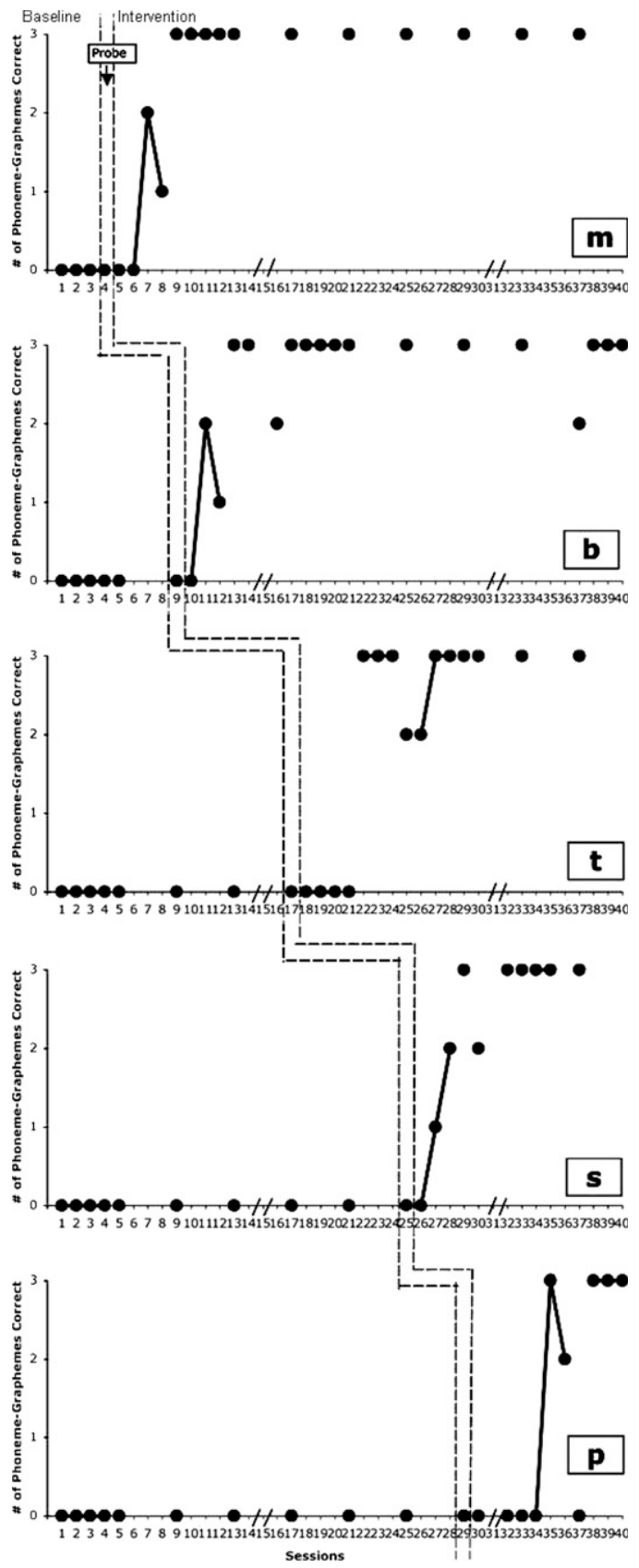

Figure I. Graph showing acquisition of phoneme-grapheme correspondences for Adam, a 3.10-year-old boy from an auditory / oral program who uses speech to communicate and uses a cochlear implant. 
Table 3. Percentage of overlapping data between baseline and intervention phases and mean number of correct responses in each phase for participants

\begin{tabular}{lcccr}
\hline & $M_{\text {Baseline }}$ & $M_{\text {Intervention }}$ & $M_{\text {Difference }}$ & $P O D$ \\
\hline Adam & 0.29 & 2.43 & 2.14 & $20 \%$ \\
Kyle & 0.00 & 2.25 & 2.25 & $10 \%$ \\
Sid & 0.36 & 2.53 & 2.17 & $22 \%$ \\
Arnold & 0.08 & 2.64 & 2.55 & $2 \%$ \\
Jason & 0.28 & 2.90 & 2.62 & $20 \%$ \\
Averages & 0.20 & 2.55 & 2.35 & $15 \%$ \\
\hline
\end{tabular}

Note. $\mathrm{M}=$ means; $\mathrm{POD}=$ percentage of overlapping data.

influence how quickly they learned the correspondences. Children who had speech perception skills in both oral and signing environments were able to learn the spoken phoneme-grapheme correspondences. Because of its success with the youngest children, this instructional strategy seems appropriate for inclusion in a literacy curriculum for young children who are DHH.

\section{STUDY TWO}

In the fall following Study One, researchers created and implemented a comprehensive and integrated prekindergarten literacy curriculum entitled Foundations for Literacy (Foundations) (Lederberg et al., 2009). Foundations was developed to include the five components of effective literacy instruction as defined by the National Reading Panel (2000): alphabetic knowledge (including phoneme-grapheme correspondences), phonological awareness, vocabulary, reading comprehension, and fluency, as well as evidence-based effective instructional strategies for early literacy instruction (NELP, 2009). Foundations also includes best practices for education of young children (e.g., active learning) (joint statement of the National Association for the Education of Young Children [NAEYC] and the National Association of

Table 4. Latency across students and unknown correspondences

\begin{tabular}{lcccccc}
\hline Latency & Adam & Kyle & Sid & Arnold & Jason & Averages by correspondence \\
\hline $\mathrm{m}$ & 4 & 4 & 5 & 4 & 1 & 3.6 \\
$\mathrm{~b}$ & 7 & 3 & 5 & 8 & 4 & 5.4 \\
$\mathrm{t}$ & 10 & 7 & 5 & 5 & 1 & 5.6 \\
$\mathrm{~s}$ & 6 & 4 & - & 2 & - & 4 \\
$\mathrm{p}$ & 9 & - & - & 1 & 1 & 3.7 \\
$\mathrm{f}$ & & \multicolumn{5}{c}{ not enough time to reach criterion } \\
Averages by student & 7.2 & 4.5 & 5 & 4 & 1.75 \\
\hline
\end{tabular}

Note. (-) indicates a known correspondence. 
Early Childhood Specialists in State Departments of Education [NAEYC and NAECS/SDE, 2003]), and a multimodality approach to teaching reading (Morrison et al., 2008). Building on the results from the first study, this curriculum presented lessons to teach phoneme-grapheme correspondences through the use of a semantic association strategy that used stories and language experiences. While adopting the CEI story strategy, new stories and language experiences were created with illustrations that were more modern and culturally inclusive. In addition, further support for children with weak language skills was provided by including sequencing cards that illustrated the stories and by targeting key vocabulary words for instruction. Consistent with research on effective prekindergarten curriculum for children with typical hearing (NELP, 2009), Foundations included more extensive phonological awareness activities and a shared storybook reading component (reading comprehension). Fluency, while not measured in this 6-week study, developed from Study Two. The single-subject assessments emerged as practice for phoneme fluency that could be recorded and measured.

The goal of Study Two was to examine the effectiveness of a semantic association strategy embedded within Foundations for teaching phonemegrapheme correspondences to young children who are DHH. A researchteacher taught five 3- to 4-year-olds using the curriculum for 1 hour a day, 4 days a week, for the entire school year. Study Two was a multiple baseline, across content study implemented for 6 weeks near the beginning of the school year. The design was similar to Study One, except that intervention assessments occurred less frequently to allow more time for instruction.

\section{Method}

\section{Setting and Participants}

The setting for this study was the auditory/oral program from the first study, and it used the same criteria for subject selection. Table 5 gives detailed demographic information about the participants. School personnel assisted in identifying children who met these criteria. Five prekindergarten students were eligible for the study, and all 5 children participated. Unlike the first study, no child was excluded because of phoneme-grapheme correspondence knowledge. While participating in this study, all students wore their personal amplification devices. The students received instruction in 1-hour sessions, 4 days per week from the research-teacher from Study One, who utilized a pullout model of instruction.

\section{Experimental Design}

A multiple baseline probe across content (phoneme-grapheme correspondences) was used to evaluate the effects of the intervention. Again, researchers 
Table 5. Participant demographics

\begin{tabular}{|c|c|c|c|c|c|c|c|}
\hline Participant & Age & Gender & $\begin{array}{c}\text { Unaided } \\
\text { PTA }\end{array}$ & Listening Age & $\begin{array}{l}\text { ESP } \\
\text { Score }\end{array}$ & $\begin{array}{c}\text { Standard } \\
\text { Scores } \\
\text { PPVT }\end{array}$ & School Placement \\
\hline Henry & 3.11 & M & $\mathrm{CI}$ & 6 months & 4 & 77 & $\begin{array}{l}\text { Auditory/ } \\
\text { oral-preschool }\end{array}$ \\
\hline Mary & 4.5 & $\mathrm{~F}$ & $\mathrm{CI}$ & 22 months & 4 & 66 & $\begin{array}{l}\text { Auditory / } \\
\text { oral-kindergarten }\end{array}$ \\
\hline Sally & 4.4 & $\mathrm{~F}$ & $\mathrm{CI}$ & 26 months & 4 & 67 & $\begin{array}{l}\text { Auditory/ } \\
\text { oral-preschool }\end{array}$ \\
\hline Vikki & 4.4 & $\mathrm{~F}$ & CI & 24 months & 4 & 68 & $\begin{array}{l}\text { Auditory/ } \\
\text { oral-kindergarten }\end{array}$ \\
\hline Wally & 3.10 & M & $\mathrm{CI}$ & 4 months & 4 & 97 & $\begin{array}{l}\text { Auditory/ } \\
\text { oral-preschool }\end{array}$ \\
\hline
\end{tabular}

Note . Listening age $=$ chronological age minus age received first implant or amplification; PTA = pure tone hearing; ESP = Early Speech Perception Test; PPVT-III = Peabody Picture Vocabulary Test-Third Edition.

were interested in evaluating the intervention in a naturalistic setting using a prescribed scope and sequence. Decision rules for criterion and analysis were again based on individual performance.

\section{Independent and Dependent Variables}

The independent and dependent variables for this study were the same as the first study. However, the intervention used the Foundations curriculum instead of our enhancement of the CEI. Three additional dependent variables were included as part of this study: (1) a pre-post, phoneme-grapheme correspondence assessment (with one opportunity to correctly produce a phoneme for a matched grapheme) that exclusively assessed the six target phoneme-grapheme correspondences in the study: $m$, long $e, b$, long $o$, $t$, and $n$. This assessment was administered immediately before and after the 6-week study; (2) An alphabetic knowledge test administered in the fall and spring. This test assessed production of all the consonant sound correspondences and the long and short vowel correspondences, as well as the ch, th, and sh clusters (see Easterbrooks et al., 2008, for a full description); and (3) A pre- and posttest on decodable words (Key Word Assessment) that assessed participants' reading/decoding skills. These tests included words that were spelled using the graphemes taught in the intervention. Some of the words were specifically taught as key words (e.g., me, boat); others were not (e.g., toe, leaf). The assessment included a production test with 17 taught words and 14 untaught words (students read the word on a 
card), and an identification test of taught words (students were shown the key [decodable] word and had to select the correct referent from a set of three pictures).

\section{Procedures}

\section{Baseline}

Baseline procedures were the same as the first study.

\section{Intervention}

In each 1-hour session of Foundations for Literacy, about 15 minutes were allotted for each of the following: phoneme-grapheme correspondences, phonological awareness, and storybook reading. The remaining 15 minutes were used for review and reinforcement of skills, as well as vocabulary and fluency practice, including activities prerequisite to phonological awareness. Phoneme-grapheme correspondence instruction in Foundations maintained the use of the semantic association strategy through stories and language activities that provided opportunities for children to practice the sound in isolation. Correspondences were taught in the following order: $m$, long $e, b$, long $o, t$, and $n$.

The teacher introduced new phoneme-grapheme correspondences approximately every fourth session (with the exception of the first two correspondences, which were taught on the same day). The framework of a weekly lesson is described below, followed by examples of each day. Again, only the activities that are relevant to learning the phoneme-grapheme correspondences are described.

\section{Day 1: Story}

The target phoneme-grapheme correspondence was introduced with a large concept card and three or four picture cards in sequence (see Appendix A).

Example of a lesson: Phoneme: /t/, Graphemes: Tt

Large concept card: Miss Giggle listening to the clock, letters $\mathbf{T}$ and $\mathbf{t}$ on the card

Teacher: Miss Giggle told Kate and Pete that she had a surprise. "The surprise is that the girl we met at the park will be coming after school everyday, too." Miss Giggle looked at her watch. "It is time for her to come," she said. Just then the doorbell rang. It was Sue and her mother. Sue had a present for Miss Giggle. Miss Giggle put the present to her ear. "I hear a sound: $t, t, t, t$," said Miss Giggle. She opened the present. It was a new clock. Miss Giggle decided to hang it on the wall. They all listened as it said " $t, t, t, t$. " [Signals to the children to make the sound / $t /$ ]. Miss Giggle 
said, "That's the sound the letter t makes," and she wrote 't' on a card and stuck it on the box.

The children then practiced saying / $t$ / while the teacher pointed to the $t$ on the card.

\section{Day 2: Language Activity}

The framework for the language activity in the Foundations curriculum was the same as the first study.

Example: The teacher surprised the students with presents. Inside the students' gift boxes were containers of Play-Doh. The teacher guided students to make clocks or watches out of Play-Doh and "listen" to them tick. The teacher prompted students to produce the /t/ sound (i.e., What sound do you hear when you listen to the clock?). The teacher corrected articulation, if needed.

\section{Day 3: Language Activity Recall}

Students participated in recall of the language activity that reinforced the phoneme-grapheme correspondence. The teacher used guided questions to help students recall activities from the previous day by creating three to five simple sentences describing the events of the activity. The students produced the phoneme in the recall activity and saw it written with the matching grapheme on the chart. The teacher then asked students to read the grapheme after it was written on the chart. A possible example of a language chart: [chart title] We Made Clocks [first sentence] Miss Jessica gave us a present. [second sentence] We made clocks. [third sentence] Vikki made a watch. [fourth sentence] We listened. The clock said, $\mathbf{t}, \mathbf{t}, \mathbf{t}$.

\section{Day 4: Review/Key Word Activity}

The key word activity was similar to the first study except the students participated in another language activity prior to hearing the word blended. This language activity was related to the key word rather than the sound. The teacher focused on helping students gain a semantic understanding of the key word as well as provided several opportunities to practice the word.

Example: Key word: boat

The teacher played a searching game with the children in which they had to search for the paper boats in the "water" (blue tissue paper in a large tub) and say boat when they found a boat. Then the teacher assisted the students in sounding out and blending the phonemes in the word boat using small concept cards that served as a semantic cue for the phoneme (e.g., clock for $t-t-t)$ (see Appendix A for illustration of the word boat). Eventually, graphemes instead of small concept cards were used for this activity. 


\section{Phoneme Book}

Similar to the CEI practice books, students read their own Phoneme Books twice a week. These books included all large concept cards for every taught phoneme-grapheme correspondence as well as a page for all taught key (decodable) words. These books provided practice for independent "reading" of taught correspondences and key words (see Appendix A).

\section{Assessment Procedures}

\section{Original Baseline}

On the first day during the baseline phase, the teacher administered a pretest consisting of one instance of each grapheme that corresponded to the four consonant sounds, $m, b, t$, and $n$, and two long vowel sounds, $e$ and $o$. The teacher then administered the baseline assessment for the single-subject studies for three sessions. Baseline assessment consisted of three trials for each of the six phonemegrapheme correspondences for a total of 18 trials in random order. Students did not receive feedback during baseline or any other phase of the assessments.

\section{Intervention Assessment}

During days 2 and 4 of the intervention, assessment included only the targeted correspondences and any previously taught correspondences that had not reached criterion. Criterion was defined as $100 \%$ correct on four consecutive assessments (i.e., days 2 and 4 of one week and days 2 and 4 of the following week).

\section{Probes}

The teacher administered a probe twice during the intervention phase, which consisted of three trials of all six correspondences identical to the baseline assessment. This served as a baseline probe for those correspondences that had not yet been taught and a maintenance probe of previously taught correspondences. If a student dropped below $100 \%$ on any particular correspondence during maintenance, it was included in the intervention assessment until criterion was met again.

\section{Treatment Fidelity}

Treatment fidelity was conducted similarly to the first study, except that Language Activity Recall was added to the checklist. A member of the grant team (different from the research-teachers) conducted treatment fidelity measures on $37 \%$ percent of 24 instructional sessions. The observer measured treatment fidelity using a checklist shown in Table 6 . Fidelity was measured by the 
Table 6. Treatment fidelity

\begin{tabular}{|c|c|c|c|}
\hline Group & Group 1 & Group 2 & Averages \\
\hline \multicolumn{4}{|l|}{ Story } \\
\hline Large concept card is visible to all children & $100.00 \%$ & $100.00 \%$ & $100.00 \%$ \\
\hline $\begin{array}{l}\text { Teacher reads/tells a story that includes } \\
\text { phoneme, letter name, and is represented } \\
\text { by picture on large concept card }\end{array}$ & $100.00 \%$ & $100.00 \%$ & $100.00 \%$ \\
\hline $\begin{array}{l}\text { Teacher produces phoneme while pointing to each } \\
\text { letter on large concept card }\end{array}$ & $100.00 \%$ & $100.00 \%$ & $100.00 \%$ \\
\hline Teacher provides written model of target letter & $100.00 \%$ & $100.00 \%$ & $100.00 \%$ \\
\hline $\begin{array}{l}\text { Teacher prompts student to imitate her } \\
\text { after each production }\end{array}$ & $100.00 \%$ & $100.00 \%$ & $100.00 \%$ \\
\hline Children attempt to imitate teacher's production & $100.00 \%$ & $100.00 \%$ & $100.00 \%$ \\
\hline Percentage observed for story & $100.00 \%$ & $100.00 \%$ & $100.00 \%$ \\
\hline \multicolumn{4}{|l|}{ Language activity } \\
\hline $\begin{array}{l}\text { Teacher refers to large concept card at } \\
\text { beginning of activity }\end{array}$ & * & * & * \\
\hline Large concept card is visible to children & $100.00 \%$ & $100.00 \%$ & $100.00 \%$ \\
\hline $\begin{array}{l}\text { Children engage in activity represented in } \\
\text { concept cards }\end{array}$ & $100.00 \%$ & $100.00 \%$ & $100.00 \%$ \\
\hline Teacher models target sound during activity & $100.00 \%$ & $100.00 \%$ & $100.00 \%$ \\
\hline $\begin{array}{l}\text { Child attempts/produces target sound during } \\
\text { activity }\end{array}$ & $100.00 \%$ & $100.00 \%$ & $100.00 \%$ \\
\hline Teacher provides corrective feedback if needed & * & * & * \\
\hline Percentage observed for language activity & $100.00 \%$ & $100.00 \%$ & $100.00 \%$ \\
\hline \multicolumn{4}{|l|}{ Language activity recall } \\
\hline Teacher refers to large cor & * & * & * \\
\hline Teacher and students recall language activity & * & $100.00 \%$ & $100.00 \%$ \\
\hline Teacher and students produce target sound & * & $100.00 \%$ & $100.00 \%$ \\
\hline Percentage observed for language activity recall & * & $100.00 \%$ & $100.00 \%$ \\
\hline \multicolumn{4}{|l|}{ Review: grapheme-phoneme } \\
\hline Teacher shows grapheme and & $100.00 \%$ & $100.00 \%$ & $100.00 \%$ \\
\hline $\begin{array}{l}\text { Teacher prompts students to imitate sound } \\
\text { while pointing to letter }\end{array}$ & $100.00 \%$ & $100.00 \%$ & $100.00 \%$ \\
\hline Students produce sound & $100.00 \%$ & $100.00 \%$ & $100.00 \%$ \\
\hline Large concept card visible to children & * & & * \\
\hline Percentage observed for grapheme-phoneme & $100.00 \%$ & $100.00 \%$ & $100.00 \%$ \\
\hline \multicolumn{4}{|l|}{ Phoneme books } \\
\hline $\begin{array}{l}\text { Child attempts/produces target sound as } \\
\text { student or teacher points to each grapheme }\end{array}$ & $100.00 \%$ & $100.00 \%$ & $100.00 \%$ \\
\hline $\begin{array}{l}\text { Child moves from page to page to practice } \\
\text { grapheme-phoneme correspondences }\end{array}$ & $100.00 \%$ & $100.00 \%$ & $100.00 \%$ \\
\hline Percentage observed for phoneme books & $100.00 \%$ & $100.00 \%$ & $100.00 \%$ \\
\hline
\end{tabular}

Note. $\left(^{*}\right)$ indicates element was not visible. 
percentage of critical elements for an activity that was observed divided by the number of times the activity was observed. If the element was not in view on the videotape (e.g., "the large concept card was visible to the child"), it was not calculated toward the total. The average percentages for all elements were all $80 \%$ or higher, with a median of $100 \%$ (see Table 6 ).

\section{Results}

The dependent variable was graphed for all children. We inspected the graphs to determine which correspondences the children knew at the original baseline. Again, knowledge of a phoneme-grapheme correspondence was defined as a child producing the correct phoneme for at least two of the three trials in any given baseline assessment. Visual inspection showed that 4 out of 5 participants demonstrated knowledge of both long vowel phonemegrapheme correspondences in original baseline or prior to instruction. Baseline probes revealed that all students except Vikki learned the $n$ correspondence between the original baseline and instruction. Further data analyses are reported only for the unknown consonant correspondences (range three to four correspondences). The data, presented for Vikki in Figure 2, indicated that changes in the dependent variable occurred when the independent variable was introduced for unknown correspondences. A functional relationship was replicated across all students for the unknown correspondences using the semantic association strategy. All students reached and maintained criteria for unknown correspondences. All students showed an ascending trend during the intervention phase (figures of all students available on request).

Statistical analysis confirms replication results. Table 7 summarizes compiled results of averages across participants and includes (1) baseline mean, (2) intervention mean, (3) mean difference, and (4) percentage of overlapping data between baseline and intervention. Effectiveness of the intervention, as measured by percentage of overlapping data between baseline and intervention, averaged $11 \%$ across participants for unknown correspondences (range $7 \%-13 \%)$. The efficiency of the intervention, measured by average latency across students (multiplied times 2 since assessment was done every other day), was 5.8 sessions (range 4.7-8.0 sessions).

Table 8 describes latency data by correspondences and students. At the beginning of the study, average latencies suggest that students needed about 1 to 2 weeks of instruction before reaching the first data point of criterion for a correspondence. However, all students demonstrated increased efficiency, and the number of sessions before reaching the first point of criterion for correspondences decreased across time. Examining efficiency of specific correspondences also supports increased efficiency, where average latency for the first correspondence $(m)$ was 8.4 sessions and then decreased to 2 sessions for the last two correspondences $(t, n)$. Individual differences in latency did not seem to relate to any of the characteristics noted in Table 5. 

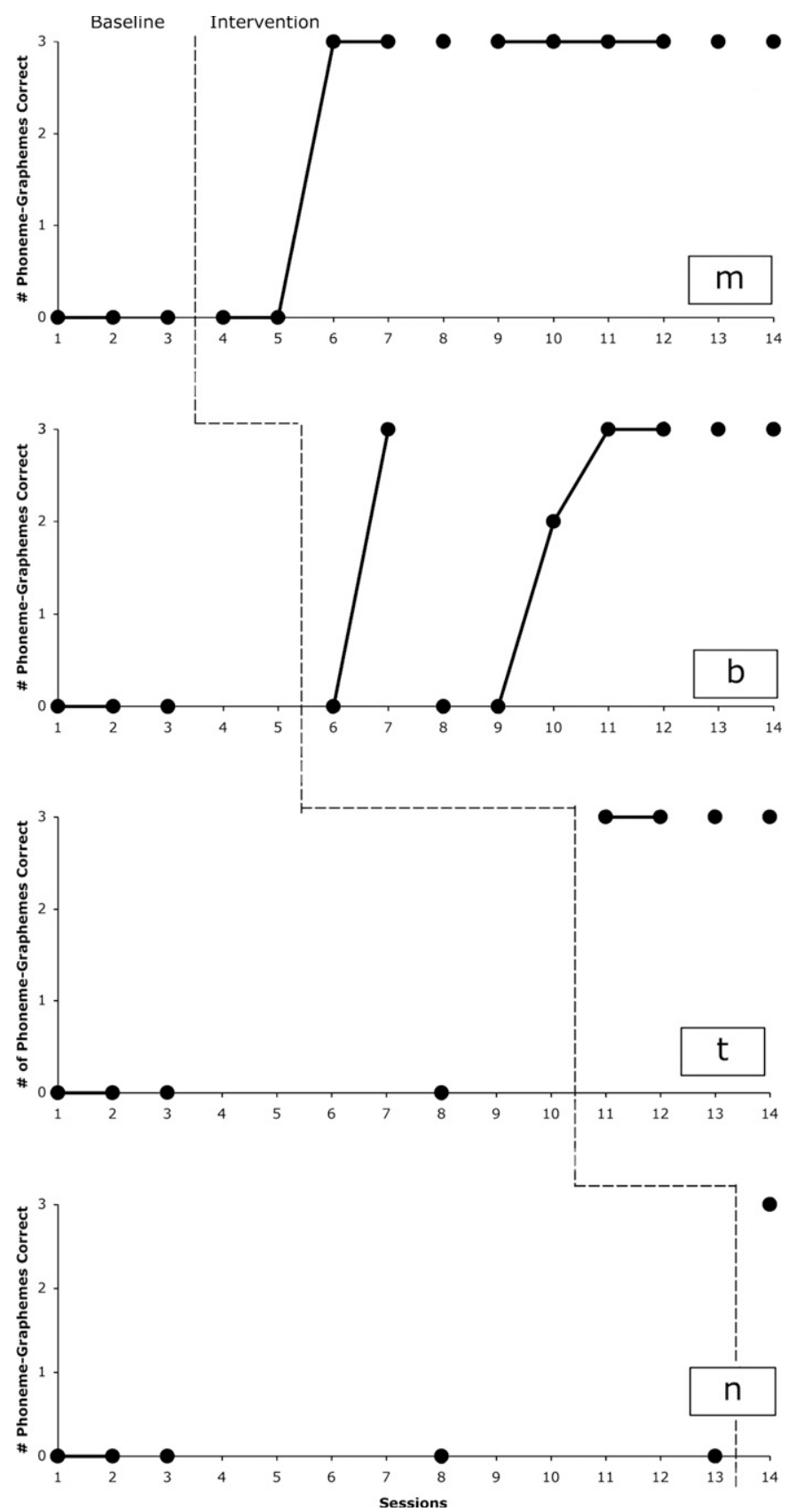

Figure 2. Acquisition of phoneme-grapheme correspondence for Vikki, a 4.4-year-old girl from an auditory/oral program who uses speech to communicate and uses bilateral cochlear implants. 
Table 7. Percentage of overlapping data between baseline and intervention phases and mean number of correct responses in each phase for participants

\begin{tabular}{lcccr}
\hline & $M_{\text {Baseline }}$ & $M_{\text {Intervention }}$ & $M_{\text {Difference }}$ & POD \\
\hline Henry & 0.17 & 2.50 & 2.33 & $12 \%$ \\
Mary & 0.41 & 2.67 & 2.25 & $13 \%$ \\
Sally & 0.61 & 2.80 & 2.19 & $13 \%$ \\
Vikki & 0.27 & 2.62 & 2.36 & $10 \%$ \\
Wally & 0.71 & 2.84 & 2.13 & $7 \%$ \\
Averages & 0.43 & 2.69 & 2.25 & $11 \%$ \\
\hline
\end{tabular}

Note. POD = percentage of overlapping data.

The results of the pre- and posttests immediately before and after the intervention indicated that, prior to the intervention, these students had only limited alphabetic knowledge. Four out of 5 did not know any of the target letter names (which would have produced a correct score on the long vowel correspondences). Furthermore, none of the students knew any of the consonant correspondences. At the end of 6 weeks, all 5 students demonstrated knowledge of the six phoneme-grapheme correspondences.

As a component of the larger grant project's assessment battery, assessors tested the children on alphabetic knowledge and decoding at the end of the school year, after a year in the Foundations curriculum. Of those phonemegrapheme correspondences tested, the results of these assessments indicated that students maintained the alphabetic knowledge they gained at the beginning of the year from this 6-week study. By the end of the year, children went from an average of four correspondences to 16 correspondences. More important, students were able to use those correspondences in a functional manner by decoding them in real words. Children from this study were able to decode $60 \%$ of words directly taught in the curriculum and $30 \%$ of the novel words.

Table 8. Latency across students and unknown correspondences

\begin{tabular}{|c|c|c|c|c|c|c|}
\hline Latency & Henry & Mary & Sally & Vikki & Wally & $\begin{array}{c}\text { Averages by } \\
\text { correspondence }\end{array}$ \\
\hline $\mathrm{m}$ & 8 & 4 & 3 & 2 & 4 & 4.2 (8.4 sessions) \\
\hline $\mathrm{e}$ & 5 & - & - & - & - & 5 (10 sessions) \\
\hline b & 2 & 2 & 6 & 6 & 2 & 3.6 (7.2 sessions) \\
\hline $\mathrm{t}$ & 1 & 1 & 1 & 1 & 1 & 1 (2 sessions) \\
\hline $\mathrm{n}$ & - & - & - & 1 & - & 1 (2 sessions) \\
\hline $\begin{array}{l}\text { Averages } \\
\text { by student }\end{array}$ & $\begin{array}{l}4.0(8 \\
t \quad \text { sessions })\end{array}$ & $\begin{array}{l}2.3(4.7 \\
\text { sessions }\end{array}$ & $\begin{array}{l}3.3 \text { (6.6 } \\
\text { s) sessions) }\end{array}$ & $\begin{array}{l}2.5(5 \\
\text { session }\end{array}$ & $\begin{array}{l}2.3(4.7 \\
\quad \text { sessions }\end{array}$ & \\
\hline
\end{tabular}

Note. (-) indicates a known correspondence. 


\section{Discussion}

The results of Study Two replicated the findings of Study One, showing that the semantic association strategy for building alphabetic knowledge is an effective and efficient method to teach phoneme-grapheme correspondences. All children reached criteria for all unknown correspondences. After reaching criterion, children maintained $100 \%$ accuracy and none made any errors. Children averaged a range from a little over 1 week to 2 weeks before reaching the first point of criterion and all children showed an increased efficiency in acquiring correspondences.

The research team decided to reduce the assessment schedule for this study by assessing every other day and probing every other week. However, this schedule proved to be a limitation in that some correspondences were not probed immediately prior to intervention (e.g., phoneme / $t /$ ). The assessment schedule from the first study, with probes immediately prior to intervention, provided better evidence for a functional relationship between the independent and dependent variables.

\section{General Discussion}

This type of research has several implications for populations of children who are DHH. These studies suggest that students who have at least some speech perception abilities can learn phoneme-grapheme correspondences using a semantic association strategy. These studies are the first research on instruction of phoneme-grapheme correspondences for children who are $\mathrm{DHH}$ at the prekindergarten age level. For this age group, the fun and engaging activities were most likely essential to the success of the strategy.

The strength of using a single-subject design for both studies was the ability to analyze assessment results by individuals. Children in Study One ranged from 3.10 to 7.10 years of age, and results suggested that age may have affected the rate of learning (i.e., older children had lower latency levels). However, latency was not related to age in Study Two, suggesting that this factor may not be important in learning among children in prekindergarten classrooms. The children in both studies varied in language levels, ranging from those with age-typical vocabulary to those with vocabulary scores more than 2 standard deviations below age-typical levels. Even with these varying factors, all children successfully learned targeted correspondences. Surprisingly, children's learning (as measured by latency) did not seem to be related to their widely differing vocabulary knowledge. The intervention may be appropriate for children of various abilities in prekindergarten classrooms. Of course, further replication with a wider variety of children is necessary before that conclusion can be drawn.

The semantic association strategy explicitly teaches phoneme-grapheme correspondences through stories that connect a semantic context to the phoneme. 
Previous examples of alphabetic knowledge instruction programs, including instruction through alliteration (e.g., stressing the initial sound of a word or object), may require students to remember a potentially complex or unknown word or phrase as a reference for the correspondence. This method of instruction may present vocabulary or speech production challenges for children who are $\mathrm{DHH}$. The semantic association of strategy instruction provides a reference that requires minimal language and an intuitive connection to an abstract idea. To further cement the connection between the meaning and the phoneme, the stories were enacted through multisensory language experiences. Here, teachers reinforced vocabulary and language related to understanding the meaning of stories, which was key to making a semantic connection. Finally, development of alphabetic knowledge is dependent on accurate phonological representations (Thomas \& Senechal, 2004). During the language activities, multiple opportunities for students to practice the phoneme in isolation and subsequent opportunities for teacher correction when needed provided an engaging and age-appropriate setting in which to reinforce correct articulation. The emphasis of teachers modeling the phoneme in isolation may have improved children's speech-reading abilities for these phonemes, a skill that has been shown to be related to reading (Harris \& Moreno, 2006). In addition, the multisensory experiences that focus on isolating phonemes from the speech stream may be particularly helpful for children with impoverished phonological representation (Morrison et al., 2008). The current studies suggest that the semantic association strategy may be an effective and efficient technique for children who are $\mathrm{DHH}$.

\section{Limitations}

The current studies have several limitations. The independent variable included several instructional strategies, such as language activities and phonological awareness activities, which undoubtedly contributed to the successful acquisition of the phoneme-grapheme correspondences for the children in these studies. The single-subject design requires repeated measures in the form of daily or twice-weekly assessments. In our studies, these assessments may have had unintended benefits. In fact, additional practice from the assessments probably increased the fluency with which children knew the correspondences; for this reason, we incorporated similar assessments into instruction for the Foundations curriculum. However, because we cannot separate the individual strategies from the whole intervention, caution must be used when drawing conclusions about the success of using the semantic association strategy alone. Additionally, the researchers did not compare the semantic association strategy to other approaches teaching alphabetic knowledge. We do not know whether the semantic association strategy is more effective than, for instance, strategies that use a meaningful articulatory or kinesthetic connection to the phoneme (e.g., LiPS or Visual Phonics). 


\section{Future Research}

Williams (2004) reviewed current literature on literacy for children who are $\mathrm{DHH}$ and outlined several areas of future research, including longitudinal studies that would "construct a detailed, theoretically-grounded representation of deaf children's emergent literacy development" (p. 362). While the importance of alphabetic knowledge for literacy development in children with typical hearing is well documented, longitudinal research is needed to establish the role of this knowledge for children who are DHH. Additionally, investigations that compare the semantic association strategy to other approaches that build phonological awareness in children who are DHH would help to identify other efficient and effective approaches. Information is also needed on how to build emergent literacy skills in children who are older than preschool/kindergarten age.

Future research may also explore how the strategies used in Foundations for Literacy could be modified for elementary-aged children whose classroom demands for literacy are qualitatively different than those of younger children. Finally, future research is needed to identify for which children auditory-based instruction to build alphabetic knowledge is appropriate, including children without speech perception abilities. Theoretically, although the children without speech perception abilities might learn to read through a different process than children who have phonological representations of spoken words, it may be that instruction using the semantic association strategy paired with Visual Phonics during preschool will build a foundation for instruction of reading programs, such as Reading Mastery (2008) in elementary school (see Trezek \& Wang, 2006).

\section{Conclusion}

Alphabetic knowledge provides an early foundation for later literacy success. Research shows that explicit instruction in building early skills that enhance development of phonological awareness, such as phoneme-grapheme correspondences, in the general education population is an essential foundation for decoding written text (Snider, 1995). Research, such as the recent study by Spencer and Tomblin (2008), supports development of these skills in children who are DHH; however, Spencer and Tomblin found that elementary school children who are DHH with cochlear implants develop phonological awareness skills at a delayed rate. The children in the current study demonstrated that, despite their young ages and language delays, they could still acquire phoneme-grapheme correspondences. These results have strong positive implications for a future practice of targeting explicit phoneme-grapheme instruction with prekindergarten children who are $\mathrm{DHH}$ in order to prevent future delays in phonological awareness development. 
While traditionally alphabetic knowledge is not taught until kindergarten, even for children with typical hearing, recent research suggests such instruction in prekindergarten can have long-term positive effects on later reading skills, including reading achievement and spelling (Kirk \& Gillon, 2007; Korkman \& Peltomaa, 1993). The current study suggests that children who are $\mathrm{DHH}$, even those who have delays in language, are able to learn the foundation for the alphabetic principle during prekindergarten. Although the longterm consequences of early instruction on the alphabetic principle need to be explored, such a finding holds promise for improving literacy skills of children who are $\mathrm{DHH}$.

\section{Acknowledgments}

This research was funded by grant \#R324E060035, "Improving Deaf Preschoolers' Literacy Skills," from the U.S. Department of Education, Institute of Education Sciences, to the second author. The opinions expressed are ours and do not represent the views of the funding agency. We also wish to thank the schools and children for their cooperation.

\section{References}

Aghababian, V., Nazir, T. A., Lancon, C., \& Tardy, M. (2001). From "logographic" to normal reading: The case of a deaf beginning reader. Brain and Language, 78, 212-223.

Aram, D., Most, T., \& Mayafit, H. (2006). Contributions of mother-child storybook telling and joint writing to literacy development in kindergartners with hearing loss. Language, Speech, and Hearing Services in Schools, 37, 1-15.

Barger-Anderson, R., Domaracki, J. W., Kearney-Vakulick, N., \& Kubina, R. M. (2004). Multiple baseline designs: The use of a single-case experimental design in literacy research. Reading Improvement, 41, 217-225.

Burgess, S. R., \& Lonigan, C. J. (1998). Bidirectional relations of phonological sensitivity and prereading abilities: Evidence from a preschool sample. Journal of Experimental Child Psychology, 70, 117-141.

Cheng, A. K., Grant, G. D., \& Niparko, J. K. (1999). Meta-analysis of pediatric cochlear implant literature. Annals of Otology, Rhinology \& Laryngology, 177(Suppl.), 124-128.

Dunn, L.M., \& Dunn, L.M. (1997). Peabody Picture Vocabulary Test- Third Edition (PPVT-III). San Antonio, TX: Pearson.

Easterbrooks, S. R., Lederberg, A. R., Miller, E. M., Bergeron, J. P., \& Connor, C. M. (2008). Emergent literacy skills during early childhood in children with hearing loss: Strengths and weaknesses. Volta Review, 108(2), 91-114.

Ehri, L. C., Deffner, N.D., \& Wilce, L.S. (1984). Pictorial mnemonics for phonics. Journal of Educational Psychology, 76(5), 880-893. 
Engelmann, S., \& Bruner, E.C. (2008). Reading Mastery. New York, NY: SRA/ McGraw-Hill.

Harris, M. \& Moreno, C. (2006). Speech reading and learning to read: A comparison of 8-year-old profoundly deaf children with good and poor reading ability. Journal of Deaf Studies and Deaf Education, 11(2), 189-201.

Holt, J. (1994). Classroom attributes and achievement test scores for deaf and hard of hearing students. American Annals of the Deaf, 139(4), 430-437.

Kazdin, A. E. (1982). Single-case research designs: Methods for clinical and applied settings. New York: Oxford University Press.

Kirk, C. \& Gillon, G. T. (2007). Longitudinal effects of phonological awareness intervention on morphological awareness in children with speech impairment. Language, Speech, and Hearing Services in Schools, 38, 342-352.

Korkman, M. \& Peltomaa, A. K. (1993). Preventive treatment of dyslexia by a preschool training program for children with language impairments. Journal of Clinical Child Psychology, 22(2), 277-287.

LaSasso, C., \& Mobley, R. (1997). National survey of reading instruction for deaf students in the United States. The Volta Review, 99, 31-60.

Lederberg, A. L, Miller, E. M., Easterbrooks, S. R., Bergeron, J. P., \& Connor, C. M. (2009). Foundations for Literacy. Unpublished curriculum. Georgia State University.

Lindamood, P., \& Lindamood, P. (2005). LIPS: The Lindamood phoneme sequencing program for reading, spelling and speech (3rd ed.) Shoreview, MN: AGS Publishing.

Moog, J. S., \& Geers, A. E. (1990). Early speech perception test for profoundly hearing-impaired children. St. Louis, MO: Central Institute for the Deaf.

Morrison, D., Trezek, B., \& Paul, P. (2008). Can you see that sound? A rationale for a multisensory intervention tool for struggling readers. Balanced Reading Instruction, 15(1), 11-26.

NAEYC \& NAECS/SDE. (2003). Early childhood curriculum assessment, and program evaluation: Building an effective, accountable system in programs for children birth through age 8. A joint position statement of the National Association for the Education of Young Children (NAEYC) and the National Association of Early Childhood Specialists in State Departments of Education (NAECS/SDE). Retrieved December 4, 2009, from http://www.naeyc.org/ files/naeyc/file/positions/pscape.pdf.

National Early Literacy Panel (NELP). (2009). Retrieved November 17, 2009, from http://www.nifl.gov/earlychildhood/NELP/NELP09.html

National Reading Panel. (2000). Teaching children to read: An evidence-based assessment of the scientific research literature on reading and its implications for reading instruction. Washington, DC: National Institute of Child Health and Human Development.

Olive, M. L., \& Smith, B. W. (2005). Effect size calculations and single subject designs. Educational Psychology, 25(2-3), 313-324. 
Paivio, A. (1971). Imagery and Verbal Processes. New York, NY: Holt, Rinehart, and Winston. (Reprinted 1979, Hillsdale, NJ: Lawrence Erlbaum Associates.)

Parker, D. (2002). Contemporary issues in audiology: A hearing scientist's perspective. International Journal of Language \& Communication Disorders, 37, 367-379.

Perfetti, C. A., \& Sandak, R. (2000). Reading optimally builds on spoken language: Implications for deaf readers. Journal of Deaf Studies and Deaf Education, 5, 32-50.

Sadoski, M. \& Paivio, A. (2004). A dual coding theoretical model of reading. In R.B. Ruddell \& N.J. Unrau (Eds.), Theoretical models and processes of reading (5th ed.) (pp. 1329-1362). Newark, DE: International Reading Association.

Scarborough, H. S., \& Brady, S. A. (2002). Toward a common terminology for talking about speech and reading: A glossary of the 'phon' words and some related terms. Journal of Literacy Research, 34, 299-334.

Schirmer, B. R. (2001). Using research to improve literacy practice and practice to improve literacy research. Journal of Deaf Studies and Deaf Education, $6,83-91$.

Schirmer, B .R., \& McGough, S. M. (2005). Teaching reading to children who are deaf: Do the conclusions of the National Reading Panel apply? Review of Educational Research, 75, 83-117.

Snider, V. E. (1995). A primer on phonemic awareness: What it is, why it's important, and how to teach it. School Psychology Review, 24, 443-455.

Spencer, L. J., \& Oleson, J. J. (2008). Early listening and speaking skills predict later reading proficiency in pediatric cochlear implant users. Ear and Hearing, 29(2), 270-280.

Spencer, L. J., \& Tomblin, J. B. (2008). Evaluating phonological processing skills in children with prelingual deafness who use cochlear implants. Journal of Deaf Studies and Deaf Education, 14(1), 1-21.

Spencer, L., Tomblin, J. B., \& Gantz, B. J. (1997). Reading skills in children with multichannel cochlear-implant experience. Volta Review, 99, 193-203.

Stahl, S. A., \& Murray, B. A. (1994). Defining phonological awareness and its relationship to early reading. Journal of Educational Psychology, 86, 221-234.

Strain, E., Patterson, K., Seidenberg, M. S. (2002). Theories of word naming interact with spelling-sound consistency. Journal of Experimental Psychology: Learning, Memory, and Cognition, 28, 207-214.

Tade, W. J., \& Vitali, G. J. (1994) Children's early intervention for speech-languagereading (CEI). East Aurora, NY: Slosson Education Publications, Inc.

Thomas, E., \& Senechal, M. (2004). Long-term association between articulation quality and phoneme sensitivity: A study from age 3 to age 8. Applied Psycholinguisitics, 25, 513-541.

Traxler, C. (2000). The Stanford Achievement Test, 9th edition: National norming and performance standards for deaf and hard-of-hearing students. Journal of Deaf Studies and Deaf Education, 5, 337-348. 
Trezek, B. J., \& Malmgren, K. W. (2005). The efficacy of utilizing a phonics treatment package with middle school deaf and hard-of-hearing students. Journal of Deaf Studies and Deaf Education, 10, 256-271.

Trezek, B. J., \& Wang, Y. (2006). Implications of utilizing a phonics-based reading curriculum with children who are deaf or hard of hearing. Journal of Deaf Studies and Deaf Education, 11, 202-213.

Trezek, B. J., Wang, Y., Woods, D. G., Gampp, T. L., \& Paul, P. V. (2007). Using visual phonics to supplement beginning reading instruction for students who are deaf or hard of hearing. Journal of Deaf Studies and Deaf Education, 12(3), 373-384.

Waddy-Smith, B. W., \& Wilson, V. (2003). See that sound! Visual phonics helps deaf and hard of hearing students develop reading skills. Odyssey, 54(1), 14-17.

Williams, C. (2004). Emergent literacy of deaf children. Journal of Deaf Studies and Deaf Education, 9(4), 352-365.

Woodcock, R.W., McGrew, K.S., \& Mather, N. (2001). Woodcock-Johnson®III NU Tests of Achievement. Itasca, IL: Riverside Publishing. 


\section{Appendix A}

\section{Story Card}

/t/

Miss Giggle told Kate and Pete that she had a surprise. "k it in the box?" asked Pete.

"No, it is not in the box" said Miss Giggle. "The surprise is that the girl, Sue, we met at the park will be coming after school everyday, too." Miss Giggle looked at her watch. "It is time for her to come." she said.

Just then the doorbell rang. It was Sue and her mother. Sue had a surprise for Miss Giggle. It was a present. She opened the present. It was a new dock.

"I hear a sound," said Miss Giggle. "t, t, t, t," She held the clock to her ear.

"ft t t." Miss Giggle decided to hangit on the wall. They all listened as it said

"t, t, t, t." That is the sound the letter " $t$ " makes. Miss Gigglewrote ' $t$ ' on a card and stuck it on the box.

\section{Large Concept Card}
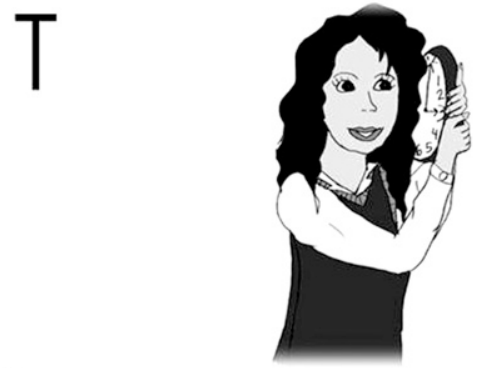

\section{Sequencing Pictures}
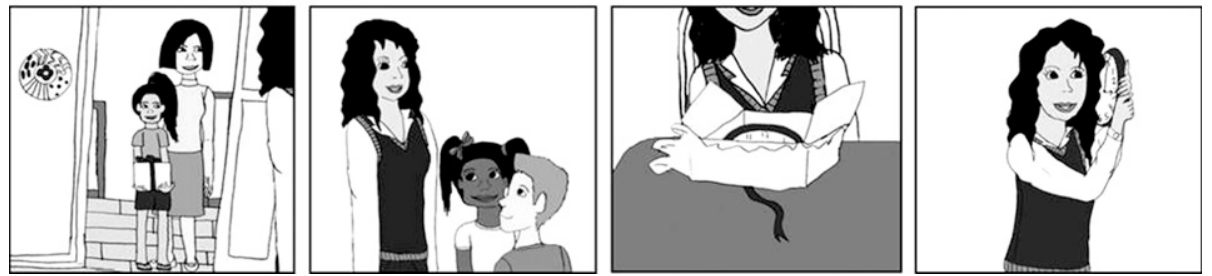
Phoneme Book Page

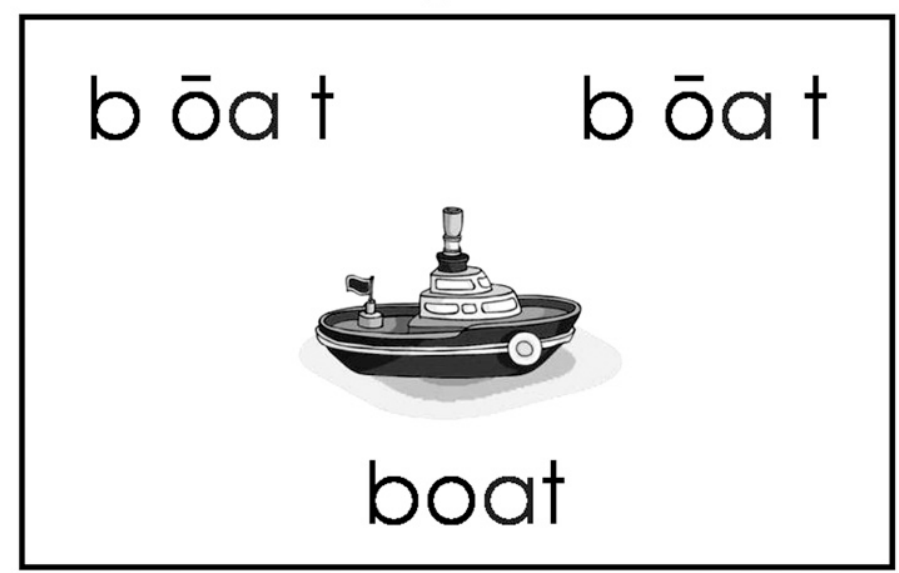

Blending Key Words

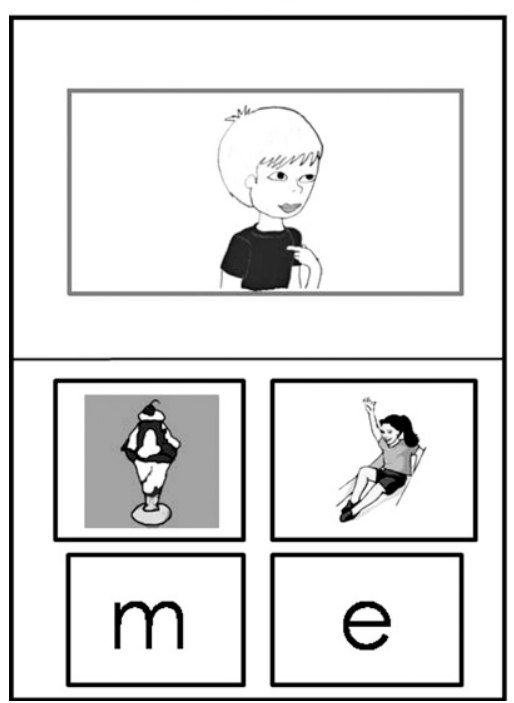

Small Concept Cards

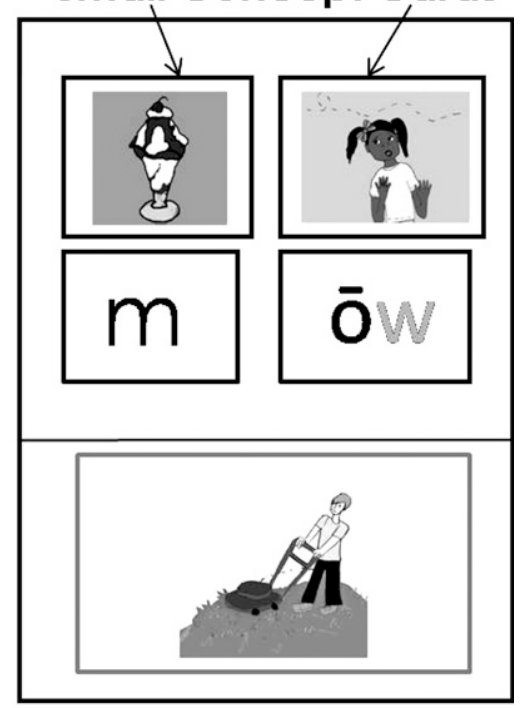



The Volta Review, Volume 109(2-3), Fall/Winter 2009, 121-141

\section{The Development and Piloting of a Decision Aid for Parents Considering Sequential Bilateral Cochlear Implantation for Their Child With Hearing Loss}

\section{J. Cyne Johnston, Ph.D.; Andrée Durieux Smith, Ph.D.;}

Annette O'Connor, Ph.D.; Karen Benzies, RN, B.Sc.N., M.N., Ph.D.; Elizabeth M. Fitzpatrick, Ph.D.; and Douglas Angus, B.Com., M.A.

A decision aid for parents considering sequential bilateral cochlear implantation for their children with severe-to-profound hearing loss was developed using local and published evidence. Eight parents of children currently using one cochlear implant, who faced a decision regarding a second cochlear implant, and five clinicians involved in the bilateral cochlear implantation decisions participated in a pilot of the decision aid. The decision aid was acceptable to both parents and clinicians. Changes in baseline decisional conflict and knowledge were examined among parents before and after use of the decision aid. Parents had significantly increased knowledge of the bilateral cochlear implant options, risks, and benefits following completion of the decision aid. Decisional conflict did not decline significantly. A decision aid for parents considering sequential bilateral cochlear implantation has potential as a decision support tool. Future work could examine the influence of the decision aid on decisional conflict of

J. Cyne Johnston, Ph.D., is a Clinical Research Associate at Alberta Children's Hospital in Calgary, Alberta, Canada. Andrée Durieux Smith, Ph.D., is a Professor Emeritus at the University of Ottawa and Scientific Director at Montfort Hospital in Canada. Annette O'Connor, Ph.D., is a Professor at the University of Ottawa in Canada. Karen Benzies, RN, B.Sc.N., M.N., Ph.D., is an Associate Professor at the University of Calgary in Canada. Elizabeth Fitzpatrick, Ph.D., is an Assistant Professor at the University of Ottawa in Canada. Douglas Angus, B.Com., M.A., is a Professor at the University of Ottawa in Canada. Correspondence concerning this article should be addressed to Dr. Johnston at cyne.johnston@albertahealthservices.ca. 
various subgroups of parents as well as their expectations of educational and communication outcomes.

\section{Introduction}

Almost immediately after the diagnosis of a hearing loss, parents of children with permanent, bilateral, sensorineural hearing loss are required to make a number of important decisions regarding the health care and communication options for their child. These decisions include the choice of communication approach for their child (e.g., listening and spoken language, sign language, Cued Speech, or total communication) and, in the case of spoken language, the choice of hearing technology, such as hearing aids or cochlear implants (CIs). Most of these parents have never experienced hearing loss themselves, which may make the decisions overwhelming (Northern \& Downs, 1991). Parents must absorb significant amounts of technical and scientific information during a period of grief about their child's hearing loss (Anagnostou, Graham, \& Crocker, 2007; Kurtzer-White \& Luterman, 2003). Decisions about treatment vary depending on the severity and characteristics of the child's hearing loss, the information received, and the needs and resources of the family.

\section{Cochlear Implantation}

A child with a bilateral, severe-to-profound hearing loss may require considerable intervention in the form of hearing technology and aural habilitation in order to develop listening and spoken language skills (Geers \& Brenner, 2003; Moog \& Geers, 2003; Samson-Fang, Simons-McCandless, \& Shelton, 2000). For these children, CIs are one of the available options. CIs are available for children with severe-to-profound hearing loss as young as 6 months of age (Thoutenhoofd et al., 2005).

Research indicates that there are benefits for patients receiving bilateral amplification compared to the use of unilateral amplification, as demonstrated on measures of speech recognition in noise and sound localization (Brown \& Balkany, 2007; Ching, van Wanrooy, \& Dillon, 2007; Johnston et al., 2009; Murphy \& O'Donoghue, 2007; Schafer \& Thibodeau, 2006). However, along with the benefits associated with bilateral devices, some risks are associated with CI surgery and the implanted device. Although infrequent, facial nerve paralysis, vestibular problems, and infection are some of the complications of CI surgery (Fayad, Wanna, Micheletto, \& Parisier, 2003; Fina et al., 2003; Gysin, Papsin, Daya, \& Nedzelski, 2000). Another major risk is the postsurgical complication of meningitis among children who have received an implant. Recent work has attributed the increased risk of meningitis, in part, to a particular positioner device that has since been withdrawn from the market (Biernath et al., 2006; United States Food and Drug Administration, 2007). 
Because of the increased support for binaural hearing for sound localization and speech intelligibility in noise, bilateral CIs (BICIs) have recently become available in some pediatric centers. A 2007 survey of 121 American CI centers indicated that $17 \%$ of those responding to the survey reported occasionally conducting BICI surgeries (Berg, Ip, Hurst, \& Herb, 2007). The occurrence of BICI surgeries and research has increased considerably in recent years (Johnston, Durieux-Smith, Angus, O'Connor, \& Fitzpatrick, 2009). There are differences among $\mathrm{CI}$ centers regarding the procedure and eligibility for BICI surgeries. For example, the province of Alberta in Canada currently conducts simultaneous BICI surgeries as the common practice of care for newly identified congenital profound hearing losses (J. Chan, personal communication, July 28, 2009). Other centers, such as the Children's Hospital of Eastern Ontario, currently conducts unilateral CI surgeries with an option later for a second implant. Priority for the second surgery is given to children at risk for cochlear calcification resulting from meningitis (L. Moran, personal communication, July 28, 2009). It can be a challenge for both parents and clinicians to keep abreast of the rapidly changing clinical landscape associated with BICIs.

When parents are considering sequential BICIs for their child, they are interested in both the benefits and risks associated with the surgery. These benefits and risks, the parents' perception of these risks and the clinical availability of the procedure in their local CI center may influence parental decision making.

\section{Parental Decision Making}

The available literature indicates that parents face challenges during the unilateral CI process (Incesulu, Vural, \& Erkam, 2003; Most \& Zaidman-Zait, 2003; Sach \& Whynes, 2005). Some literature describes the difficulty in making the decision to proceed with unilateral CIs for their children whereas other literature reports that it is the surgical process itself that is stressful. Incesulu et al. (2003) reported that $81 \%$ of Turkish parents responding to a survey indicated that choosing a unilateral CI decision was the most difficult aspect of the process for them. Most and Zaidman-Zait (2003) also described the high parental stress during the implantation decision-making process in Israeli $\mathrm{CI}$ clinics and the parental need for information to aid in the process. In contrast, Sach and Whynes (2005) of the United Kingdom reported that the majority of the 216 families interviewed using a qualitative approach found the decision regarding implantation to be straightforward. They did, however, describe the overall stress for families undergoing the CI process. This literature speaks to the importance of providing families with adequate information to support their decisions; Including patients or their families in their health decisions is an important component of knowledge translation (Coulter, 1997; Holmes-Rovner et al., 2001).

A recent needs assessment conducted with 8 parents using a semi-structured interview process indicated that although parents perceive and report that the 
unilateral CI decision was straightforward and consistent with their values regarding listening and spoken language communication, they still would have preferred to have additional information when making the decision (Johnston et al., 2008). These results were quite similar to those obtained by Sorkin and Zwolan (2008), who requested additional information from 148 surveyed parents making the unilateral CI decision. In addition, in the Johnston et al. (2008) study, parents reported being more uncertain of the benefits and risks associated with the sequential BICI decision. Parents and clinicians interviewed in the Johnston et al. (2008) study requested additional evidence-based information on the benefits and risks of BICIs to help with making decisions.

\section{Decision Aids for Supporting Decision Making}

One approach to providing evidence-based information for health care consumers is through the use of decision aids (O'Connor \& Edwards, 2001). Decision aids are "tools designed to help people participate in decision making about health care options. They provide information on the options and help patients clarify and communicate the personal value they associate with different features of the options" (International Patient Decision Aid Standards [IPDAS], 2008). Decision aids are particularly important in situations where there is a choice between two or more health care options and there is no clear standard of care based on the available evidence (O'Connor \& Edwards, 2001). This is known as "preference-sensitive" care decisions. Wennberg (2002) further distinguishes between "effective" and "preference sensitive" care. When adequate scientific evidence documenting clear benefits and few harmful effects associated with one health choice is available (i.e., a clear standard of care or "effective" care), there is often little conflict regarding the choice to be made. However, many health care decisions are not based on clear evidence, and sometimes the evidence that is available indicates that the choices may carry both harmful and beneficial results that may be differentially viewed depending on the personal preferences of the client (O'Connor, Legare, \& Stacey, 2003; Wennberg, 2002). These preference-sensitive decisions may also include medical procedures that have insufficient evidence because of recent introduction of the procedure into the clinical context. Decision aids are tools designed to help patients become informed regarding preference-sensitive options.

A Cochrane systematic review of the effectiveness of decision aids identified 55 independent, randomized controlled trials that examined the effectiveness of decision aids for health care treatment or screening decisions $\left(\mathrm{O}^{\prime} \mathrm{Connor}\right.$, Bennett, et al., 2009). The review showed that the decision-making quality and process improved with the use of decision aids. Specifically, the meta-analysis showed that the aids improved knowledge and reduced decisional conflict among those who used decision aids compared with those who did not. (Decisional conflict is the state of uncertainty about the best course of action [O'Connor, 1995]). Decision aids were also shown to increase participation in 
decision making without increasing anxiety, as well as create more realistic expectations of outcomes. The effectiveness of decision aids in improving the decision-making process and in appropriately translating research knowledge for consumers makes them applicable in many health care situations. In fact, decision aids have been developed for more than 252 health decisions (Cochrane Inventory of Patient Decision Aids, 2008).

According to research identifying a parent's need for additional information and uncertainty in decision making (Johnston et al., 2008) and the relatively recent introduction of pediatric BICIs into both the research and the clinical context, the BICI decision appears to be a preference-sensitive decision. For parents to make a decision that is well informed and consistent with parents' personal values, it is essential that the available relevant research is provided to them. The effectiveness of decision aids in improving the decision-making quality and process, as evidenced by the results of the Cochrane systematic review, makes them the most relevant tool for disseminating the current state of knowledge, explaining the choices, and exploring the personal preferences of parents (O'Connor, Bennett, et al., 2009). As such, a decision aid on the topic of sequential pediatric BICIs may be useful for parents.

The primary purpose of the study was to develop and pilot a decision aid for parents considering a second $\mathrm{CI}$ for their children with severe-to-profound hearing loss. The secondary purpose was to explore parental knowledge and decisional conflict before and after use of the decision aid. There were two research questions: "Is the decision aid acceptable to parents and clinicians?" and "How does exposure to the decision aid change knowledge and/or decisional conflict among parents?"

\section{Method}

\section{Decision Aid Development}

A previously published needs assessment was conducted to assess the needs of parents considering unilateral or bilateral CIs (Johnston et al., 2008). Eight parents of children using CIs and eight CI clinicians were interviewed using a semi-structured format to investigate the decision-making process and the needs of parents regarding unilateral and bilateral CIs. In addition to showing that parents wanted more information on CIs generally, the work also indicated that parents lacked information on the benefits and risks associated with BICIs. To address this need for additional information, the Ottawa Decision Support Framework ( $\mathrm{O}^{\prime}$ Connor et al., 1998a) was chosen as the theoretical framework to guide the decision aid's development and piloting. A standardized Ottawa Patient Decision Aid template that conforms to IPDAS standards (Elwyn et al., 2006) was adapted for the BICI decision aid.

The objective of the decision aid was to provide parents with information on the options, risks, and benefits associated with sequential BICIs. The tool was 
designed to help people participate in decision making with their clinicians by clarifying and communicating their personal values and any additional needs. The objective of the decision aid was to supplement and guide clinical interactions, not to replace them.

The benefits associated with BICIs were systematically gathered from the available published literature and synthesized (Johnston et al., 2009). Twentynine studies that examined the benefits associated with pediatric BICIs were included in the review. Sound localization and speech recognition in noise appear to be more improved with BICIs compared with unilateral CIs. The data from studies that used the same outcome measures were combined to provide an estimate of overall performance for both the children with unilateral implants and those with bilateral implants.

Five studies examined the sound localization performances of children using BICIs compared to a unilateral CI at various angles of stimulus presentation on the standardized Minimum Audible Angle (MAA) task (Grieco-Calub, Litovsky, \& Werner, 2008; Litovsky, Johnstone, \& Godar, 2006; Litovsky, Johnstone, Godar, Agrawal, et al., 2006; Peters, Litovsky, Lake, \& Parkinson, 2004; Senn, Kompis, Vischer, \& Haeusler, 2005). In total, 35 children participated in these five studies that used the MAA testing paradigm. Results indicated that $46 \%(17 / 31)$ of the children using BICIs performed the task at the $20^{\circ}$ threshold compared with $14 \%(5 / 35)$ of children using a unilateral CI. Two studies examined the speech recognition in noise performances of children using BICIs compared to a unilateral CI measured by the AdSpon in the ipsilateral noise presentation condition (Galvin, Mok, \& Dowell, 2007; Galvin, Mok, Dowell, \& Briggs, 2007). None of the children using one $\mathrm{CI}$ could perform the task at levels of children with typical hearing, whereas $13 \%(2 / 16)$ of children with BICIs could perform the task at this level.

Risks of CI surgery were also systematically gathered from the literature and local databases (Johnston et al., 2009). These published data were used to create the benefits and risk summaries as presented in the decision aid. The draft decision aid was reviewed by an expert panel composed of research and clinical audiologists, a cochlear implant surgeon, and a decision aid methodologist. Multiple drafts of the decision aid were circulated among the members of the expert panel until an acceptable version was created. The resulting decision aid is available in Appendix A. Appendix B* provides the information supporting the development of the decision aid, including references from the literature that were used to inform the benefit and risk rates.

It is important to note that the risks and benefits presented in the decision aid reflect those of a child who has already undergone one CI surgery, which

\footnotetext{
${ }^{*}$ Due to the scope and length of Appendix B, it is available exclusively online at www.agbell.org/TheVoltaReview.
} 
is particularly relevant for the surgical risks associated with not accepting a second CI. Because the child has already received one CI and either experienced or did not experience complications in his or her first surgery, there is no increased surgical risk when not accepting the second CI. However, the risks associated with meningitis and device failure continue beyond the original surgical date. The surgical risks that are presented for the acceptance of the second $\mathrm{CI}$ are the same as the risks associated with the first surgery.

\section{Decision Aid Pilot}

To assess the acceptability of the decision aid to parents and clinicians, an exploratory research pilot study was undertaken in a single Canadian CI center. Acceptability of the decision aid was assessed using a posttest research design. A pretest-posttest research design was used to examine parents' decisional conflict and knowledge before and after using the decision aid.

\section{Participants and Recruitment}

While BICIs were not the standard of care in this center, clinicians maintained a list of families who were potential candidates for a second CI but had not yet received one. A convenience sample of these parents was recruited to participate in the study. Eligible participants were parents who had children (ages 1 to 17 years) with one CI who were considering a second implant for their child. Participating children were eligible for a second CI because of the severity of their loss. All participants used services provided by the same regional CI center.

Eight parents of nine children eligible for a second CI participated in the pilot study. There were 7 mothers and 1 father among the parents. Parents ranged in age from 32 to $42(M=36.8, S D=3.24$ years). All parents had completed high school and 7 of the 8 had some postsecondary education or a completed bachelor's degree. All parents spoke English. Four of the families also used one or more additional languages: French (2), Arabic (1), and American Sign Language (1). The nine children of these parents ranged in age from 2 to 8 years $(M=3.9$, $S D=2.09$ years). Seven of the children had been identified with their hearing loss prior to 7 months of age. Two of the children were identified at age 2 . The average age for receiving the first $\mathrm{CI}$ was $2.4(S D=1.54)$ years of age (range $=$ 1 to 5 years). The time interval between receiving the first $\mathrm{CI}$ and participation in the study ranged between 3 months and 2 years $(M=1.5$ years, $S D=1.16)$. All children used auditory-verbal therapy (AVT) as their primary method of acquiring listening and spoken language. Two children used American Sign Language as a secondary communication approach and one child also used pictograms. Data regarding current device use in the second ear were not gathered; however, all children had a severe-to-profound or profound loss in both ears that limited the effectiveness of hearing aid use in the second ear. 
CI audiologists and (re)habilitation therapists from the CI center were also invited to participate in the study. All clinicians had more than 7 years of experience working with children who receive CIs. Four women and one man participated. Five clinicians (audiologists and listening and spoken language specialists) participated in the study. All of these participants have a wide range of experience working with children with CIs and their families. BICIs had only recently been introduced at this CI center.

Consent for participation was obtained from both parents and clinicians prior to study commencement. Ethical approval was received from the Children's Hospital of Eastern Ontario and the University of Ottawa, Research Ethics Boards.

\section{Procedure and Outcome Measures}

Parents were asked by a member of the research team to complete a questionnaire eliciting the parent's education level, child and parent's current age, age of the child at identification of hearing loss, age the child received the first implant, and additional clinical characteristics of the child. Parents were then asked to complete baseline measures of knowledge and decisional conflict regarding BICIs.

The knowledge test, a 5-item questionnaire developed for this study, used a standardized template and was endorsed for content validity by the expert panel used during the decision aid's development. Response categories were true (coded as correct) or false or unsure (coded as incorrect). The parents' correct answers to each item were summed to create an overall knowledge score. Content in the knowledge test reflected topics covered in the decision aid. The test is available in Step 3 of the decision aid (see Appendix A).

Data about the parents' decision process were also gathered using a Decisional Conflict Scale (O'Connor, 1995). The Decisional Conflict Scale is a 16-item questionnaire designed to identify the difficulties in making health care choices. Response categories ranged from 0 (strongly agree) to 4 (strongly disagree). The decisional conflict measure consists of a total score (ranging from 0 to 100 , with 0 meaning no decisional conflict and 100 meaning extremely high decisional conflict) and five subscales: uncertainty, informed, values clarity, support, and effective decision. Higher scores indicate greater decisional conflict. Temporal stability and $\alpha$ coefficients exceed 0.81 . Other research indicates that the measure is sensitive to change and this measure has been used in more than 30 research studies ( $\mathrm{O}^{\prime}$ Connor et al., 1998a). The measure is able to discriminate between individuals who delay decision making and those who make decisive choices when faced with health decisions.

Following the completion of the baseline measures, parents were then asked to read the decision aid and complete the steps of decision making as set out in the decision aid. The decision aid leads readers through four steps that include an introduction of the options, explanation of the benefits and risks of 
the options, exercises for readers to identify the reasons for each option that matter most to them, and identification of any additional decisional needs. Following the reading of the decision aid, parents were asked to complete the final knowledge and decisional conflict measures.

Finally, parents were invited to complete a standardized acceptability questionnaire that consisted of both open- and closed-ended questions. Closedended questions included items that evaluated the amount, length, clarity, and helpfulness of the information in the decision aid. Participants were asked to rate, on a 4-point scale from "poor" to "excellent," the various information sections of the decision aid. Other items examined whether the information was presented in a balanced manner and whether they would recommend the aid to others. This acceptability tool has been used in studies examining decision tools developed for osteoporosis, hormone replacement therapy, lung cancer, and prenatal testing (Cranney et al., 2002; Drake, Engler-Todd, O'Connor, Surh, \& Hunter, 1999; Fiset et al., 2000; O'Connor et al., 1998a; O'Connor et al., 1998b). A predetermined acceptability level of at least $70 \%$ for the various elements of the decision aid is recommended in the Ottawa Toolkit for Decision Aid Development (O'Connor, Brehaut, et al., 2006).

All outcome measures were available in English. The research procedure lasted between 30 and 40 minutes and was conducted at a mutually agreeable location, either in the family's home or at the clinic. Clinicians were also asked to review the decision aid and to complete only the acceptability measure following their review of the decision aid.

\section{Analysis and Interpretation}

For the acceptability of the decision aid, an analysis of the frequency of parents and clinicians who recommended the decision aid, found it to be the right length, and found that it was helpful was conducted. Any suggested changes were examined closely during this pilot phase because the purpose was to improve the decision aid prior to widespread use.

The group's mean overall knowledge and decisional conflict scores were also calculated. The pre- and post-decision-aid overall knowledge and decisional conflict scores were examined using a paired $t$ test. Pre- and post data were available for all 8 participants for both measures. Pre- and post-decisionaid knowledge and decisional conflict measures were completed approximately 20 minutes apart.

\section{Results}

\section{Acceptability}

The primary research question was, "Is the decision aid acceptable to parents and clinicians?" Figure 1 presents the percentage of respondents, both 


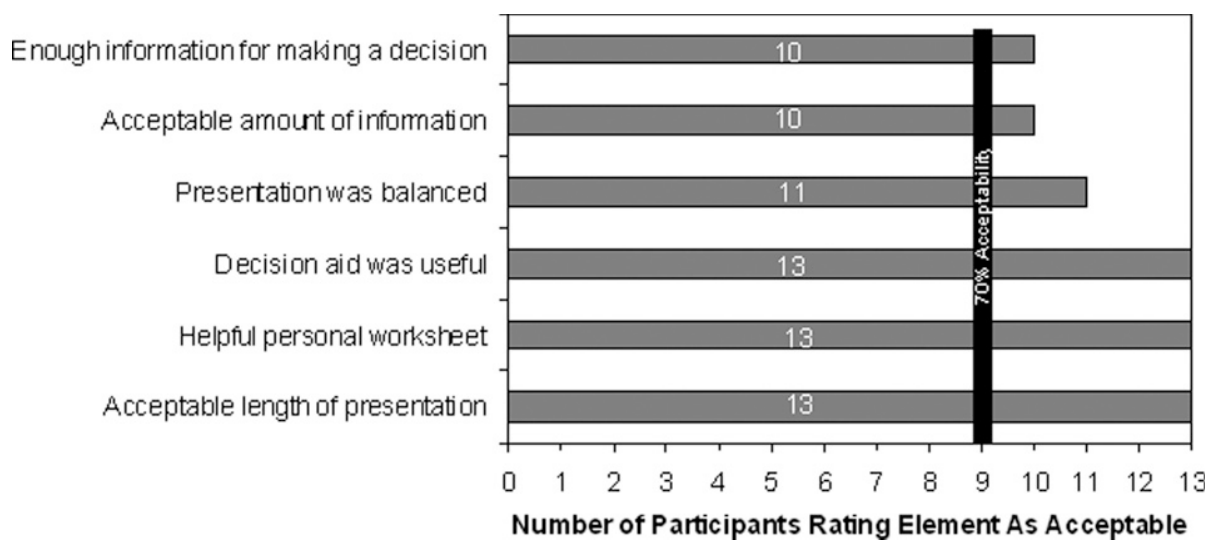

Figure I. Number of respondents, both parents and clinicians, reporting acceptability of various elements of the decision aid $(N=13)$

parents and clinicians $(N=13)$, reporting acceptability of various elements of the decision aid. All of the included elements were acceptable to over $70 \%$ of participants. Figure 2 shows the participant rating of the various information sections of the decision aid. No participants rated any section as "poor." The area rated as "fair" by the greatest number of participants was the area describing the criteria for BICIs.

Parents and clinicians were also encouraged to provide written comments on what they liked about the decision aid, as well as suggestions for

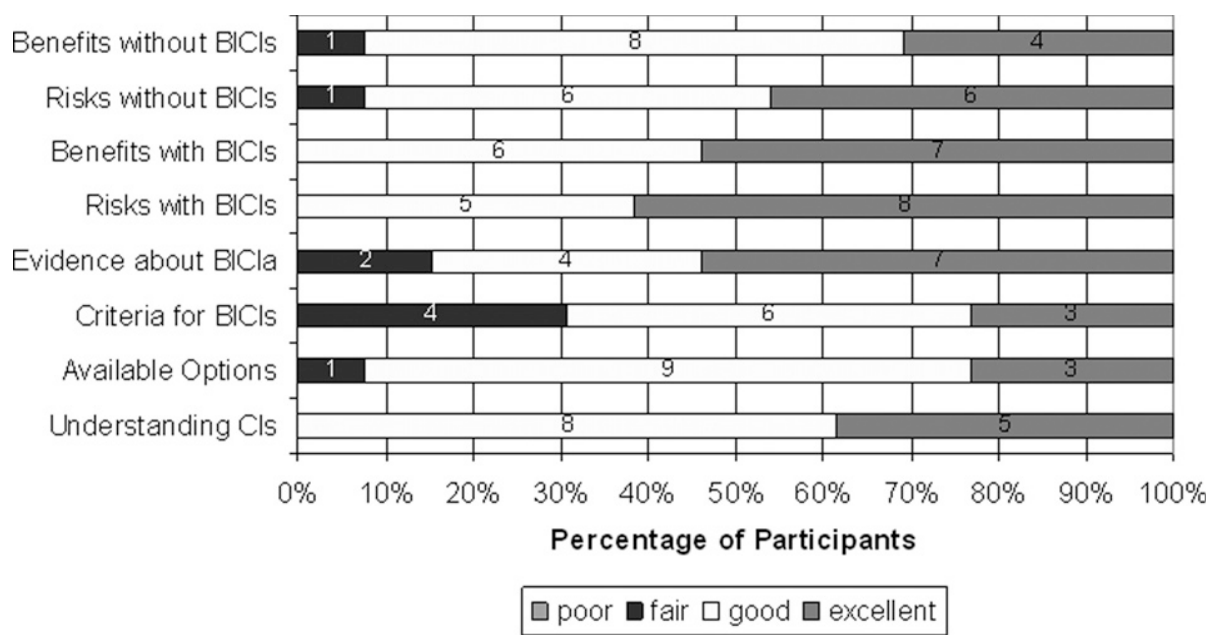

Figure 2. Participants' ratings of various sections of the decision aid $(N=13)$ 
improvement. Five of 8 parents commented on the advantages of seeing the benefits and risks clearly displayed. Comments included "The facts are very clear and concise" and "The benefits and risks were great to see." Other comments from both parents and clinicians spoke to the positive elements of the decision aid in general, such as "Written information to take away in a rational format." Parents appreciated receiving additional information: "It's more information that I did not have before."

The suggestions for improvements were consistent with the rating from parents and clinicians on the various sections of the decision aid. "It needs more regarding candidacy criteria" was a comment received from a parent and a clinician. Others suggested more information on the effect of the timing of the surgery and the importance of a backup device for some families.

\section{Knowledge}

The secondary research question was "How does exposure to the decision aid change knowledge and/or decisional conflict among parents?" The average knowledge score of participating parents before reading the decision aid was $2.63 / 5$ (range $=0-5, S D=1.60$ ). Following the reading of the decision aid, the average score was $4.25 / 5$ (range $=3-5, S D=0.89$ ). Parents showed a statistically significant increase in their knowledge of the BICI options, risks, and benefits following the reading of the decision aid, $t(1,7)=-3.87, p=0.0061$ (two sided).

\section{Decisional Conflict}

The average total decisional conflict score of participating parents before reading the decision aid was 14.26 (range $=0-34.38, S D=13.16$ ). Following the reading of the decision aid, the average total decisional conflict score was 6.44 (range $=0-15.63, S D=5.87$ ). There was a trend toward a reduction in decisional conflict among participants but it was not statistically significant, $t(1,7)=1.82, p=0.111$ (two sided).

Though there was not a statistically significant reduction of decisional conflict scores for the group, there were a number of meaningful changes in decisional conflict among two participants. A total decisional conflict score below 25 is associated with the implementation of a decision and lower decisional conflict. Six of the 8 participants had decisional conflict scores below 25 at the onset of the study. The 2 parents with decisional conflict scores above 25 (34.38 and 32.81) reduced their scores below the 25-point threshold following the reading of the decision aid (15.63 and 0$)$. The parent's predisposition toward the BICI remained unchanged following the use of the decision aid. Seven of the 8 parents reported leaning toward the 
BICI option for their children on completion of the decision aid; 1 remained uncertain.

\section{Discussion}

Previous research indicated that parents found the BICI decision challenging. In particular, parents requested additional information on the risks and benefits of BICIs because of their lack of knowledge about the procedure and its outcomes (Johnston et al., 2008). The decision aid in the current study was developed to meet this decisional support need of parents. Though there were some small changes suggested by parents and clinicians who piloted this decision aid, the tool was acceptable to the users in this pilot. The feedback provided by parents is important and will be examined closely by the expert panel when they meet to incorporate these results into the final decision aid. The significant improvement in knowledge among users of the decision aid indicates that the tool is meeting an informational need of parents.

The results of this pilot are similar to those of other studies evaluating the use of decision aids in clinical contexts. A systematic review of the effectiveness of decision aids indicates that improved knowledge and reduced decisional conflict are common among those who use decision aids compared with those who do not use the decision aids (O'Connor, Bennett, et al., 2009). The results of this pilot indicated a significant increase in knowledge of participating parents. Though decisional conflict did not significantly decline in the small group of participants in this pilot, there were some clinically meaningful decisional conflict changes for 2 of the 8 participants. A larger scale evaluation is required to determine if the sequential BICI decision aid is effective in reducing decisional conflict.

Previous research indicates that decision aids increased participation in decision making without increasing anxiety as well as created more realistic expectations of outcomes (O'Connor, Bennett, et al., 2009). Outcomes were not examined in this pilot study but may be important for future research and of interest in a larger scale evaluation of this decision aid. Parents of children with hearing loss most often have not experienced a hearing loss themselves and are often faced with a great deal of new scientific and technical information (Northern \& Downs, 1991). Finding a way to help parents absorb this information without increasing anxiety may be an important clinical tool.

This is the first decision aid developed for a pediatric CI topic and is also the first decision aid developed for an audiology topic (Cochrane Inventory of Patient Decision Aids, 2008). This aid for parents making decisions about sequential BICIs is evidence-based and conforms to IPDA standards (IPDAS, 2008). It will join the 255 other decision aids, for a variety of topics, that help provide decisional support for preference-sensitive health care decisions. 
These decision aids are available in a variety of clinical contexts around the world and are listed online at http://decisionaid.ohri.ca/AZinvent.php.

\section{Limitations}

Because the primary purpose of this study was to examine the acceptability of the decision aid before a larger scale evaluation of the effects of the decision aid, this study was underpowered to detect a significant change in decisional conflict. Previous literature indicates that effect sizes on the Decisional Conflict Scale have been in the range of 0.43 to 0.82 (O'Connor et al., 1998a). A future evaluation of this decision aid should include 51 to 68 parents in both the intervention and control groups. Between 51 and 68 parents are required to determine an effect size of 0.40 in a randomized controlled trial on the Decisional Conflict Scale with a Type 1 error of 0.05 and a power between $80 \%$ and $90 \%$. This number of parents would offer sufficient power to detect before and after changes in subgroups who differ in baseline predisposition toward options (e.g., unsure versus leaning toward a specific option), education level (e.g., above or below the median numbers of years of education of father), and knowledge (e.g., above and below the baseline median knowledge score).

The rates of benefits and risks were developed from literature in the public domain and a standard decision aid template was used to make the decision aid as universal as possible. However, the decision aid was designed and piloted at one CI center in Canada that specializes in helping its clients develop listening and spoken language. Because the decision aid development team was from a single Canadian center and piloted with a small sample of parents, readers will need to assess the findings to ascertain if they can be adapted to other CI centers.

This decision aid was developed within the context of the publically funded Canadian health care system. Therefore, direct costs associated with the second surgical implantation and the CI device were not a concern for parents or clinicians in this study. Clinicians in other settings may need to address this potential parental concern depending upon the costs and available funding for the second CI procedure.

Residual hearing in the second ear may be a concern for some parents but was not addressed in the benefit and risk section of the decision aid. This topic was not raised by the parents in this study, perhaps because all children had severe-to-profound or profound losses. Some parents in other centers may need to consider the loss of residual hearing in the second ear as a potential risk for the bilateral surgery. In these cases, further discussion of this risk with their clinician may be needed. A review of outcomes comparing BICI and bimodal device (CI and hearing aid) use by Schafer, Amlani, Seibold, and Shattuck (2007) may be relevant for addressing the concerns of these parents. 


\section{Conclusions}

A decision aid was developed for parents making the sequential BICI decision. The decision aid was developed using available local and published evidence and conformed to IPDAS standards. Results found that the aid was acceptable to both parents and clinicians in helping make difficult decisions. The decision aid has the potential to become a useful support tool because users of the aid showed increased knowledge of the BICI options, risks, and benefits. Some participants experienced meaningful reductions of their decisional conflict surrounding the sequential BICI after reading the decision aid. However, a more representative evaluation with a larger sample of parents is needed. A randomized controlled trial would provide the strongest evidence regarding the influence of a decision aid on parents' decision making. In addition, it may be important to examine the decision aid with parents in different clinical contexts, including those in which parents are responsible for some of the costs associated with the surgery. Future work could also examine the influence of the decision aid on decisional conflict for various subgroups and the influence that the decision aid has on expectations of child and family outcomes.

\section{Acknowledgments}

The first author received doctoral support from an Ontario graduate scholarship in science and technology as well as a University of Ottawa graduate scholarship. Additional doctoral support was provided by the Canadian Language and Literacy Research Network.

\section{References}

Anagnostou, F., Graham, J., \& Crocker, S. (2007). A preliminary study looking at parental emotions following cochlear implantation. Cochlear Implants International, 8, 68-86.

Berg, A.L., Ip, S.C., Hurst, M., \& Herb, A. (2007). Cochlear implants in young children: Informed consent as a process and current practices. American Journal of Audiology, 16, 13-28.

Biernath, K.A., Reefhuis, J., Whitney, C.G., Mann, E.A., Costa, P., Eichwald, J., et al. (2006). Bacterial meningitis among children with cochlear implants beyond 24 months after implantation. Pediatrics, 117, 284-289.

Brown, K.D., \& Balkany, T.J. (2007). Benefits of bilateral cochlear implantation: A review. Current Opinions in Otolaryngology Head and Neck Surgery, 15, 315-318.

Ching, T.Y., van Wanrooy, E., \& Dillon, H. (2007). Binaural-bimodal fitting or bilateral implantation for managing severe to profound deafness: A review. Trends in Amplification, 11, 161-192. 
Cochrane Inventory of Patient Decision Aids. (2008). Retrieved June 10, 2008, from http:/ / decisionaid.ohri.ca/cochinvent.php.

Coulter, A. (1997). Partnerships with patients: The pros and cons of shared decision making. Journal of Health Services Research and Policy, 2, 112-121.

Cranney, A., O'Connor, A.M., Jacobson, M.J., Tugwell, P., Adachi, J.D., Ooi, D.S., et al. (2002). Development and pilot testing of a decision aid for postmenopausal women with osteoporosis. Patient Education and Counseling, 47, 245-255.

Drake, E., Engler-Todd, L., O'Connor, A.M., Surh, L., \& Hunter, A. (1999). Development and evaluation of a decision aid about prenatal testing for women of advanced maternal age. Journal of Genetic Counseling, 8, 217-233.

Elwyn, G., O'Connor, A., Stacey, D., Volk, E., Edwards, A., Coulter, A., et al. on behalf of the International Patient Decision Aids Standards (IPDAS) Collaboration. (2006). Developing a quality criteria framework for patient decision aids: Online international Delphi consensus process. British Medical Journal, 333, 417.

Fayad, J.N., Wanna, G.B., Micheletto, J.N., \& Parisier, S.C. (2003). Facial nerve paralysis following cochlear implant surgery. Laryngoscope, 113, 1344-1346.

Fina, M., Skinner, M., Goebel, J.A., Piccirillo, J.F., Neely, J.G., \& Black, O. (2003). Vestibular dysfunction after cochlear implantation. Otology and Neurootology, 24, 234-242.

Fiset, V., O'Connor, A.M., Evans, W., Graham, I., DeGrasse, C., \& Logan, J. (2000). Development and evaluation of a decision aid for patients with stage IV non-small cell lung cancer. Health Expectations, 3, 125-136.

Galvin, K.L., Mok, M., \& Dowell, R.C. (2007). Perceptual benefit and functional outcomes for children using sequential bilateral cochlear implants. Ear and Hearing, 28, 470-482.

Galvin, K.L., Mok, M., Dowell, R.C., \& Briggs, R.J. (2007). 12-month postoperative results for older children using sequential bilateral implants. Ear and Hearing, 28, 19S-21S.

Geers A.E., \& Brenner, C. (2003). Background and educational characteristics of prelingually deaf children implanted by 5 years of age. Ear and Hearing, 24, 2-14.

Grieco-Calub, T.M., Litovsky, R.Y., \& Werner, L.A. (2008). Using the observerbased psychophysical procedure to assess localization acuity in toddlers who use bilateral cochlear implants. Otology and Neurootology, 29, 235-239.

Gysin, C., Papsin, B.C., Daya, H., \& Nedzelski, J. (2000). Surgical outcomes after paediatric cochlear implantation: Diminution of complications with the evolution of new surgical techniques. Journal of Otolaryngology, 29, 285-289.

Holmes-Rovner, M., Llewellyn-Thomas, H., Entwistle, V., Coulter, A., O'Connor, A., \& Rovner, D.R. (2001). Patient choice modules for summaries of clinical effectiveness: A proposal. British Medical Journal, 322, 664-667. 
Incesulu, A., Vural, M., \& Erkam, U. (2003). Children with cochlear implants: Parental perspective. Otology and Neurotology, 24, 605-611.

International Patient Decision Aid Standards (IPDAS). (2008). What are patient decision aids? Retrieved June 10, 2008, from http://ipdas.ohri.ca/what.html. Johnston, J.C., Durieux-Smith, A., Angus, D., O'Connor, A., \& Fitzpatrick, E. (2009). Estimation of risks associated with paediatric cochlear implantation. Cochlear Implant International, 8, 53-67.

Johnston, J.C., Durieux-Smith, A., Fitzpatrick, E., Benzies, K., O'Connor, A., Angus, D., et al. (2009). Bilateral paediatric cochlear implants: A critical review. International Journal of Audiology, 48, 601-617.

Johnston, J. C., Durieux-Smith, A., Fitzpatrick, E., O'Connor, A., Benzies, K., \& Angus, D. (2008). An assessment of parents' decision-making regarding paediatric cochlear implants. Canadian Journal of Speech-Language Pathology and Audiology, 32, 169-182.

Kurtzer-White, E., \& Luterman, D. (2003). Families and children with hearing loss: Grief and coping. Mental Retardation and Developmental Disability Research Review, 9, 232-235.

Litovsky, R.Y., Johnstone, P.M., \& Godar, S.P. (2006). Benefits of bilateral cochlear implants and/or hearing aids in children. International Journal of Audiology, 45, 78S-91S.

Litovsky, R.Y., Johnstone, P.M., Godar, S., Agrawal, S., Parkinson, A., Peters, R., et al. (2006). Bilateral cochlear implants in children: Localization acuity measured with minimum audible angle. Ear and Hearing, 27, 43-59.

Moog, J.S., \& Geers, A.E. (2003). Epilogue: Major findings, conclusions and implications for deaf education. Ear and Hearing, 24, 121S-125S.

Most, T., \& Zaidman-Zait, A. (2003). The needs of parents of children with cochlear implants. The Volta Review, 103, 99-113.

Murphy, J., \& O'Donoghue, G. (2007). Bilateral cochlear implantation: An evidence-based medicine evaluation. Laryngoscope, 117, 1412-1418.

Northern, J., \& Downs, M.P. (1991). Hearing in children (4th ed.). Baltimore, MD: Williams \& Wilkins.

O'Connor, A.M. (1995). Validation of a decisional conflict scale. Medical Decision Making, 15, 25-30.

O'Connor, A.M., Bennett, C.L., Stacey, D., Barry, M., Col, N.F., Eden, K.B., et al. (2009). Decision aids for people facing health treatment or screening decisions. Cochrane Database of Systematic Reviews, 3,Art. No.: CD001431. DOI: 10.1002/14651858.CD001431.pub2.

O'Connor, A., Brehaut, J., Tugwell, P., Santesso, N., Bennett, C., \& Stacey, D. (2006). Toolkit for applying IPDAS standards in developing and evaluating Ottawa patient decision aids, Ottawa, Ontario: Ottawa Health Research Institute.

O'Connor, A., \& Edwards, A. (2001). The role of decision aids in promoting evidence-based patient choice. In A. Edwards \& G. Elwyn (Eds.), Evidencebased patient choice (pp. 220-242). Oxford, England: Oxford University Press. 
O'Connor, A.M., Legare, F., \& Stacey, D. (2003). Risk communication in practice: The contribution of decision aids. British Medical Journal, 327, 736-740.

O'Connor, A.M., Tugwell, P., Wells, G.A., Elmslie, T., Jolly, E., Hollingworth, G., et al. (1998a). A decision aid for women considering hormone therapy after menopause: Decision support framework and evaluation. Patient Education and Counseling, 33, 267-279.

O'Connor, A.M., Tugwell, P., Wells, G.A., Elmslie, T., Jolly, E., Hollingworth, G., et al. (1998b). Randomized trial of a portable, self-administered, decision aid for post-menopausal women considering long term preventive hormone therapy. Medical Decision Making, 18, 295-303.

Peters, B.R., Litovsky, R., Lake, J., \& Parkinson, A. (2004). Sequential bilateral cochlear implantation in children. International Congress Series, 1273, 462-465.

Sach, T.H., \& Whynes, D.K. (2005). Paediatric cochlear implantation: The views of parents. International Journal of Audiology, 44, 400-407.

Samson-Fang, L., Simons-McCandless, M., \& Shelton, C. (2000). Controversies in the field of hearing impairment: Early intervention, educational methods, and cochlear implants. Infants and Young Children, 12, 77-88.

Schafer, E.C., Amlani, A.M., Seibold, A., \& Shattuck, P. (2007). A metaanalytic comparison of binaural benefits between bilateral cochlear implants and bimodal stimulation. Journal of the American Academy of Audiology, 18, 760-776.

Schafer, E.C., \& Thibodeau, L.M. (2006). Speech recognition in noise in children with cochlear implants while listening in bilateral, bimodal, and FM-system arrangements. American Journal of Audiology, 15, 114-126.

Senn, P., Kompis, M., Vischer, M., \& Haeusler, R. (2005). Minimum audible angle, just noticeable interaural differences and speech intelligibility with bilateral cochlear implants using clinical speech processors. Audiology and Neurootology, 10, 342-352.

Thoutenhoofd, E., Archbold, A., Gregory, S., Lutman, M., Nikolopoulos, T., \& Sach, T.H. (2005). Paediatric cochlear implantation: Evaluating outcomes. London: Whurr.

United States Food and Drug Administration. (2007). Advice for patients with cochlear implants: New information on meningitis risk. Retrieved May 18, 2008, from http://www.fda.gov/MedicalDevices/Safety/AlertsandNotices/ PatientAlerts/ucm064671.htm.

Wennberg, J.E. (2002). Unwarranted variations in healthcare delivery: Implications for academic medical centres. British Medical Journal, 325, 961-964. 


\section{Appendix A}

\section{Should my child have a second cochlear implant?}

A decision aid to discuss options with your health care team

This decision aid is for you if:

- Your child has a cochlear implant.

- You are wondering about a cochlear implant for your child's other ear.

What is a cochlear implant?

- A cochlear implant is a surgically implanted electronic device that provides a sense of sound to a person who is profoundly deaf or severely hard of hearing. The internal component works by directly stimulating the auditory nerves inside the cochlea with electrical impulses. External components include a microphone, speech processor and transmitter.

\section{What are your options?}

Accept a second cochlear implant. The procedure is the same as the first. After a general anaesthetic, the device is implanted by surgery. Your child will stay in the hospital for about 2 days. Healing takes about a month and then the device is activated. Your child will have continuing auditoryverbal or other type of therapy. The second implant provides auditory stimulation to your child's second ear. The second implant can also act as a "back-up" in case of damage or malfunction of the first implant.

Decline a second cochlear implant. You continue with the current implant and follow-up therapy. You may wish to consider an implant at a later date. Some research indicates that when children receive the second implant within a shorter period after the first one they see greater benefits than when they receive the implant later.

What other health factors may affect your choice?

Check $\square$ any that apply and discuss your concerns with your doctor.

Your child may not be a candidate for a second implant if he or she has the following $\rightarrow$ $\square$ Absent auditory nerve in second ear

Medical reasons for not having surgery

Working through the $\mathbf{4}$ steps of this decision aid may prepare you for decision making.

Step 1: What are the benefits and risks of each option?

Step 2: Which reasons to choose each option matter most to you?

Step 3: What else do you need to prepare for decision-making?

Step 4: What are the next steps? 


\section{Step 1: What are the benefits and risks of each option?}

What does the research show? Blocks of 100 faces show a 'best estimate' of what happens to 100 children who already have one cochlear implant who make different choices over 1 year. Each face $(-)$ ) stands for one child. The shaded areas show the number of children affected. The numbers are averaged from more than one study.

There is no way of knowing in advance if your child will be the one who is affected.

Because this is a new procedure, there is not a lot of research on the long-term effects of bilateral implants. The numbers presented here are based on the literature. Your cochlear implant centre may have different rates. Please talk to your clinician about the rates at your centre.

\section{Benefits}

+ More children will be able to locate sounds in their environment with a second implant. For example, a child could hear the direction of a parent's voice more easily - - - $\rightarrow$

$+\quad$ More children will be able to understand speech in a noisy environment at normal levels with a second implant. For example, being able to understand people talking in a group setting

$+\quad$ The same number of children will have normal receptive vocabulary with a second implant as those with one implant

\section{Risks}

$+\quad$ There is a risk of surgical complications with a second cochlear implant just like the first surgery $-\rightarrow$ These may include ear draining or skin infections, or infections in the head area behind the middle ear.

$+\quad$ There is a risk of a permanent facial palsy with a second cochlear implant just like the first surgery

A facial palsy is an inability to control some muscles in the face.

$+\quad$ There is a risk of meningitis with a second cochlear implant surgery just like the first surgery Meningitis is an infection in the fluid around the brain and spinal cord.

Risks over a FIVE YEAR period

+ There is a risk of a damaged I defective implant with a second cochlear implant just like the first implant

Damage to the implant can happen from falling and hitting the implant, or from a problem with the implant itself. The device needs to be replaced in this case.

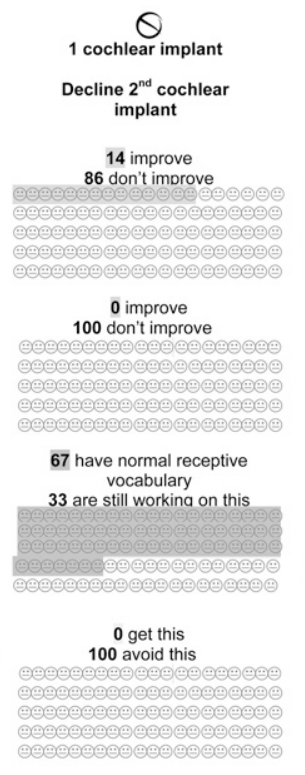

\section{0 of 1000 have this}

2 of 1000 have this 998 of 1000 avoid this

\section{7 have a damaged implant} 93 avoid this

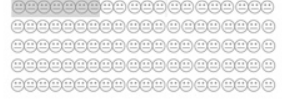

(द)

2 cochlear implants

Accept $2^{\text {nd }}$ cochlear implant

46 improve 54 don't imbrove

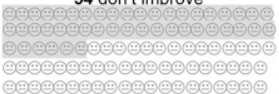

13 improve

87 don't improve

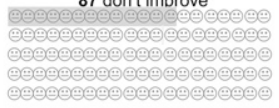

67 have normal receptive vocabulary

33 are still workina on this

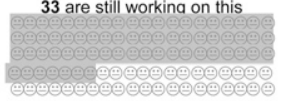

12 get complications 88 avoid this

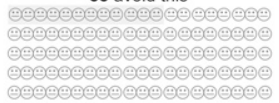

\section{1 of 1000 have this
999 of 1000 avoid this}

2 of 1000 have this

998 of 1000 avoid this

14 have a damaged implant 86 avoid this

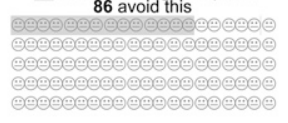

The rate at our centre is slightly better. About 4/100 children with one implant experience a damaged or defective implant.
Comments from local clinic

The clinic has not measured sound patients.

The clinic has measured some improvements in understanding of speech in noise for most children with two implants

The clinic's experience is that children who have in developing speech and language with one implant will continue to do so with two implants.

Our clinic has similar rates.

Our centre has no had a child experience this. There is a risk of this in the future.

Our centre has similar rates

Platinum or $*$ Gold symbols mean stronger study results. $\star$ Silver or $\star$ Bronze symbols mean weaker results 
Step 2. Which reasons to choose each option matter most to you?

Common reasons to choose each option are listed below.

Check $\checkmark$ how much each reason matters to you on a scale from 0 to 5 .

' 0 ' means it is not important to you. ' 5 ' means it is very important to you.

Reasons to

Accept a second cochlear implant

How important is it to improve your child's ability to locate sounds in their environment such as being able to determine the direction of a person's voice?

\section{Not} Important Important

How important is it to improve your child's ability to understand people talking in a noisy setting such as a classroom or restaurant?

(1) (1) (2) (3) (4) (5)

How important is it to expose your child's second ear to early speech and language stimulation?

(1) (1) (2) (3) (4) (5)

List other reasons to accept a second cochlear implant:

(1) (1) (2) (3) (4) (5)

Reasons to

Not Very

Decline a second cochlear implant

Important Important

How important is it to avoid the risks of surgery such as ear draining, skin infections, or infections in the head area behind the middle ear?

(1) (1) (2) (3) (4) (5)

How important is it to wait until there is more scientific evidence on the effects of a second cochlear implant?

(1) (1) (2) (3) (4) (5)

List other reasons to decline a $2^{\text {nd }}$ cochlear implant:

(1) (1) (2) (3) (4) (5)

Now, think about which option has the reasons that are most important to you.

Which option do you prefer? Check $\square$ one

$\square 2$ cochlear implants / Accept a second cochlear implant

$\square 1$ cochlear implant / Decline a second cochlear implant

$\square$ I don't know 
Step 3: What else do you need to prepare for decision making? Knowledge

Find out how well this decision aid helped you learn the key facts.

Check $\square$ the best answer.

1. Which option has the highest chance of your child being able to locate sounds in the environment?

2. Which option has the highest chance of your child being able to understand speech in a noisy environment?

3. Which option has an increased chance of ear draining, skin infections, or infections in the head area behind the middle ear?

4. Which option improves receptive vocabulary?

5. Which option has the most scientific evidence on long term outcomes?

$\begin{array}{ccc}2 \text { cochlear } & \begin{array}{c}1 \text { cochlear } \\ \text { implants }\end{array} & \begin{array}{c}\text { implant } \\ \text { Both are } \\ \text { equal }\end{array} \\ \begin{array}{c}\text { Accept } 2^{\text {nd }} \\ \text { implant }\end{array} & \begin{array}{c}\text { Decline 2 } 2^{\text {nd }} \\ \text { implant }\end{array} & \end{array}$

Check your answers at the bottom of the page.

Do you know the current evidence on benefits and risks of $\quad \square$ Yes $\quad \square$ No each option?

$\Delta \perp \Delta$ Values

Are you clear about which benefits and risks matter most to you?

Yes $\square$ No

\section{Support}

Do you have enough support and advice from others to make a choice?

Uncertainty

Do you feel sure about the best choice?

Yes $\square$ No

$\square$ Yes $\square$ No

Step 4: What are the next steps?

List your plans: (for example, discuss the options with your health care team and/or learn more about the options)

This information is not intended to replace the advice of a health care provider.

Answers for the key facts- 1.2 implants, accept $2^{\text {nd }}$ implant 2.2 implants, accept $2^{\text {nd }}$ implant 3.2 implants, accept $2^{\text {nd }}$ implant, 4. Both equal 5. 1 implant, decline $2^{\text {nd }}$ implant

Content Editors: C Johnston, A Durieux-Smith, L Moran, Dr. D Schramm, E. Fitzpatrick

Funded in part by: Canadian Language and Literacy Research Network, Ontario Graduate Scholarship in Science and

Technology. Dr. D. Schramm and E. Fitzpatrick have both received funding from cochlear implant companies in conducting

research on cochlear implantation.

Format is based on the Ottawa Decision Guide (c) 2000, A O'Connor, D Stacey, University of Ottawa, Canada.

Date (c) $2007 \quad$ Next update due 2009. 

The Volta Review, Volume 109(2-3), Fall/Winter 2009, 143-153

\section{Commentary}

\section{Contemporary Reflections on Speech-Based Language Learning}

\section{Marianne Gustafson, M.S., CCC-SLP}

In "The Relation of Language to Mental Development and of Speech to Language Teaching," S.G. Davidson displayed several timeless insights into the role of speech in developing language and reasons for using speech as the basis for instruction for children who are deaf and hard of hearing (see Appendix). His understanding that speech includes more than merely accurate production and perception of sounds and words was quite remarkable. He recognized the linguistic value of prosodic elements such as phrasing, emphasis, and inflection, and distinguished between the ability to understand the meaning of these suprasegmentals versus facility in producing them. Equally notable was Davidson's recognition of the interplay between language and thought. While some might argue today about his exclusivity regarding oral education, who could deny that language acquisition is a primary educational goal, or that language plays a role in cognitive development, verbal intelligence, and the expression of feelings and emotions? We'd also have to acquiesce with his call for promoting reading, for teaching idioms, and for direct instruction about grammar, rhetoric, and composition. Finally, Davidson was quite prescient not only in recognizing the importance of "the logical faculties, and the mental dexterity, adroitness, and resourcefulness that count so largely for success in all the walks of life," but in believing that students with hearing loss could do the same work in these areas as do children with typical hearing (Davidson, 1899).

This is not to say that nothing has changed over the past hundred years. In referring to communication and education, our labels are more inclusive and options have expanded. We refer not simply to "oral" methods, but most often use terms such as auditory / oral, auditory-verbal, and listening and spoken language in referring to approaches that emphasize speech as a basis for communication. A common denominator in these philosophies is that access to spoken language is a key to developing literacy skills, such as reading and writing, and to developing the use of speech for communication with a goal of educating students with hearing loss in mainstreamed classrooms alongside their peers with typical hearing. Mastery of language is a prerequisite to

Marianne Gustafson, M.S., CCC-SLP, is an associate professor in the Department of Communication Studies and Services at the National Technical Institute for the Deaf at the Rochester Institute of Technology. 
reading, and its typical foundational skill is the development of phonological awareness. This in turn facilitates the reading acquisition process through the association of letters/letter sequences with the spoken words they represent (Trezek \& Malmgren, 2005). Studies have shown that among children who are deaf, the better readers make use of phonological coding strategies for decoding print (Harris \& Moreno, 2006) and have longer working memory spans for short-term storage of phonemes, words, and sentences (Geers, 2003). Although it is not the only coding strategy used by readers who are deaf, there is evidence that speech-based coding is more efficient than visual coding. This ability to hold more information in working memory may assist semantic and syntactic processing when reading (Marschark \& Mayer, 1998).

Compared to a century ago, we have an overwhelming advantage in providing access to spoken language due to constantly advancing techniques and technologies that allow access to sound over a reliance on lipreading. Listening and lipreading skills can be improved through methods such as Cued Speech (Cornett, 1967), a system of hand shapes and placements that disambiguate lip patterns and thus more accurately represent speech. Moreover, the development of listening skills for access to spoken language is far superior because of the availability of both high quality digital hearing aids (HAs) and cochlear implants (CIs). Both provide access to a broad range of the speech spectrum, including low- to high-frequency acoustic information needed for distinguishing phonemes (individual speech sounds). HAs and CIs transmit multiple aspects of the auditory signal with greater accuracy than in years past, and also allow customization to an individual's auditory needs. Advancements in speech processing strategies and internal hardware of CIs coupled with the early age at which implantation is possible are leading to improved outcomes. There is a growing body of research suggesting that CIs enhance the development of speech perception and phonological skills with concomitant gains in literacy skills, including vocabulary, word reading (James, Rajput, Brinton, \& Goswami, 2008), and reading comprehension.

Today's HAs and CIs also seek to increase the range of prosodic elements the spectral and temporal auditory information that has linguistic meaning. These are the elements of speech that Davidson stressed as important for comprehending the richness and nuances of meaning, and were accessible to his students mainly through utilizing cues from bodily and facial expression in conjunction with lipreading (Davidson, 1899). Prosodic components of spoken language occur at the word, phrase, sentence, and discourse levels rather than at the phonemic level that is often the focus of auditory learning, and they are discerned through attention to variations in pitch, loudness, and timing. Prosody signals communicative and pragmatic intent, including attitude, emotion, irony, sincerity, uncertainty, and emphasis. CI users have been shown to have difficulty in auditorily perceiving intent and/or emotion in sentences, but seem able to make gains through instructional attention to prosodic cues (Klieve \& Jeanes, 2001). Prosody also plays grammatical and semantic roles, 
particularly at the word level where pauses signal clause structure and syllabic stress distinguishes meaning in words/word groups that have variant pronunciations, such as "record" or highchair vs. high chair (Crystal, 1979). Stress seems difficult for $\mathrm{CI}$ users to discern and reproduce, perhaps because of technological and instructional attention to segmental features. HA users tend to have the advantage of transmission of low frequency spectral information and acoustic stimulation associated with the pitch changes that indicate stress and intonation (Most \& Peled, 2007).

A vast improvement in the past hundred years has been the additional educational opportunities over an expanded period of the life of those who are deaf and hard of hearing. Emphasis is placed on increasingly early identification (Dornan, 2009), sound amplification or cochlear implantation, and parent/ infant programs as well as expanded post-secondary educational opportunities. Unlike Davidson, we believe we can still improve spoken language (Brown, 2005), reading and writing regardless of a child's past communicative and educational experiences. In fact, English-as-a-second-language approaches are often used for assessment and instruction, especially at the post-secondary level (Bochner \& Walter, 2005). Davidson's goal of students learning advanced course work "through speech" could be seen as a foreshadow of mainstreaming and how students today can often be placed side by side with their peers with typical hearing in educational settings. Over 100 years later we can still celebrate what he called the "oral method, as practiced in the best institutions" (Davidson, 1899). In contemporary words, the utilization of listening skills and speech-based education offer a viable and valid approach to developing the linguistic and academic potential of children who are deaf and hard of hearing.

\section{References}

Bochner, J., \& Walter, G. (2005). Evaluating deaf students' readiness to meet the English language and literacy demands of postsecondary educational programs. Journal of Deaf Studies and Deaf Education, 10(3), 232-243.

Brown, P. (2005). Speech and Language Professionals. Retrieved November 2009 from Rochester Institute of Technology/National Technical Institute for the Deaf. http://www.ntid.rit.edu/speechlang/slpros/index.php.

Cornett, O. (1967). Cued speech. American Annals of the Deaf, 112, 3-13.

Crystal, D. (1979). Prosodic development. In P. Fletcher, \& M. Garman (Eds.), Language Acquisition (pp. 33-48). Cambridge, MA: Cambridge University Press.

Davidson, S.G. (1899). The relation of language to mental development and of speech to language teaching. The Volta Review, 1(2), 129-139.

Dornan, D. (2009). Research supports hearing loss as a neurological emergency. Volta Voices, 16(3), 26-28.

Geers, A.E. (2003). Predictors of reading skill development in children with early cochlear implantation. Ear and Hearing, 24(1), 59S-68S. 
Harris, M., \& Moreno, C. (2006). Speech reading and learning to read: A comparison of 8-year-old profoundly deaf children with good and poor reading ability. Journal of Deaf Studies and Deaf Education, 11(2), 189-201.

James, D., Rajput, K., Brinton, J., \& Goswami, U. (2008). Phonological awareness, vocabulary, and word reading in children who use cochlear implants: Does age of implantation explain individual variability in performance outcomes and growth? Journal of Deaf Studies and Deaf Education, 13(1), 117-137.

Klieve, S., \& Jeanes, R. (2001). Perception of prosodic features by children with cochlear implants: Is it sufficient for understanding meaning differences in language? Deafness and Education International, 3(1), 15-37.

Marschark, M., \& Mayer, T. (1998). Mental representation and memory in deaf adults and children. In M. \&. Marschark (Ed.), Psychological Perspectives on Deafness (Vol. 2). Hillsdale, NJ: LEA.

Most, T., \& Peled, M. (2007). Perception of suprasegmental features of speech by children with cochlear impants and children with hearing aids. Journal of Deaf Studies and Deaf Education, 12(3), 351-361.

Trezek, B.J., \& Malmgren, K.W. (2005). The efficacy of utilizing a phonics treatment package with middle school deaf and hard-of-hearing students. Journal of Deaf Studnes and Deaf Education, 10(3), 256-271. 


\title{
Appendix: The Relation of Language to Mental Development and of Speech to Language Teaching
}

\author{
By S.G. Davidson
}

Most of the adverse criticism to which oral schools have been subjected is due to a misunderstanding of the purpose and methods of their work. The average person not connected with such institutions thinks of them as established primarily for the teaching of speech and speech-reading. He regards these two branches as ends of instructions - as mere form studies akin to the practice of penmanship or drawing - and thinks that the time devoted to them is just so much taken from work required for the development of the faculties and the increase of knowledge. While he recognizes the social and pecuniary value of accurate speech and speech-reading to graduates of our schools, and acknowledges the proficiency therein to which many of the deaf attain, he also knows that, with a considerable number of our pupils, we accomplish no more in this direction than to make it possible for them to understand and be understood by their teachers and their most intimate friends. Holding these opinions, and finding results in what he considers their specialty so frequently defective, it is not surprising that he should conclude that oral schools do not meet the requirements of the deaf as a class.

That is the view commonly taken by the opponents of pure oral instruction must be evident to anyone who reads the argument they advance; and the persistency with which some moralists dwell upon the post-graduate advantages of speech and speech-reading, and the manner in which they direct attention to those pupils who are exceptionally expert in these accomplishments, would seem to indicate that even they regard such attainments as the supreme end and justification of the method.

Every oral teacher can doubtless recall occasions when this ... view of the method has been the basis of unjust reflections upon the quality of his work. I remember, as a typical instance, a visit made to my class-room by several gentlemen representing a western institution. The pupils expressed themselves as intelligently and correctly in their written exercises as hearing children of the same age could do, they understood the superintendent and their teacher without difficulty, and their speech was perfectly intelligible. I was congratulating myself upon the favorable impression they were evidently making, when the leader of the delegation requested permission to test their lip-reading. Picking out from a newspaper a paragraph describing, in technical terms, a

S.G. Davidson was an instructor in the Pennsylvania Institution for the Deaf, Mt. Airy, Philadelphia. This article was originally published in 1899 in The Volta Review, Volume 1, Issue 2. 
bridge building at some place with an unpronounceable name, he proceeded to read it rapidly, with chin resting on his breast and lips scarcely moving. Of course no one in the class understood him, and, although an effort was made to explain matters, the way in which he and his companions eyed one another showed that they thought he had effectually disposed of all pretensions of the oral method. The fact that these children had received, through speech and speech-reading, practically as good an education as is given the hearing child through the ear, was quite lost sight of, and the method was condemned because it had not made it possible for them to understand speech under impossible conditions. It is a similar mental obliquity, mistaking the means for the ends, that impels a person, after listening to a well-written graduating essay, read by a teacher because we do not train our pupils for public speaking, to remark: "That is very good; but," with a note of contempt in the voice, "I thought this was an oral school. Can't your pupils read their own papers?"

The typical oral school of America recognizes its obligation to give distinct and agreeable speech and perfect speech-reading whenever possible; but that which really distinguishes it is the manner in which and the extent to which it uses speech as a means of teaching language, and both speech and language as means of developing the intelligence. It is this that sets it apart, on the one hand, from the combined schools which teach speech, but do not teach through speech, and on the other hand, from those oral schools in Europe which, to paraphrase Mr. Heidsiek, make good articulation and accurate lip-reading the Alpha and Omega of every endeavor, and insist that their pupils shall receive instruction exclusively by word of mouth. Mr. Heidsiek, I am glad to see, recognizes the difference between the German Method and the Pure Oral Method as practices in the best American schools, for he notes, in connection with his observations in this country, that our teachers place mental development above purity of articulation.

What we should ask, then, is that people, when passing judgment upon our method, will examine into the psychological results of teaching through speech; and what we should exalt, for the admiration of the public and as vindication of our work, is not fluency of speech and expertness in lip-reading, but the mental development of our pupils and their attainments in knowledge. Good speech and speech-reading are to be reckoned as so much extra to the credit of the method, while if poor they deduct nothing from its value if they have been sufficient for their educational purposes.

Our oral schools, recognizing that intimate relations between thought and language, insist that all instruction shall be given in the vernacular ... Our thoughts and feelings are unconsciously molded by our vernacular, the language we have used from childhood. On this point, all psychologists and educators are agreed. The sign language is quite capable of developing and conveying thought, but the kind and quality of thought development must be as different from that resulting from the use of English as is the language that produces it from the English language ... [Justifying] the contention of our 
oral schools that the English language must be made the vernacular of the deaf if they are not to be a class unto themselves ... and if they are to have a means of expression adequate to the highest mental development.

It has been argued that it is possible and best to combine the sign method and the English language method of instruction so as to give a greater mental discipline than be either separately ... Advocates of the combined method claim that signs are necessary to the interpretation of language. It is true that written words are expressionless unless vivified by our recollection of them as spoken words. They can, by themselves, effectively represent only concrete ideas. The various moods of the mind, the emotions, the abstractions of the intellect, and the heart are not visible in them. A prominent educator has said that it is impossible to convey abstract thought to the deaf except through the medium of signs. If the only alternative were spelled or written language, I should be inclined to agree with him; but we have, in speech, a means of expressing to the deaf, almost as effectively as to the hearing, every emotion of the mind, all the varying lights and shadows of the soul, every shade of meaning of which language is capable. It is a mistake to suppose that because speech is visibly, not audibly, represented to the deaf, the mental effect of communication by this means must be the same as by writing or spelling. I have even seen it asserted that there is no essential difference between signs made on the lips and signs made with the arms. A little reflection would make it evident that lip signs must represent sound - that, varying as the speech varies, they must express, to some extent at least, the emotions and sentiments that the voice conveys to the ear of the hearing person. It is impossible that words taken from the lips, warm with the emotion that impelled their utterance, should be the cold, lifeless sign of an idea that the written word is.

It would be absurd to claim that speech-reading can altogether take the place of hearing in the interpretation of language, but I am convinced that its possibilities in this direction are far greater than is generally supposed. They can be fully appreciated only by one who, having heard, is now deaf and forced to depend on this method of communication. Such a person will say that accent, emphasis, and inflection are almost as clear to the eye as they were to the ear so much so, indeed, that it is at times difficult for him to believe he does not really hear. This is, of course, merely memory associating the qualities of articulate speech with the positions of the lips, the expression of the face, and the variations in the force and rapidity of utterance; but it proves that these qualities are visible as well as audible, and it is only necessary that pupils should be led to observe them, and to associate with them the corresponding thought or emotion, to have, not a perfect, but a practically sufficient, substitute for sound in all its intellectual functions. The fact that the deaf talk in monotone, without phrasing, emphasis, or inflection, should not be taken as proof that they do not recognize these qualities in the speech of others. The modes of speech can be acquired only through imitation, which is impossible to the deaf child, 
because, being unable to hear his own voice, or to watch his own lips, he has no means of comparing his manner of speaking with that of other people.

The meaning of a sentence depends not only upon the meaning of the individual words composing it, but also upon the relation of the words and groups of words to one another. These relations, which are only to a slight extent represented in written language, are expressed vocally by phrasing. This quality of speech is almost as clear to the eye in lip-reading as to the ear in hearing, and may be made to contribute largely both to the comprehension and mastery of language and to the intellectual growth.

It is hardly necessary to discuss the value of emphasis in the expression of thought. The fact that there is no way of conveying verbal emphasis to the deaf who have no speech - except on a very limited and altogether unsatisfactory way by manual spelling - has made it impossible to do much with them in higher literature, where so much of both the beauty and the sense of expression depends upon it. As a natural result we have teachers protesting the impossibility of the work done in this line in oral schools, and insisting that our children shall be restricted for their mental pabulum to "the simple English in the third reader or some little story book."

And how large a use we make of emphasis in our every-day life! How it multiplies the resources of language! Take the very ordinary statement: I know what he said. It is capable of expressing four different ideas according to the word emphasized. If it be $I$ that is emphasized, it conveys the idea that $I$ know, though others do not. If know is emphasized, it expresses positive knowledge; I know, - I do not merely think. If the emphasis is placed upon the he, I know what he said, though not what others said. If upon said, I know what he said, thought it may not agree with what he did or what he thought. By the experiments made in the course of my language and literature lessons I have fully satisfied myself that emphasis may be as easily recognized by sight as by sound.

The emotion back of a sentence is equally plain to the eye. Every passion uttered by the tongue is painted in the face and stamped on the lips. In the expression of love, the speech is soft, smooth, languishing; in anger, it is strong, vehement; in joy it is quick and vivacious; in sorrow, slow and interrupted; in fear, tremulous and hesitation; and in each case, the manner of speech influences the expression of all the features and the movement of the lips and throat muscles so that the words, when understood, are glowing with life and color. That this should give instruction through speech a tremendous advantage over any other method should be evident in the nature of things, and that it does so can be proved by watching a class under the instruction of a good oral teacher, or by a comparison of results.

I have among the classes that come to me for instruction in the language branches one that began its education in our manual department and remained there for a number of years before being transferred to the oral department... Its lip-reading is very poor, and as its time in school is limited, much work must be down with it by writing. Now, I find that I may cover every slate in 
my school room with sentences illustrative of a language construction I am teaching, and they will not grasp the idea; whereas, a few sentences delivered with proper expression and emphasis will usually make it clear to any of the other classes. There are certain lines of work that no amount of planning on my part, or of hard work on the part of pupils, will enable me to do with this one-time manual class - partly because its [cognitive development] was fixed by its early training. With other classes, I have yet to discover any kind of work done in connection with language and literature by hearing pupils of grammar school grades that they cannot do.

The value of lip-reading as a means of teaching language is illustrated in reproduction exercises. Pupils whose lip-reading is fairly good will reproduce a story told orally very much better than one which they have read from writing or print. Speech, with its phrasing, emphasis, and the expression it produces in the features, causing them to reflect the thought, gives life and tone to the story, makes it clear to the comprehension, and impresses it upon the consciousness with no more effort on the part of the pupil than is required to read the words from the teacher's lips.

Oral schools are notable for the amount of reading done by their pupils. This is one of the things Prof. Heidiek remarks as distinguishing them from all other schools. Manual teachers frequently complain of the difficulty of interesting their pupils in reading, while oral teachers apparently experience no trouble in this direction. Of the forty children under my instruction in language, there are only three who do not heartily enjoy a story book, and two of these are pupils who were transferred from the manual department. The experience of other schools may not agree with ours, but if this difference does exist, it is another indication that the speech method, by giving expression to language, makes its perusal more enjoyable by the emotions it awakens in the child's own nature.

The speech method has decided advantages over all others in the teaching of the colloquialisms and idiomatic phrases that belong to the language of daily life. This kind of language is not found in text books, it does not lend itself to and is not much used in the expression of literary though, so the pupil cannot pick it up incidentally through his studies or his reading. If he gets it at all it must be through its use by his teacher as the occasion demands. Any one who had taught manually knows how difficult it is to compel one's self to spell out tediously on the fingers these little phrases and sentences, when the thought they convey is so much more rapidly and graphically expressed by a look or a gesture. Who wishes to form each separate letter entering into "I would not do that," when a frown and a shake of the head amounts to the same thing? And if it be spelled or written, how much less impressive it is than when spoken by the oral teacher. All these expressions flow as naturally from his tongue when he is talking with his pupils as when he is addressing hearing people and they are almost as expressive and produce practically the same... effect in the one case as in the other. 
The fact that all thought is expressed in spoken or written language does not relieve us of the necessity of teaching language systematically, as a branch of study by itself. In the lower grades, economy of time and perfection of results, both as regards language and intelligence, require that we shall make use of all the powers we find in the child to give him, as rapidly as possible, the expression for the concepts he had formed before entering school. It is in devising methods for accomplishing this that the ingenuity of the primary and intermediate teacher is demonstrated. I find a general impression abroad that oral schools neglect this work, relying chiefly upon speech exercises for the teaching of language.

The truth is there is no other class of schools which so thoroughly appreciates the necessity of rapid advancement in language, for upon it depends not only growth in knowledge and mental development, such as may be given to the younger children in manual schools through signs, but also the mastery of speech and of lip-reading. It would pay manual teachers to investigate the language methods employed in oral schools. I venture to say that in no institution in the world can there be found a more complete and perfectly systematized course of instruction for primary and intermediate grades than in the school where we are holding this meeting, and one important consequence of the abandonment of the manual method in the Mt. Airy school has been the improvement it has compelled in the processes of language teaching.

Systematic instruction in language as a branch of study, independent of its use in the teaching of other subjects, should continue throughout the school course. The rules of language which the child learns unconsciously by induction in the lower grades, should be reviewed in the higher classes in the systematic study of grammar, analysis, rhetoric, and composition. These will not only contribute to exactness, force, and beauty of expression, which are of the utmost advantage to every man and woman, but will cultivate, to a greater extent than any other study of our grammar grades, the logical faculties, and the mental dexterity, adroitness, and resourcefulness that count so largely for success in all the walks of life. There is no reason why our pupils should not do, with advantage, practically all the work in these branches that is required of hearing children. With the skill in speech-reading to which they have attained by the time they reach the advanced grades, the exposition of the rules and the drill in their application can be given with almost as much facility as in the public schools. During the past year I tried the experiment of teaching a class grammar altogether through lip-reading, no text-book being allowed, and the only writing being sentences put on the slate for parsing or analysis, and exercises written by the pupil in the evening to illustrate the rules taught in the school-room. Although [developmentally behind] many classes to which I had previously taught the subject, its progress was far greater. The time devoted to these lessons averaged about two hours a week through the last school year, and at the end every pupil, with the exception of one who had been absent a great portion of the year, was able to pass an examination on the tests for admission to the Boston High School. This should certainly indicate 
that speech is a competent method of instruction in the more advanced subjects of the course, as well as in the work of the lower grades.

I am convinces that speech has a value with the deaf, as with the hearing, in the development of mind and soul, quite apart from the language to which it gives utterance or the thought directly conveyed. One of our children, born deaf, who recently memorized and recited Kipling's Recessional as an exhibition exercise, was asked if he enjoyed it. "Yes" - decidedly. If he knew what it meant. He was very certain that he did; and when asked to write it out in his own language, sat down to the task with perfect confidence. But he soon came and confessed that he did not know the meaning of the words. He seemed surprised and said he understood it in his heart, but not in his head - that it made him feel good when he read it. The recitation of the hymn had evidently awakened emotions that he did not have the language to express. This is but one of many instances in which pupils have shown that vocalization, though inaudible to them, nevertheless exerts ... [an influence] somewhat akin to that experienced by the hearing child.

To summarize: Oral schools teach every thing through the English language as the only means for the expression of ideas and the development of the intelligence. They make speech the basis of instruction because of its value in interpreting language. They regard as of supreme importance the mental development of the child, and the work in both speech and language is directed to this end.

And, in conclusion, - merely as an expression of my own opinion, based upon experience in language teaching at different times by signs, spelling, and speech, - I would say that the oral method, as practiced in the best institutions, accomplishes far more in the education of the deaf than is possible under any other method. 



\title{
Book Review
}

\section{Scanning Deaf Identities}

\author{
A Lens on Deaf Identities \\ Irene W. Leigh, Ph.D. \\ Oxford University Press, New York, NY \\ Hard Cover, 2009, \$45.00, 240 pages
}

The name of Dr. Irene Leigh's newest book, A Lens on Deaf Identities, stimulates reflection with a profundity beyond the title. There are a variety of lenses through which one can view identity, and each lens determines your perception of what you see. Yet, the lens doesn't change the reality of a person's existence; it only shifts the angle from which it is perceived. Rather than zooming in for a snapshot and focusing on a single image of deaf identity, Leigh's discussion fills a void in our literature by mimicking a deep focus lens while allowing the reader to experience a broad spectrum of existences.

In her sincere, provocative, and timely 240-page text, Leigh draws on her many years of reflection on deaf identity to address countless questions on the subject with impressive depth and breadth. Scanning and synthesizing a rich collection of literature, research, theory, and real life examples, Leigh projects a 360-degree panorama of the subject matter.

The deaf community, like the world at large, is rapidly becoming more diverse and globally connected. Leigh's book is a straightforward, open reflection on the multidimensional aspects of the complex web of interfaces, contexts, and dynamics that contribute to varied deaf identities and identity formation in a multicultural world. Her approach is unique, authentic, and holistic in that she responds to the full continuum of deaf ways of being. The author's values of social responsibility challenges readers to recognize and respect that there are multiple ways of being deaf in today's world.

A Lens on Deaf Identities has much to offer researchers, practitioners, and students from a variety of disciplines who wish to understand and respond to the diversity of identities among individuals who are deaf, hard of hearing, and late-deafened. Leigh enlightens both the novice and the experienced professional with her comprehensive discussion about what it means to exist in diverse ways in a multicultural world. Parents of children with hearing loss as well as adults who are deaf or hard of hearing will also grow from their immersion in this thought-provoking book.

Leigh encourages us to be open to shifting lenses as we observe deaf existences, pointing out that identities and the social forces that influence them are dynamic. While she recognizes that there is still much to be explored regarding 
deaf identities when the cover closes at the end of her book, she has certainly succeeded in producing the most comprehensive and instructive reflection on the subject to date.

Martha A. Sheridan, MSW, Ph.D. is a Professor of Social Work in Gallaudet University's Master of Social Work Program. 
